\title{
Exploring the Effects of Implementation Intentions and Goal Formation on Anxiety and Communication Effectiveness when Discussing Difficult Interpersonal Topics
}

\author{
Colleen C. Malachowski \\ West Virginia University
}

Follow this and additional works at: https://researchrepository.wvu.edu/etd

\author{
Recommended Citation \\ Malachowski, Colleen C., "Exploring the Effects of Implementation Intentions and Goal Formation on \\ Anxiety and Communication Effectiveness when Discussing Difficult Interpersonal Topics" (2012). \\ Graduate Theses, Dissertations, and Problem Reports. 4893. \\ https://researchrepository.wvu.edu/etd/4893
}

This Dissertation is protected by copyright and/or related rights. It has been brought to you by the The Research Repository @ WVU with permission from the rights-holder(s). You are free to use this Dissertation in any way that is permitted by the copyright and related rights legislation that applies to your use. For other uses you must obtain permission from the rights-holder(s) directly, unless additional rights are indicated by a Creative Commons license in the record and/ or on the work itself. This Dissertation has been accepted for inclusion in WVU Graduate Theses, Dissertations, and Problem Reports collection by an authorized administrator of The Research Repository @ WVU.

For more information, please contact researchrepository@mail.wvu.edu. 
Exploring the Effects of Implementation Intentions and Goal Formation on Anxiety and Communication Effectiveness when Discussing Difficult Interpersonal Topics

\title{
Colleen C. Malachowski
}

\author{
Dissertation submitted to the \\ Eberly College of Arts and Sciences \\ at West Virginia University \\ in partial fulfillment of the requirements \\ for the degree of
}

\author{
Doctor of Philosophy \\ in \\ Communication Studies
}

\author{
Melanie Booth-Butterfield, Ph.D., Chair \\ Rebecca M. Chory, Ph.D. \\ Matthew M. Martin, Ph.D. \\ Christine E. Rittenour, Ph.D. \\ Richard T. Walls, Ph.D.
}

Department of Communication Studies

Morgantown, West Virginia

2012

Keywords: planning, goals, implementation intentions, anxiety, remediation, need for cognition, self-efficacy, cognitive flexibility, communication effectiveness

Copyright 2012 Colleen C. Malachowski 


\section{ABSTRACT \\ Exploring the Effects of Implementation Intentions and Goal Formation on Anxiety and Communication Effectiveness when Discussing Difficult Interpersonal Topics}

\section{Colleen C. Malachowski}

This study addressed the effects of two specific types of planning (i.e., goal intention and implementation intention formation) on interpersonal discussions of difficult topics (e.g., discussing the future of a relationship, discussing past romantic partners, discussing the current status of a relationship). Goal intentions specify a certain end point (e.g., "I intend to reach $x$ "), and implementation intentions (Gollwitzer, 1999) specify when, where, and how a goal will be achieved (e.g., "If $x$, then $y$ "). In addition, four personality traits (i.e., need for cognition, cognitive flexibility, self-efficacy, and trait dyadic communication apprehension) were examined in order to further understand the role of these traits in impacting planning and state anxiety, self-perceived communication effectiveness, message length, and motivation. Using Berger's (1995a, 1997) Planning Theory as a guiding framework, this post-test only equivalent groups experimental design evaluated differences in state anxiety, self-perceived communication effectiveness, message length, and motivation among three conditions: implementation intention formation $(n=60)$, goal intention formation $(n=64)$, and a control group $(n=58)$. In Time 1, participants reported on a range of difficult topics that they perceived to be both anxiety-provoking and important. After this, each group was given an experimental manipulation, in which participants were guided through the formation of an implementation intention or a goal. The control group was a no message control group. In Time 2, which took place two weeks later, participants were asked to audio-record a message in which they talked about the difficult topic they reported on in Time 1. Results revealed that planning did not impact state anxiety, self-perceived communication effectiveness, or motivation. Individuals in the goal formation group formed messages with fewer words than did individuals in the control group. Selfefficacy interacted with the goal formation condition to impact message length, such that individuals with high self-efficacy recorded shorter messages than those in the control group. Taken together, it appears that planning had minimal impact on state anxiety associated with the discussion of difficult topics in interpersonal relationships. 


\section{TABLE OF CONTENTS}

ABSTRACT ii

LIST OF TABLES vi

ACKNOWLEDGEMENTS vii

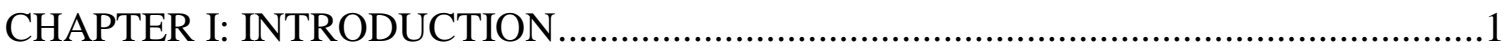

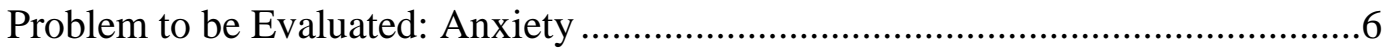

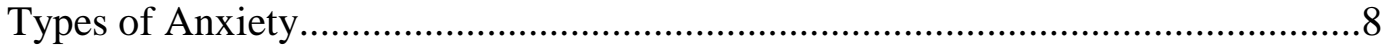

Communication Apprehension .......................................................... 8

Social Anxiety............................................................................... 9

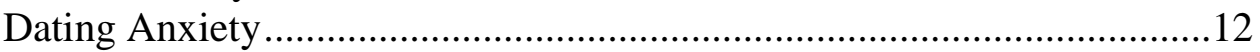

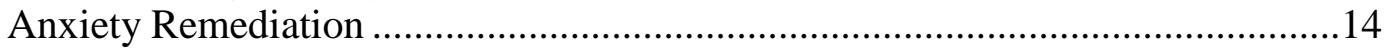

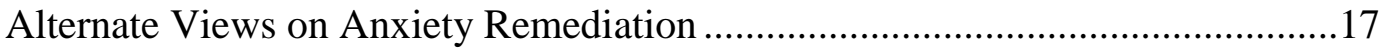

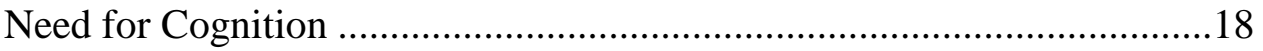

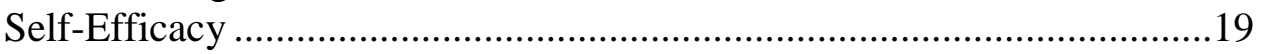

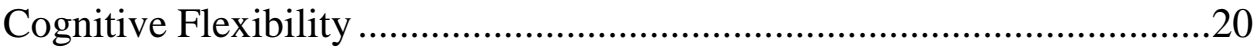

Theoretical Framework: Planning Theory ……................................................22

Assumptions and Propositions ............................................................24

Difficulties/Criticisms of Planning Theory ...........................................32

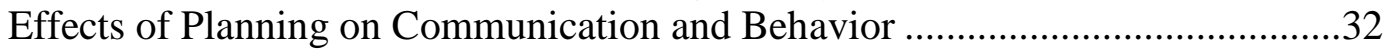

Proposed Solution: Implementation Intentions .................................................. 34

Effects of Implementation Intentions on Communication and Behavior ..............37

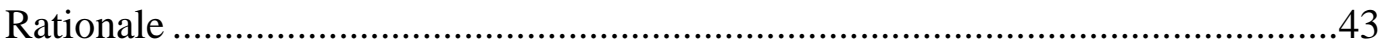

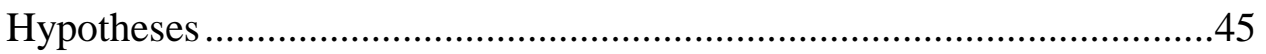

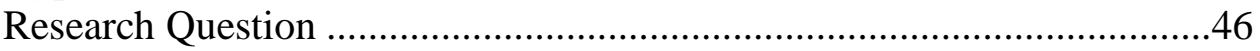

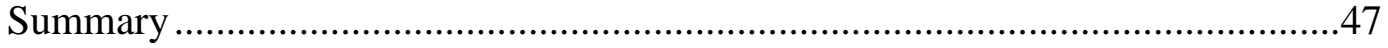

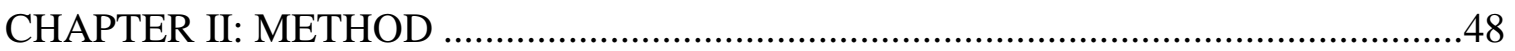

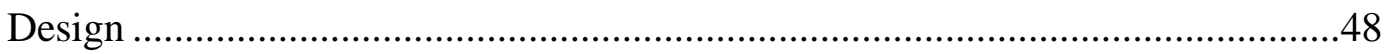

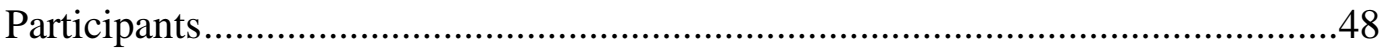

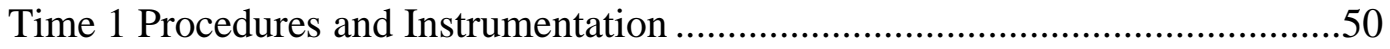

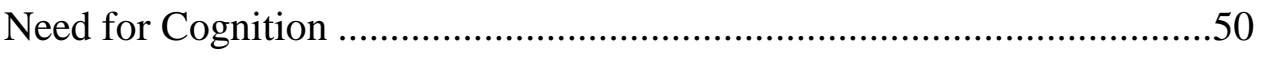

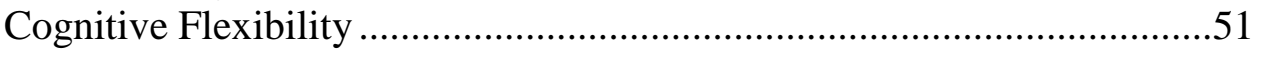

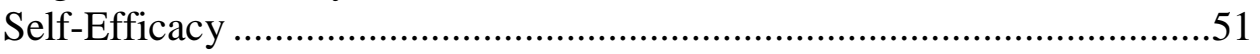

Trait Dyadic Communication Apprehension ........................................52

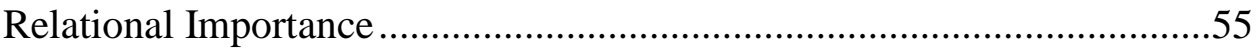

Understanding Participant Mortality............................................................58

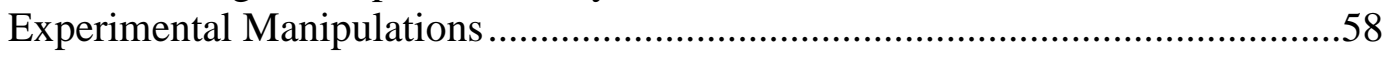

Implementation Intention Manipulation .........................................58

Goal Formation Manipulation...........................................................60

Control Group Description ......................................................61 


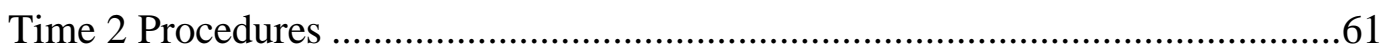

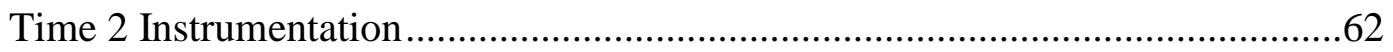

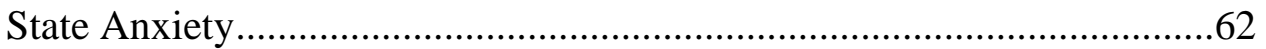

Self-Perceived Communication Effectiveness.........................................63

Message Length ................................................................................63

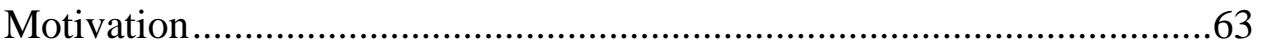

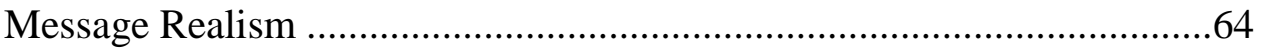

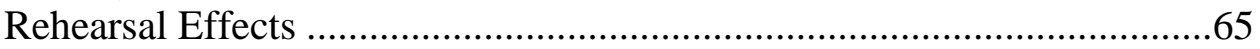

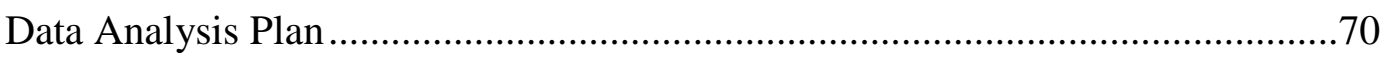

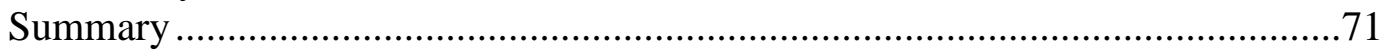

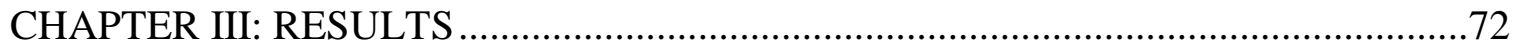

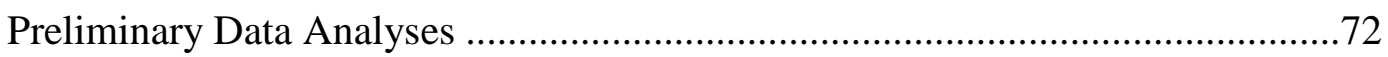

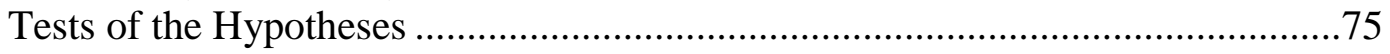

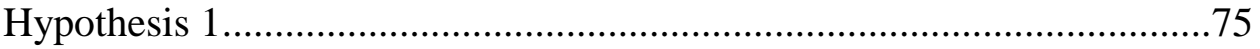

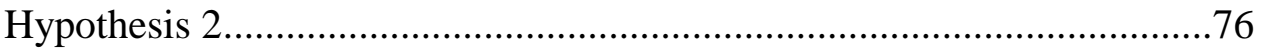

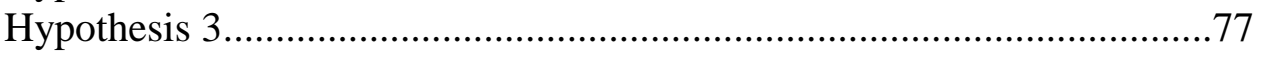

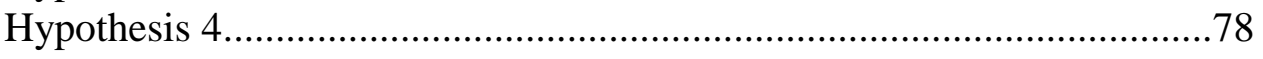

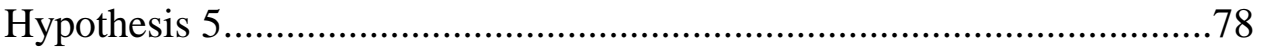

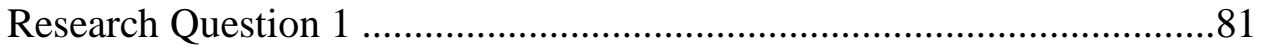

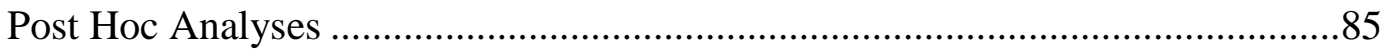

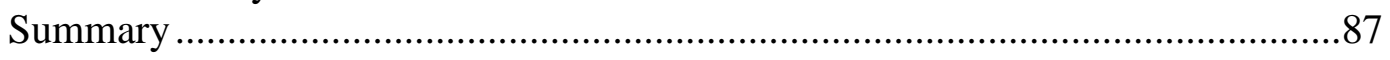

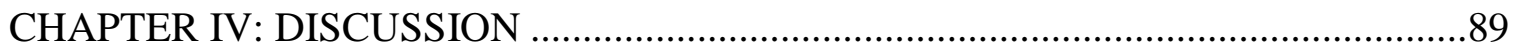

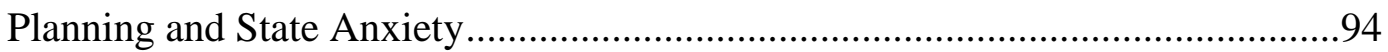

Planning and Self-Perceived Communication Effectiveness..................................97

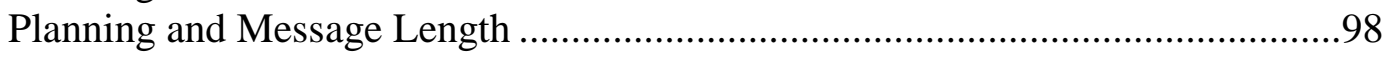

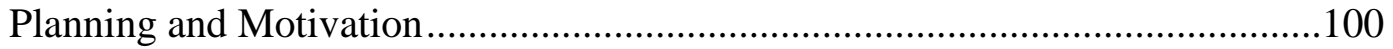

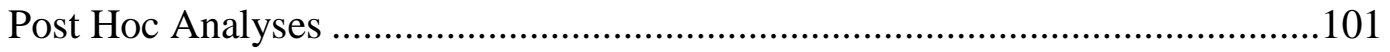

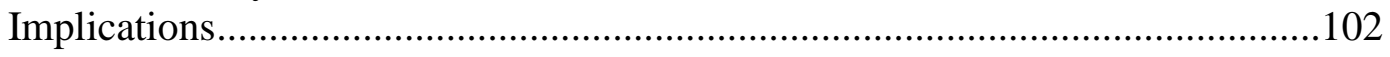

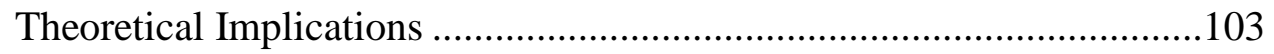

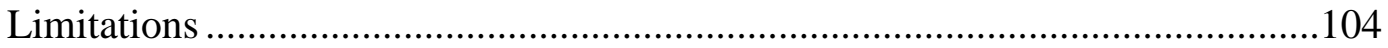

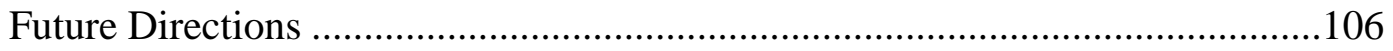

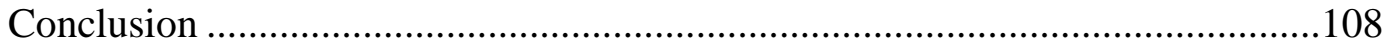

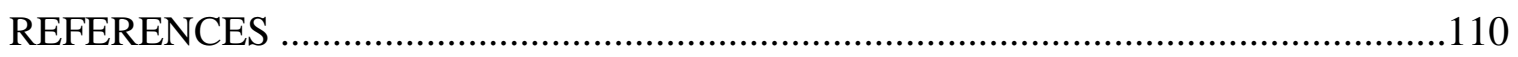

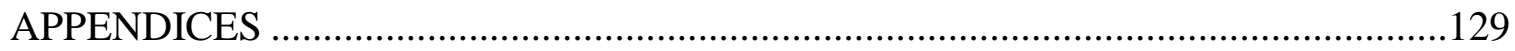

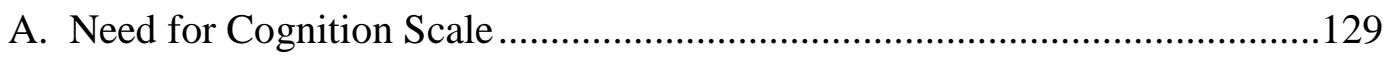

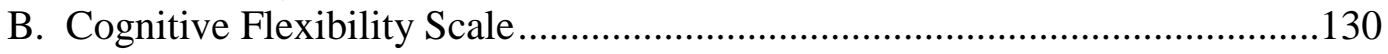

C. Self-Efficacy Scale ....................................................................................131

D. Trait Dyadic Communication Apprehension Scale .......................................132

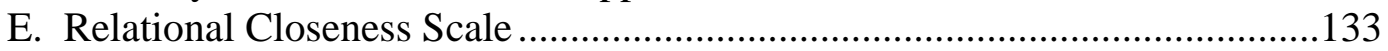




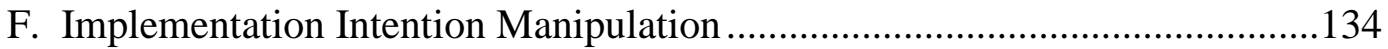

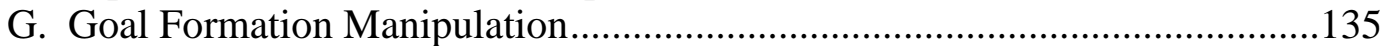

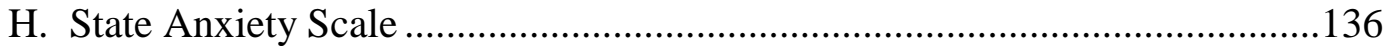

I. Self-Perceived Communication Effectiveness ............................................137

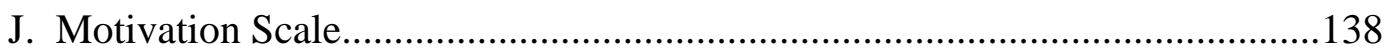

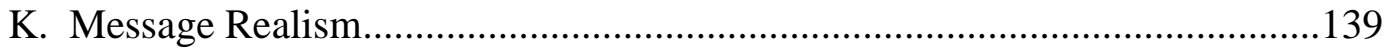




\section{LIST OF TABLES}

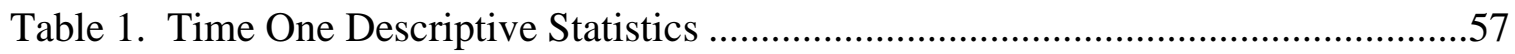

Table 2. Time Two Descriptive Statistics ...............................................................66

Table 3. Implementation Intention Group Descriptive Statistics................................67

Table 4. Goal Formation Group Descriptive Statistics ............................................68

Table 5. Control Group Descriptive Statistics .....................................................69

Table 6. Correlation Matrix for Traits, Dependent Variables, and Covariates.................73

Table 7. One-Way Analysis of Variance Comparing the Means and Standard Deviations

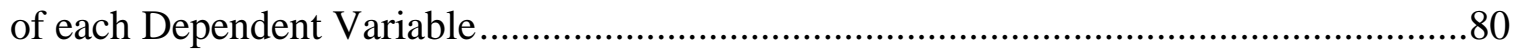

Table 8. Linear Regression Standardized Regression Weights for Interactions among

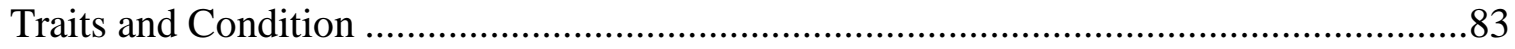

Table 9. Means and Standard Deviations for the Message Length by Group and

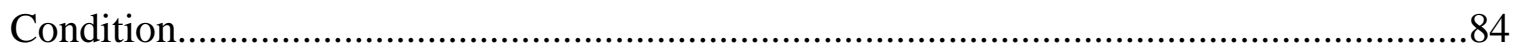

Table 10. Relationships among State Anxiety, Traits, and Outcome Variables..............94 


\section{ACKNOWLEDGEMENTS}

Before deciding if I was going to pursue my Ph.D. at West Virginia University, Dr. Weber offered me some valuable words of wisdom: “The Master's program at WVU is like running a sprint," he explained, "and the $\mathrm{Ph} . \mathrm{D}$. program is like running a marathon." As a Boston Marathon runner, this statement resonated strongly with me. Despite having sworn that I would never run a marathon again, I just finished my Master's sprint and felt ready to take on the next challenge. Reflecting back on my Ph.D. experience, Dr. Weber was right, and I have many people to thank throughout my marathon journey. Thank you, Dr. Weber, for providing me with the guidance and encouragement to apply to doctoral school.

First and foremost, I would like to thank my Advisor, Dr. Melanie BoothButterfield, who ran by my side throughout every step of the program. Without you, this dissertation would not have been possible, and your endless support and positivity is what really kept me going throughout the program, pushing me to run "upward and onward." At the points where I was putting too much pressure on myself, you helped me to prioritize, relax, and cheer up with a few comical stories or pictures of Izzy and Zooey. Your Communication Apprehension class also helped me to find the line of research that I am most passionate about, and inspired this dissertation. In that respect, you did much more than advise me on this dissertation - you helped me to discover who I am as a communication scholar and encouraged me to pursue my research.

I would also like to thank my committee members, Dr. Martin, Dr. Rittenour, Dr. Chory, and Dr. Walls. I want to thank Dr. Martin for always taking the time to advise me not only with this dissertation, but on several issues throughout my entire graduate 
experience. Your office door was always open, and I knew I could come to you for guidance. Further, you have been particularly influential in my job search, and I will be forever grateful for that. I also want to thank Dr. Rittenour for supporting me throughout this process. You were especially helpful in guiding me to develop the prompt that we used in this dissertation. Your kindness and encouragement really seemed to come at the moments when I needed it the most! Dr. Chory, thank you for all of the statistics help you provided with this dissertation, and more importantly, for supporting all of my life choices throughout the program. I am so thankful to have you not only as a committee member, but also as a Ph.D. coordinator and friend. Dr. Walls, thank you for providing me with a wonderful Memory class, which was especially useful for the theoretical framework of this dissertation. You were a remarkable teacher and your classes inspired me to become a better teacher as well.

In addition to my advisor and committee members, I want to thank Sean Horan and Brandi Frisby for mentoring me throughout graduate school. Sean, you took me under your wing since I was your GTA in Comm. 100 and you have looked out for me ever since. You got me through the most difficult parts of this program and helped to keep me grounded. Brandi, I want to thank you for taking me on several projects my first year and always checking in on me. I am eager to continue researching with you in the future, and I want to thank you for being a supportive friend.

Importantly, I also want to thank my parents, Richard and Patricia, as well as my siblings, Dan, Matt, and Gayle. Mom, I want to thank you for sending me over 200 cards (yes, I still have them all!) throughout graduate school and providing me with endless love and encouragement. In April of my senior year at Boston College, you gave me a 
wall plaque that read, "Faith is taking the first step even when you don't see the whole staircase." This quote has certainly guided my post BC experience. Your unwavering faith is what got me through this program, as you have always supported my educational endeavors, even if that meant driving all day to stay in a creepy cabin at Coopers Rock. Similar to the Boston Marathon, you stuck by me throughout the grueling training process. For four years, you been cheering me on at the finish line because you always had faith that I would get there. Dad, you have always been a voice of reason and have helped me to remain level-headed throughout this program, without losing sight of my goals and keeping me in touch with the real world. Dan, being in similar situations, you have provided me with an example of perseverance. Matt, once again, you were there for me as I climbed heartbreak hill, telling me not to give up. Gayle, thank you for supporting me and providing me with a breaking point on my long journeys home.

I would also like to thank my friends who have been especially supportive throughout this program including Amy, Zach, Mo, Jenn, and Pooja. Thank you for sticking by me even when I was so wrapped up in my own work that I lost touch with the world. Thanks to my colleagues, CJ, Steph, Syd, Shannon, Lori, Jessalyn, and Zac who also supported me. Syd, thanks for letting me borrow Sully to play with and relax!

Finally, I want to thank Tom. I truly believe that if we can make it through this, we can make it through anything. Thank you for driving over 864 hours over the past three years to see me, meet me in Johnson City, or to take me to a Komondor farm. I understand that this was excruciating, but our long-distance marathon is now over. We have weathered the storm (both literally and figuratively), and I am ecstatic to start a life together! Thank you and I love you. 


\section{Chapter One}

\section{Introduction}

Message production scholars have long been interested in the effects of planning on interpersonal interactions and communicative outcomes, as communication and cognitive processes are inextricably linked (Berger, 1995a). One such example of this occurrence is the study of how anxiety (often an emotional process) impacts verbal fluency (a communicative process). Berger (1997) suggested that the study of interpersonal interactions is most productive when recognizing the potential importance of both cognitive and social factors in the production of interactions. In fact, Kellermann (1992) argued that all communication is strategic and automatic, meaning that strategic communication is "based on goals, plans, and scripts," while automatic communication is "based on functions, connections, and ingrained habits" (p. 288). Further, scholars have identified goals as the impetus for most communication behavior (Berger, 1997; Dillard, 1997), and plans are often created in order to facilitate the action of goals (Dillard, 1990).

One specific form of planning is implementation intentions (IIs; Gollwitzer, 1999). IIs are if-then plans that specify exactly how a goal will be achieved. The primary aim of IIs is to secure goal attainment through specific plans. Whereas goal intentions specify a certain end point (e.g., "I intend to reach $x$ "), IIs specify the when, where, and how that goal will be attained (e.g., "If $x$, then $y$ ”). Using Berger's (1995a; 1997) Planning Theory, this study explored the effects of goal formation and IIs on anxiety associated with the discussion of difficult topics in interpersonal relationships.

The study of planning and message production is important because planning strategic interactions enhances face preservation and self monitoring (Berger, 1995a), and 
reduces communication regret (Berger, 1995b). As Berger (1995b) eloquently stated, “...if human communicators were to utilize more often their unique capacities for forethought and planning and their ability to monitor carefully ongoing communication episodes, they might find themselves regretting what they have said a lot less often" (p. 21). This statement suggests two important ideas. First, communicators have the ability to plan. That is, humans have the cognitive capabilities to plan interactions that may aid in successful goal attainment. Second, planning may improve communication satisfaction by reducing conversational regret, an important feature given that communication is irreversible. Therefore, it is useful for researchers to develop a more comprehensive understanding of the role of planning and goal formation in interpersonal interactions because this knowledge may be used to improve overall communication within relationships.

Berger and Kellermann (1994) explained that conversation memory organization packets (MOPs) provide a theoretical basis for understanding message production, planning, and goal formation. A conversation MOP is a knowledge structure that "organizes behavioral sequences appropriate to a given situation to achieve one's goals" (Kellermann \& Lim, 1990, p. 1163). In other words, MOPs organize small routines or conversations so that goals can be accomplished (Kellermann, 1995). Research on the conversation MOP indicates that individuals move through early topics of the conversation MOP (e.g., biographic/demographic information) more quickly as the desire to become acquainted with another individual increases (Kellermann \& Lim, 1990). Further, Kellermann (1991) found that dyads with both similar and different acquaintanceship goals tend to display routine conversational behavior, providing further 
support that conversational sequencing follows a structured routine (i.e., normative progression).

The effects of planning and goal formation have been examined on several cognitive and behavioral processes, one of which is anxiety. For example, Allen and Honeycutt (1997) examined the effects of planning on nonverbal indicators of anxiety (i.e., the use of adaptors). After being randomly assigned to either a planning or distraction condition, participants were asked to engage in a role-playing activity in which they had to convince another person to seek help for a drinking problem. Participants in the planning-task condition were given three minutes to rehearse what they would say to the person, while participants in the distracter-task condition were given a tedious language task. Participants in the distracter condition displayed more adaptors (e.g., playing with hair, playing with objects) than those in the planning condition, indicating that planning may decrease nonverbal anxiety in interactions.

It is plausible that similar results would be found in other anxiety-provoking situations, such as the discussion of taboo topics. A taboo topic is a conversational area that is perceived as being forbidden or unmentionable (Baxter \& Wilmot, 1985). Roloff and Ifert Johnson (2001) found that dating partners were more likely to reintroduce a taboo topic concerning some aspect of the relationship through a planned interaction rather than an unplanned conversation. These authors suggest that this may be due, in part, to the anxiety associated with discussing a taboo topic. Further, Stutman and Newell (1990) reported that individuals who rehearsed what they would say prior to a confrontation were better able to control their anxiety and arousal, and stay in emotional 
control, than those who did not rehearse prior to the confrontation. Indeed, these studies indicate that planning may affect anxiety stemming from a diverse range of topics.

Other taboo topics that have been identified in close relationships (i.e., friendships and/or romantic relationships), and that may possibly benefit from planning, include discussing the state of the relationship, relationship norms, extra-relationship activities, prior romantic relationships, conflict-inducing topics, and negative life experiences (Baxter \& Wilmot, 1985). Baxter and Wilmot (1985) explained that these taboo topics also often result in topic avoidance. For example, Anderson, Kunkel, and Dennis (2011) reported that the most frequently avoided topic (of Baxter and Wilmot's six taboo topics) for dating couples is past sexual experiences. Anderson et al. explained that this topic was avoided due to the threatening nature of the content, potential emotional upset, identity issues (e.g., experience level discrepancies, measuring up, and perceptions of inadequacy), and the notion that the past should simply remain in the past. Based on these findings, both taboo topics and commonly avoided topics may be perceived as difficult topics to discuss in interpersonal relationships. In the present investigation, a difficult topic was conceptualized as a topic that causes anxiety in an interpersonal relationship. Thus, while there may be some conceptual overlap among difficult topics, taboo topics, commonly avoided topics, and anxiety-provoking topics, this study evaluated topics that are particularly anxiety-provoking.

In a study conducted on taboo topics in friendships, Afifi and Guerrero (1998) explored how same-sex and cross-sex friends avoid topics related to relationship issues, negative life experiences, dating experiences, sexual experiences, and outside friendships. They reported that individuals avoided discussing negative life experiences and 
relationship issues with males more than females. Further, cross-sex friends avoided topics concerning dating and sexual experience for self-protection. Taken together, it appears that the threatening nature of taboo topics and the desire for self-protection may stimulate anxiety associated with the discussion of these topics because of an underlying fear of negative evaluation. This anxiety (or fear of negative evaluation) may impede effective communication about these topics within relationships. For these reasons, it is fruitful to uncover the ways in which this anxiety may be alleviated when discussing difficult interpersonal topics because this may improve overall relational communication. Planning and goal formation are two specific ways in which this anxiety may be alleviated.

Studying the discussion of difficult topics in interpersonal relationships is important because studies indicate that self-disclosure and openness are components in defining intimacy in friendships (Monsour, 1996). Further, self-disclosure is one of the most common features in definitions of friendship closeness (Parks \& Floyd, 1996), and Afifi and Guerrero (1998) noted that hundreds of studies indicate positive relationships among self-disclosure and relational progress. For example, Collins and Miller's (1994) meta-analysis on self-disclosure indicated three primary disclosure-liking effects: (1) individuals who engage in intimate self-disclosure tend to be liked more than those who disclose at lower levels, (2) individuals disclose more to those they like, and (3) individuals like others after disclosing to them. These findings support the importance of disclosing in building positive affect in relationships. The discussion of difficult topics in friendships and romantic relationships may include self-disclosure, or potentially lead to further discussion in which self-disclosure occurs. Therefore, it is important to learn 
more about the discussion of difficult topics in interpersonal relationships because this may help individuals to increase intimacy (Monsour, 1996), closeness (Parks \& Floyd, 1996), and liking (Collins \& Miller, 1994) within relationships.

In general, studying the effects of planning on anxiety is significant because anxiety disorders around the globe have been rising in the $21^{\text {st }}$ century (Dowbiggin, 2009). Thus, developing a more comprehensive understanding of the impact of planning on cognitive and social processes may help to control or alleviate this mounting issue in order to improve relational communication regarding anxiety-provoking topics. Further, this line of research may offer scholars practical and cost-effective solutions for reducing anxiety that may inhibit goal attainment.

It order to understand and explore these implications further, it is first necessary to review why anxiety is problematic and how it impedes effective communication. Accordingly, the causes and behavioral effects of anxiety will first be reviewed. Next, three specific forms of anxiety will be delineated: communication apprehension, social anxiety, and dating anxiety. After this, anxiety remediation studies will be examined to understand the ways in which anxiety may be alleviated, in order to improve communication within relationships.

\section{Problem to be Evaluated: Anxiety}

\section{Understanding Anxiety}

The study of fear and anxiety as a scientific construct dates back to the work of Darwin (1965/1872), who examined anxious reactions as part of an adaptive response in both humans and animals. Darwin contended that fear and anxiety are part of a larger process of natural selection and are necessary for survival. He explained that fear and 
anxiety may be observed through physical manifestations including perspiration, dry mouth, increased heart rate, trembling, unpleasant facial expressions, changes in vocal quality, and the erection of hair. Extending this line of research, Freud (1936) explored anxiety through a psychological lens. More specifically, Freud identified anxiety as a clinical syndrome, stemming from an objective danger (also called a stressor) and a perceived threat.

Currently, there are two common approaches to the study of anxiety in the communication field: state and trait (McCroskey, 1997). State anxiety refers to the "here and now" response a person has in a given situation, while trait anxiety is an invariant characteristic of an individual (Beatty, Behnke, \& McCallum, 1978; Booth-Butterfield \& Booth-Butterfield, 2004; McCroskey, 1997). In other words, state anxiety manifests only in particular situations, while trait anxiety refers to the tendency or predisposition to perceive stressful situations as dangerous or threatening (Spielberger, 1985). Research indicates that trait anxiety is usually reflected in the frequency and intensity of anxious states experienced by an individual (Spielberger, 1985). McCroskey and Beatty (1984) found that trait communication apprehension correlates positively with Speilberger's measure of state anxiety $(r=.69)$, further highlighting the relationships between trait and state anxiety.

Anxiety may also be emotional and/or behavioral (Trower, Gilbert, \& Sherling, 1990). Common anxious emotions include fear of negative evaluation, depression, and frustration (Beatty \& Beatty, 1976; Trower et al., 1990), and these emotions may motivate anxious behavior (McCroskey \& Beatty, 1998). Anxious behaviors include avoidance, withdrawal, immobilization, and other physiological responses (e.g., increased 
heart rate, perspiration, trembling, etc.). These responses may be problematic for many individuals, possibly interfering with daily functioning and day-to-day interactions.

\section{Types of Anxiety}

Communication Apprehension. One type of anxiety that may interfere with day-to-day functioning is communication apprehension (Beatty \& Beatty, 1976). The original conceptualization defined communication apprehension as "a broadly based anxiety related to oral communication" (McCroskey, 1970). Subsequent research defined communication apprehension as the anxiety individuals feel in either real or anticipated communication interactions (McCroskey, 1977). Individuals who are highly communicatively apprehensive avoid certain situations, withdraw from communication interactions, and often have disfluencies in their messages (Beatty, 1987; Richmond \& McCroskey, 1998).

While several causes of communication anxiety anxiety have been identified, three common causes are biology, reinforcement, and a lack of communication competence (Beatty, Plax, \& Kearney, 1985; Beatty \& Valencic, 2000; Booth-Butterfield \& Booth-Butterfield, 2004). Trower et al. (1990) explained that anxious reactions are part of a biological defense system that is innate in human beings. This biological system serves as an individual safety system motivated by reinforcement. Physiological evidence has been found to support such claims (Beatty \& Heisel, 2007), and indicates that verbal planning results in different cortical responses. Specifically, Beatty and Heisel (2007) asked 66 students to form a plan in which their goal was to retrieve $\$ 50$ from a friend who had borrowed the money, and still remain on good terms with the friend. These authors monitored electrical activity in the prefrontal cortex during verbal 
planning, and found that electrical activity increased during plan failure compared to the condition that required no change in plans. These results are important because they provide physical evidence for changes in mental representations of goal states, temporal ordering of action, information retrieval from the short-term memory, and attention shifts when planning verbal interactions (Beatty \& Heisel, 2007).

Further, McCroskey and Beatty (1998) asserted that anxiety may result from an inability to communicate one's feelings and emotions. Thus, lacking communication competence may cause frustration and fear, resulting in anxiety which may impede effective communication within relationships. Again, this may be especially problematic when attempting to engage in social interactions or escalate a relationship. It is plausible that goal formation and planning may help to reduce anxiety stemming from a lack of communication competence. In other words, forming goals or planning interactions may increase an individual's ability to communicate, while simultaneously decreasing communication apprehension. In addition to communication apprehension, scholars have identified two other specific types of anxiety that may be especially problematic in interpersonal interactions: social anxiety and dating anxiety. Accordingly, the following sections will outline the differences in social and dating anxiety, explaining how each may be problematic for interpersonal relationships.

Social anxiety. Social anxiety is characterized by an "excessive fear and avoidance of social or performance-based situations in which one could be scrutinized by others" (Glick \& Orsillo, 2011, p. 1). Social anxiety consists of fear of negative evaluation, social avoidance and distress, and avoidance of new situations and unfamiliar peers (LaGreca \& Lopez, 1998). According to Trower et al. (1990), social anxiety is an 
anticipatory cycle that begins with the fear of negative evaluation of the social self (i.e., self-presentation performances) and fear symptoms interfering with performance.

Further, these authors explained that social anxiety is a unique product of the social environment (e.g., the people involved in a situation), as opposed to the physical environment (e.g., the way in which a room is set up). For these reasons, social anxiety may be especially impactful on interpersonal relationships.

Two common predictors of social anxiety that have been identified by communication researchers are friendship quality (LaGreca \& Harrison, 2005) and sex (LaGreca \& Lopez, 1998). Both of these factors may influence the overall social environment of a particular situation. Specifically, LaGreca and Harrison (2005) found that relational victimization and negative interactions in adolescent friendships (ages 14 to 19) predicted high social anxiety and depressive symptoms. These authors contended that these symptoms may stunt other relationships as well, possibly resulting in low selfesteem. These results support the notion that social anxiety is rooted in fear of negative evaluation from others, particularly peers. Additionally, LaGreca and Lopez (1998) found that girls reported more social anxiety than boys, and girls with higher levels of social anxiety reported fewer friendships, less intimacy, and less support from their friends. Thus, it is important to consider the sex of the individual when examining social anxiety. Again, these findings are important because they indicate that social anxiety generally hinders relational quality.

Along with obstructing relational quality, social anxiety may also result in detrimental behavioral and emotional problems. Behaviorally, Burke and Stephens (1999) argued that social anxiety is a significant motivation for college student binge 
drinking. These authors articulate that the relationship between social anxiety and heavy drinking for college students may be moderated by alcohol expectancies and self-efficacy beliefs specific to socially anxious situations. They proposed a social cognitive model that may be used to guide binge drinking intervention efforts associated with social anxiety. Importantly, this model emphasizes the cognitive processes that accompany social anxiety and may lead to detrimental behavioral outcomes. Binge drinking is not the only detrimental behavior that may result from social anxiety. In fact, Leary and Dobbins (1983) reported that individuals who were high in heterosexual anxiety had more apprehension about sex, and reported more sexual dysfunction than those who were low in heterosexual anxiety. This study indicates that heterosexual anxiety is directly related to both sexual cognitions (e.g., sexual apprehension) and sexual behavior, providing further indication of the importance of examining anxiety from a cognitive and social lens.

Along with behavioral problems, social anxiety has also been found to lead to other anxious emotions. Glick and Orsillo (2011) found that individuals high in social anxiety reported more fear of losing control over emotions, more thought suppression, more distress about emotions, and less perceived control over emotions than those low in social anxiety. Finally, in order to further understand the cognitive thought processes of clinically anxious individuals, Ononaiye, Turpin, and Reidy (2007) examined attentional bias threats that occur at the preconscious and conscious levels of anxious and nonanxious individuals. Participants performed a visual dot probe task which included four word groups: somatic sensation words (e.g., nervous, blushing), negative evaluation words (e.g., stupid, criticized), social situation words (e.g., assessment, public), and 
physical threat words (e.g., injury, ambulance). Results indicated that highly socially anxious individuals demonstrated an attentional bias toward physical threat words compared to those who were low in social anxiety. This study solidifies the argument to evaluate the role of cognitive processes when remediating anxiety.

Overall, the results of these studies indicate that social anxiety is an important construct to examine interpersonally because its effects are capable of not only damaging the self-construct of an individual, but surrounding interpersonal relationships as well. Similarly, dating anxiety may also hinder effective interpersonal relationships. To that end, the following literature identifies the detrimental effects of dating anxiety on interpersonal relationships, while also describing the differences between this type of anxiety and social anxiety.

Dating anxiety. Dating anxiety is another specific form of anxiety that may harm effective communication within interpersonal relationships. According to Glickman and LaGreca (2004), dating anxiety refers to the worry, distress, and inhibition experienced during interactions with dating members of the opposite sex. This conceptualization has been criticized for focusing specifically on heterosexual relationships (Chorney \& Morris, 2008), and scholars have turned to other definitions, including that of Hope and Heimberg (1990), who conceptualized dating anxiety as the, “...distress associated with interactions with potential romantic partners prior to the development of a full-fledged relationship" (p. 220). Nevertheless, scholars do seem to agree that dating anxiety is composed of the anxiety, avoidance, and fear of negative evaluation related to dating situations (Glickman \& LaGreca, 2004), and is distinctly different from social anxiety because it stems from a romantic interest. This anxiety and fear is problematic because it 
may lead to ineffective communication in dating relationships. Martinson and Zerface (1970) suggested that dating anxiety is especially prevalent in college students and is often coupled with social anxiety. However, this anxiety may be helped by forming goals or IIs focused on these avoidance fears.

Several predictors of dating anxiety have been identified. For example, younger adolescents (ages 15 and 16) tend to display more dating anxiety than older adolescents (ages 17 and 18), and boys report more social distress when dating than girls (Glickman \& LaGreca, 2004). Further, LaGreca and Mackey (2007) found that adolescents' number of opposite-sex friends significantly predicted dating anxiety, such that individuals who had more friends of the opposite sex had less dating anxiety. These authors also explained that individuals with less positive and more negative interactions with their friends and romantic partners reported having more dating anxiety, as well as those who have never had a romantic relationship, or did not have a current romantic partner.

Shyness, introversion, and loneliness are additional predictors of dating anxiety. Leck (2006) found that for women, shyness and introversion were negatively related to lifetime dates and satisfaction with dating frequency. Similarly, Prisbell (1988) reported that individuals with high loneliness reported significantly fewer dating skills, less satisfaction with dating, and less dating frequency than those with low loneliness. Indeed, all of these factors may impede effective communication within relationships.

Communication competence is another factor that contributes to dating anxiety. Sidelinger, Frisby, and Booth-Butterfield (2009) found that interpersonal communication competence mediated the relationships between negative perceptions of self and dating anxiety. In addition, Lesure-Lester (2001) reported a negative correlation between dating 
competence and social anxiety. These findings are especially pertinent in the present investigation because they highlight the relationships among communication, competence, and anxiety in general.

Like social anxiety, dating anxiety may also result in harmful behavioral and emotional problems. Behaviorally, Glasgow and Arkowitz (1975) found that low frequency dating men rated themselves as significantly less skilled and more socially anxious than high frequency dating men, supporting a self-evaluation hypothesis. Self ratings for female subjects as well as partner ratings for female subjects were in agreement in that low frequency dating females were less socially skilled. Emotionally, dating anxiety has also been found to be positively related to depressive symptoms (Glickman \& LaGreca, 2004), and increased heart-rate (Twentyman \& McFall, 1975). While these behavioral and emotional problems may hinder effective communication in relationships, studies do indicate that these problematic reactions may be remediated. The following literature examines successful anxiety remediation, while introducing potential new avenues for anxiety remediation: IIs and planning.

\section{Anxiety Remediation}

Although the aforementioned literature paints a rather grim picture of anxiety, there is a large body of research that indicates that anxiety may be remediated. One such way to remediate dating anxiety is through counseling and arranged interactions. In comparing treatment programs for 24 male, non-daters, Martinson and Zerface (1970) randomly assigned participants to individual psychological counseling or arranged interactions. Participants in the counseling condition attended counseling for one hour a week for five weeks. Participants in the arranged interactions met once a week for five 
weeks with a female student who was interested in improving her social skills. Both programs were effective in reducing anxiety, but the arranged interaction program was more effective than the counseling program in decreasing fear of dating and increasing dating. Similarly, Kalkan (2008) found that cognitive-behavioral group training decreased dating-anxiety for adolescents.

Visualization is another effective way to reduce anxiety (Ayres \& Hopf, 1985). Visualization refers to nonverbal processes used to create or recreate sensations associated with real or hypothetical experiences (Ayres \& Hopf, 1991). Literature indicates that visualization is effective in helping people overcome anxiety associated with public speaking (Ayres \& Ayres, 2003; Ayres \& Ayres Sonandre, 2003; Ayres \& Heuett, 2000; Ayres \& Hopf, 1992), employment interviews (Ayers et al., 2001), and behavioral disruptions (Ayres, 2005). Visualization is effective in reducing apprehension both immediately (Ayres \& Hopf, 1989) and over time (Ayres \& Hopf, 1990).

Skills training, systematic desensitization, and cognitive modification are additional forms of remediation that may be used to alleviate communication-based anxiety. Allen, Bourhis, Emmers-Sommer, and Sahlstein's (1998) meta analysis indicated that systematic desensitization (five studies), skills improvement (17 studies), cognitive modification (two studies), and one study combining approaches (skills plus cognitive modification, skills plus systematic desensitization) were successful at reducing dating anxiety. The study in which treatments were combined was most successful, while skills training alone was found to be least successful. Specifically, the average positive $d$ effect size was .336 , indicating a small to moderate improvement in dating anxiety. Further, the results revealed that feelings of anxiety were reduced more than the 
behavioral outcomes, which indicates that because anxiety is an emotional reaction, it might be affected more immediately by intervention, whereas behavioral changes may require more time and effort. The authors argue that dating anxiety remediation is a noteworthy area of study because remediation may increase communication competence and prevent sexual frustration and aggression that can lead to rape.

There is also a large body of instructional communication literature that suggests that public speaking anxiety may be treated (Allen, Hunter, \& Donohue, 1989; Bodie, 2010), and there are strategies that may be used to alleviate anxiety for apprehensive students in the classroom (Booth-Butterfield, 1986; Kelly, 1989). For example, highly apprehensive students prefer structured assignments with specific instructions (BoothButterfield, 1986), as opposed to assignments that allow for more individual creativity. More specifically, Booth-Butterfield (1986) found that providing apprehensive students with specific, detailed instructions is successful in alleviating anxiety associated with that task. Therefore, providing an individual with a structured, specific plan (as was done in the current investigation) should also alleviate state anxiety associated with difficult topics. Further, Kelly's (1989) skills training program, which teaches students how to engage in informal conversations, visualization, and systematic desensitization has been successful in reducing anxiety as well.

Another potential remediation for anxiety that has yet to be examined in the communication discipline is IIs. Because research indicates that planning reduces nonverbal indicators of anxiety (Allen \& Honeycutt, 1997), physiological indicators of anxiety (Beatty \& Heisel, 2007), and increases the likelihood of reintroducing anxiety provoking taboo topics in relationships (Roloff \& Ifert Johnson, 2001), it should follow 
that IIs (a specific form of planning) may be used to remediate anxiety. Further, goal formation may be another way to reduce anxiety. Recently, Crocker, Canevello, Breines, and Flynn (2010) examined the associations among interpersonal goals and anxiety. Participants in this study were asked to form interpersonal approach goals (i.e., "be constructive in your comments to others") and interpersonal avoidance goals (i.e., "avoid doing things that would be harmful to others") over a 12-week period. Results indicated that forming compassionate interpersonal goals decreased anxiety when talking to a roommate, and the authors suggested that goals may be used to increase support in interpersonal relationships. Thus, simple goal formation may also be effective in reducing anxiety associated with the discussion of difficult topics. However, before explicating Berger's (1995a, 1997) Planning Theory and the potential impact of IIs and goal formation on anxiety associated with the discussion of difficult topics in interpersonal relationships, it is necessary to understand alternative views on anxiety remediation as well. Thus, the following section introduces anxiety perspectives related to communibiology (Beatty, McCroskey, \& Heisel, 1998).

\section{Alternate Views on Anxiety Remediation}

Not all scholars agree that anxiety may be effectively remediated through social and learning theories. For example, Beatty et al. (1998) proposed a theory in which they suggested that communication apprehension represents individuals' inborn, biological functioning, independent of social learning processes. These scholars found that communication apprehension was strongly and positively related to introversion and neuroticism, both of which are traits believed to be heavily influenced by generic inheritance (Eysenck \& Eysenck, 1985). Beatty et al. commented, “.... a comparison of a 
temperament-based theory of communication apprehension to learning theories shows that genetic models are superior to learning models in terms of predictive power, explanation, and parsimony" (p. 203). In proposing that communication apprehension is a neurotic introversion, Beatty et al. argued that temperament is the dominant influence of communication apprehension, and that anxiety remediation efforts must consider the role of traits. As such, the present investigation heeded this advice by considering the role of three traits that may be particularly impactful when administering planning treatments for anxiety: need for cognition, self-efficacy, and cognitive flexibility.

Need for Cognition. Need for cognition refers to "an individual's tendency to engage in and enjoy effortful cognitive endeavors" (Cacioppo, Petty, \& Kao, 1984, p.306). Research on this trait suggests that individuals who are high in need for cognition are more inclined to seek, acquire, think about, and reflect back on information to make sense of stimuli than those who are low in need for cognition (Cacioppo \& Petty, 1982). In contrast, individuals who are low in need for cognition are more likely to rely on social comparison processes (e.g. comparing self to celebrities, friends, family) to make sense of situations. Thus, Cacioppo and Petty (1982) concluded that individuals who are high in need for cognition are more receptive to intellectual types of stimuli (e.g., problem solving, reading, comprehensive exams) than those low in need for cognition. Further, individuals who are high in need for cognition tend to be more affected by argument quality (Cacioppo, Petty, \& Morris, 1983) and more resistant to counter message arguing (Haugtvedt \& Petty, 1992) than those low in need for cognition.

In addition, Haddock, Maio, Arnold, and Huskinson (2008) found that need for cognition influences receptivity to affect and cognition based persuasive messages. More 
specifically, cognitive messages elicited more receptivity for those who were high in need for cognition, whereas affective messages elicited more receptivity for those low in need for cognition. These findings are particularly important to the current study, which provided simplistic plans (i.e., an II or a goal) to participants. Based on these findings, it should hold that individuals who are low in need for cognition will be more receptive to simplistic plans that require little thought than those who are high in need for cognition. Accordingly, the present investigation assessed participants' need for cognition before administering the experimental manipulation.

Self-Efficacy. Self-efficacy, or an individual's belief in his/her ability to achieve a certain task (Bandura, 1997), plays a key role in human functioning. Bandura (2006) explained that efficacy beliefs influence whether people think optimistically or pessimistically about accomplishing a goal, and he suggested that efficacy guides the amount of effort individuals put into certain task. Generally speaking, individuals who feel highly self-efficacious are confident in their abilities to achieve a certain task, while those who are low in self-efficacy do not have confidence in their abilities to achieve a certain task (Bandura, 2006).

Self-efficacy is another state that may be particularly influential when examining the effects of planning on anxiety associated with the discussion of difficult topics in interpersonal relationships. For example, individuals who are confident in their ability to communicate about a difficult topic may be more impacted by planning because they may feel more certain that they can actually carry out the plan. In contrast, individuals who are not confident in their ability to talk about a difficult topic may be more resistant to planning because they may not believe that they can actually carry out the proposed 
plan. Therefore, this investigation also assessed participant's self-efficacy in talking about difficult topics with individuals they are close with before administering the experimental manipulation.

Cognitive Flexibility. Cognitive flexibility refers to a "person's (a) awareness that in any given situation there are options and alternatives available, (b) willingness to be flexible and adapt to the situation, and (c) self-efficacy in being flexible" (Martin \& Rubin, 1995, p. 623). Individuals who are cognitively flexible believe they can be successful in different communication situations and can make the necessary changes to achieve interaction goals (Martin \& Anderson, 1998). This trait is suspected to be related to anxiety remediation efforts involving planning because research indicates that individuals who are high in cognitive flexibility report greater self-efficacy and selfmonitoring skills than people lower in cognitive flexibility (Martin \& Rubin, 1995). Therefore, an individual who is cognitively flexible may feel more confident in their ability to engage in an anxiety-provoking conversation because they feel efficacious and possess the ability to monitor themselves in a sensitive situation. Further, research indicates that cognitive flexibility is negatively correlated with Machiavellianism and verbal aggression, and positively correlated with argumentativeness and tolerance for disagreement (Martin, Anderson, \& Thweatt, 1998). Because anxiety-provoking discussion topics may lead to disagreement due to their sensitive and controversial nature (Baxter \& Wilmot, 1985), individuals who are cognitively flexible may be able to engage in such conversations more readily than those low in cognitive flexibility. Additionally, individuals who are flexible view themselves as being both responsive and assertive 
(Martin \& Anderson, 1998), both of which are useful traits when engaging in an anxietyprovoking discussion.

Importantly, Chesebro and Martin (2003) reported that cognitive flexibility was positively related to conversational sensitivity and negatively related to interpersonal aggression. Further, cognitive flexibility has also been found to be positively related to self-compassion (Martin, Staggers, \& Anderson, 2011), which may provide support that a flexible individual would feel less anxiety in a difficult situation because they will feel more kindness toward themselves. Therefore, the current investigation also assessed cognitive flexibility prior to the experimental manipulation.

Although McCroskey and Beatty (1998) argued that “changing one's CA level typically is very difficult, and for some, impossible" (p. 228), other scholars believe that "treatment is of great importance even within a communibiological paradigm" because cognitive therapies may be used to alter cognitions about anxiety (Kelly \& Keaten, 2000). Therefore, this study examined cognitive therapies rooted in planning, while also considering the impact of these three traits on planning processes. Thus, the following section will introduce Berger's (1995a, 1997) Planning Theory, which may be used to understand the potential impact that IIs and goal formation have on anxiety associated with the discussion of difficult topics in interpersonal relationships. These remediation techniques may then be used to combat the problematic effects that anxiety has on communication in relationships, and may be applied to specific situations in order to improve relational communication. 


\section{Theoretical Framework: Planning Theory}

Goal formation and planning provide a useful lens from which to investigate additional remediation for problems related to anxiety. According to Berger (1995a), goals are defined as "end states toward which a person strives" (p. 143), while plans are conceptual representations of actions. Stated differently, goals refer to future states of affairs which an individual is committed to achieving or maintaining, and a plan is that which specifies the set of actions necessary to achieve a goal. Explicitly, plans follow from goals (Dillard, 1990), and Bates and Samp (2011) noted that "plans specify the means by which to achieve one's goals via communication" (p. 209).

Plans are driven by mental scripts stored in the long-term memory, and the steps that take place in planning a goal include determining the sequence of action, anticipating outcomes, adjusting outcomes based on anticipated results, and identifying plans within actions (Berger, 1995a). In exploring the sources of knowledge individuals draw upon to make plans to reach social goals, Berger and Jordan (1992) found that specific episodes, ensembles of episodes, hypothetical episodes, role models, instructions, and previous plans were used as sources to make plans and goals. Generalized knowledge sources were applied more frequently to plan familiar goals, while specific, vivid instances were employed most frequently when developing integration plans (e.g., become friends with a new roommate). Examining plans and scripts in conjunction with anxiety is important because it taps into the cognitive processes that may direct anxiety in social interactions.

Berger (1995a) also delineated the differences between implicit goals (i.e., goals that individuals are generally unaware of and unable to articulate) and explicit goals (i.e., goals that are known and articulated). Thus, it is possible to have a goal that one may not 
be fully, consciously aware of. This is an area of criticism in Berger's Planning Theory because it may not be possible to study a phenomenon that does not exist at a conscious level (Berger, 2002). To that end, communication scholars have focused primarily on explicit goal planning, which was the aim of the present investigation.

Berger (2002) articulated the difference between online planning and offline planning. Online planning takes place during an interaction and offline planning takes place before an interaction occurs. It is difficult to predict and test how an individual will change his or her plans during an interaction because this often depends on the roles of other individuals; however, Berger (2002) suggested that offline planning is more effective in achieving goals than online planning because offline plans are often embedded in the long term memory. In contrast, online planning is related to the short term memory. For both of these reasons, the current investigation will focus on offline planning.

Next, Dillard (1990) explained that individuals have influence goals and secondary goals. Influence (or primary) goals reflect an individual's desire to bring about behavioral change in a target person, and secondary goals shape the influence process. Primary goals are more central to the interaction, while secondary goals are more peripheral. Dillard, Segrin, and Harden (1989) identified five secondary goals: identity goals (i.e., objectives related to self-concept), interaction goals (i.e., goals concerned with social appropriateness), personal resource goals (i.e., goals focused on increasing or maintaining relational and/or physical assets), relational resource goals (i.e., goals focused on personal rewards and gratifications which arise from participation in a relationship with the target), and arousal management goals (i.e., the desire to maintain a 
state of arousal). The authors concluded that primary goals serve to initiate and maintain social action, while secondary goals act as a set of boundaries that guide verbal choices available to sources. Using both primary and secondary goals, Dillard (1990) posited the Goals-Plans-Actions sequence: decision to engage, plan generation, plan selection, tactic implementation, target response, and goal assessment. This investigation examined the impact of planning on anxiety (e.g., arousal), which may be labeled as secondary goal in interactions (e.g., to manage anxiety).

\section{Assumptions and Propositions of Planning Theory}

Berger (1997) posited five fundamental assumptions undergirding the plan-based approach to strategic communication. The first assumption states that "social actors" actions are based on their interpretations of their own and others' actions, not on the actions themselves" (p. 7). Because a large portion of interpretation occurs implicitly, or outside of one's conscious awareness, Berger contended that it is more important to measure interpretations of actions. In other words, it is an individual's interpretation of a situation that matters because the interpretation is what provides contextual meaning to a situation. Second, Berger explained that interpretive processes are largely unconscious, meaning that individuals often evaluate behavior without thinking. This assumption supports assumption one, highlighting again, the role of implicit interpretation. The third assumption suggests that knowledge of goals and plans are used to guide an individual's actions and understand others' actions. This assumption sheds light on the importance of explicit goals and commonly used scripts in understanding interactions. Fourth, Berger explains that knowledge structures may be influenced by mediated (e.g. self-help books, television) or unmediated (e.g., trial and error, observing others) experiences. Finally, 
Berger points out that knowledge structures are important to examine and understand in social actions, but there are other factors that may contribute to the effectiveness of an interaction as well.

Along with these five assumptions, Planning Theory is comprised of 11 propositions and eight corollaries. These propositions and corollaries may be used to explain the genesis of plans, which is important for understanding the cognitive processes involved in plan development. Further, these propositions address the importance of goal desire and the hierarchy principle. While all propositions and corollaries will be discussed, special attention will be given to the propositions most relevant to the current investigation.

Proposition 1 and its corollary suggest that individuals derive plans from two main sources: the long term memory and current information inputs. Individuals will first turn toward their long term memory to access plans because it is less taxing than generating a new plan. Berger (1997) wrote,

Proposition 1: When persons derive plans to reach goals, their first priority is to access the long-term memory to determine whether an already-formulated or canned plan is available for use.

Corollary 1: When individuals fail to find canned plans in long-term memory, they will resort to formulating plans in the working memory utilizing potentially relevant plans from a long-term store, from current information inputs, or both (pp. 26-27). 
Simply stated, individuals will first look for existing plans in the long-term memory, before turning toward different information inputs (e.g., books, media sources) to generate a new plan.

Proposition 2 stated, "As the desire to reach a social goal increases, the complexity with which plans are formulated also tends to increase" (Berger, 1997, p. 29). This proposition suggests that detailed plans not only lay out a course of action, but also anticipate events and contingencies that might interfere with goal achievement. For example, anxiety is one such contingency that may interfere with goal achievement. Therefore, it is important to assess desire, or motivation when evaluating goals and plans, as this desire may aid in combating contingencies.

Proposition 3 and its corollary offer insight into the complexity of plans. Individuals may possess strategic knowledge regarding how to obtain a goal in general, but lack specific knowledge about how to achieve that goal. For example, an individual might know that talking about a difficult interpersonal topic will relieve their anxiety associated with that topic (strategic knowledge), but may feel unsure about how to specifically bring up that topic in conversation (specific knowledge). If, however, both strategic and specific knowledge are present, plan complexity tends to increase. Specifically, Proposition 3 and its corollary state, Proposition 3: Increases in strategic domain knowledge and specific domain knowledge tend to produce increases in the complexity of plans within that domain.

Corollary 1: Maximally complex action plans will be generated when high levels of both strategic domain knowledge and specific domain knowledge 
are obtained. Low levels of strategic domain knowledge or high levels of strategic domain knowledge with low levels of specific domain knowledge produce plans with lower levels of complexity (Berger, 1997, p. 31).

It is important to note that research has not always supported proposition 3 and its corollary with regard to verbal fluency. For example, Berger, Karol, and Jordan (1989) examined the relationships among plan complexity, access to planned actions, and verbal fluency while pursuing a persuasion goal. Results indicated that complex planners were less fluent than less complex planners under high access conditions (i.e., situations where one could obtain several alternatives). Thus, the present investigation explored this idea of specificity by evaluating the effects of IIs (explained below), which are geared at specific, yet simple, plan formation.

Proposition 4 combines the ideas presented in the previous propositions, by predicting an interaction between desire and knowledge.

Proposition 4: Strength of desire and levels of strategic and specific domain knowledge interact to produce differences in plan complexity. High levels of desire and high levels of knowledge produce more complex plans. Low and high desire levels coupled with low knowledge levels should produce less complex plans (Berger, 1997, p. 32).

That is, plans will be more detailed and complex when an individual is both motivated and possesses specific knowledge regarding their goal.

Next, Proposition 5 states, "Increased concerns for the meta-goals of efficiency and social appropriateness tend to reduce the complexity of plans to reach social goals" (Berger, 1997, p. 33). Importantly, this proposition concerns ideas surrounding social 
desirability and efficiency. Berger explained that individuals generally wish to achieve their goals quickly and appropriately.

Proposition 6 and its corollaries are especially important when considering the role of anxiety in planning and goal attainment. Berger (1997) wrote, Proposition 6: When people experience thwarting internal to the interaction, their first response is likely to involve low-level plan hierarchy alternatives. Continued thwarting will tend to produce more abstract alterations to plan hierarchies.

Corollary 1: Elevated levels of goals desire will propel planners to make more abstract alterations to plan hierarchies when their plans to reach social goals fail.

Corollary 2: Planners with high levels of goals desire, who experience repeated thwarting of goal-directed actions, will manifest higher level alterations to their plans earlier in the goal failure-plan alteration sequence than will planners with lower levels of goal desire who experience repeated goal failure (p. 35).

These statements suggest that individuals may experience both internal and external blockage, or thwarting, when carrying out a goal. Anxiety is a prime example of internal blockage because it may interfere with thoughts when trying to discuss a difficult interpersonal problem, or carry out a plan. An example of external blockage or thwarting may be that the person an individual wishes to talk to is not available. Research needs to explore the role of planning by reducing any internal thwarting that may occur due to anxiety when discussing difficult interpersonal problems.

Proposition 7 and its corollaries state, 
Proposition 7: Attainment of a superordinate goal will produce positive affect. Interruption of a plan will result in the induction of negative affect.

Corollary 1: The intensity of affect experienced after goal attainment or interruption is positively related to the importance of the goal.

Corollary 2: Given the unavailability of contingency plans, the closer to the goal the interruption occurs, the more intense the negative affect will be. The presence of contingency plans will tend to dampen the intensity of negative affect experiences.

Corollary 3: The greater the investment of time and energy in the pursuit of a goal, the more intense the negative affect experienced will be when interruption occurs. Again, the presence of contingency plans will tend to dampen the intensity of negative affect (Berger, 1997, p. 38).

This proposition and corresponding corollaries were incorporated by assessing individuals' self-perceived effectiveness in achieving the goal because perceived effectiveness should reflect (to some extent) an individual's affect associated with an event. Further, this study was a longitudinal investigation, increasing the investment of time and energy associated with the goal pursuit.

Proposition 8 and its corollary state,

Proposition 8: Repeated thwarting of plans will lead to the instantiation and enactment of progressively less socially appropriate plans.

Corollary 1: The importance of the goal determines the extent to which one will continue to deploy successfully less socially appropriate plans in response to thwarting. The more important the goal, the more one will be 
willing to employ less socially appropriate plans (Berger, 1997, pp. 38$39)$.

Taking this proposition into consideration, this study explored goals and plans associated with the discussion of difficult interpersonal topics. It was expected that the issues evaluated were of importance to the participants, if they were, in fact, anxiety-provoking and difficult. However, a measurement of goal importance was assessed in order to determine if participants perceived the goals to be important.

Next, Proposition 9 states, "With repeated thwarting over time, resulting in the induction of higher levels of negative affect, plans will become progressively less complex" (Berger, 1997, p. 39). This proposition recognizes the importance of feedback loops in impacting desire to continue goal pursuit. In other words, continued plan failure results in negative affect (e.g., anxiety), which may hinder one's desire to continue goal pursuit and result in more simplistic plans.

Proposition 10 proposes a curvilinear effect among action fluidity (i.e., verbal and nonverbal smoothness) and alternative plans stating,

Proposition 10: Under conditions of goal failure, individuals whose plans contain no alternative actions and those whose plans contain numerous action alternatives at the point of thwarting will manifest lower levels of action fluidity than those whose plans contain a small number of contingent actions (Berger, 1997, p. 40). This proposition indicates that goal failure can impact verbal fluidity, which should also be assessed when evaluating goal pursuit. Further, alternative plans must be taken into consideration when assessing fluidity. 
Finally, Proposition 11 suggests that plans must be readily available when needed. This notion is also especially important in the development and use of IIs, which should be automatic (Gollwitzer, 1999). Berger (1997) wrote,

Proposition 11: Increased access to planned actions will generally increase action fluidity levels in such a way that the curvilinear relationship between the number of alternatives and action fluidity will be maintained but displaced upward relative to the same function obtained under conditions of reduced action access (p. 41).

This proposition is in accordance with priming theories (Collins \& Loftus, 1975) and concepts of automatic and controlled cognitive processes (Posner \& Snyder, 1975), which suggest that an idea that is primed or available is more likely to be accessed (i.e., cognitive accessibility). In other words, something that is automatic will be completed without any type of thought. This study attempted to make an II automatic for participants by having them practice their II over an extended period of time, expectedly increasing their action fluidity during goal pursuit.

While not all of the aforementioned propositions and corollaries are directly pertinent to the current study, all propositions are useful in understanding the in-depth processes that take place when forming plans. Therefore, all propositions are helpful in developing a more comprehensive understanding of how plans can most effectively be implemented. However, like any theory, Planning Theory does have some criticisms, which were taken into consideration in the present investigation. 


\section{Difficulties/Criticisms of Planning Theory}

While it is evident that the propositions and corollaries of Planning Theory offer a broad range of issues for researchers to examine, this theory is not without its criticisms. For example, Dillard (1997) discussed the differences between approach and avoidance goals, explaining that approach and avoidance goals contain different motivations and have different effects. He explained that the researcher must know what type of goal he or she is studying. As previously mentioned in Proposition 6, anxiety may result in “internal thwarting," interfering with goal attainment. Therefore, this study specifically examined anxiety as an avoidance goal.

Dillard (1997) also asserted that one must be committed to a goal in order to pursue the goal. Therefore, the participant must see the goal as being important, otherwise goal pursuit will likely be low. This investigation evaluated goal importance, in order to assess the extent to which participants valued the goal they were asked to pursue. While this theory is wide in scope, this examination focused on the specific aspects presented in the propositions mentioned above.

\section{Effects of Planning on Communication and Behavior}

Studying the effects of planning on goal pursuit is productive because literature suggests that planning affects anxiety (Allen \& Honeycutt, 1997), perceived conflict resolution (Bates \& Samp, 2011), stress (Battman, 1989), initiation of social relationships (Berger \& Bell, 1988), speech pauses (Berger \& Jordan, 1992; Greene, McDaniel, Buska, \& Ravizza, 1993), and speech fluency (Berger et al., 1989). More specifically, Allen and Honeycutt (1997) reported that individuals use fewer object adaptors when planning before a social interaction, indicating that planning reduces nonverbal anxious behaviors. 
Additionally, Berger et al. (1989) found that complex planners were less fluent than less complex planners under high access conditions (i.e., situations where one could obtain several alternatives). Thus, as stated above, it may be better to form a simple plan rather than a complex plan. Similarly, Greene et al.'s (1993) study indicated that individuals pause more and for a greater duration when forming messages of incompatible goals. These results are in accordance with those of Berger and Jordan (1992), who reported that individuals paused more when developing more difficult plans. Planning has also been found to reduce stress and increase task efficiency (Battman, 1989). For example, Battman (1989) found that individuals who were required to organize client calls in an efficient order produced more efficient routes when planning prior to the task.

With regard to conflict situations, which may be classified as difficult interpersonal situations, Bates and Samp (2011) examined the effects of planning (plan vs. not plan) on the likelihood of conflict resolution in romantic relationships. Participants included 82 dating couples who discussed a relational problem and a problem-solving task for 10 minutes. Results indicated that planning was not associated with perceived conflict resolution. However, the authors mentioned that planning offline may result in plan fixation during conversation, and suggested that individuals be taught how to resolve conflict before being asked to form a plan. IIs should work to specify when, where, and how the participant should pursue his or her goal.

Aside from being used in existing, interpersonal relationships, research also indicates that planning may be useful in the initiation of social relationships. For example, Berger and Bell (1988) asked participants to describe how they would request a date from a member of the opposite sex and how they would integrate themselves with a 
new roommate. Plans were judged for effectiveness (i.e., likelihood of success) and analyzed for types of actions by independent coders. Results indicated that loneliness and shyness were inversely correlated with plan effectiveness in the roommate situation for both sexes. Males with ineffective dating plans reported higher shyness and loneliness than their counterparts. Importantly, this research informs studies conducted on anxiety and planning because loneliness, shyness, and anxiety are all positively correlated (Leck, 2006; Prisbell, 1988).

Taken together, it is clear that planning impacts several behaviors, including anxiety. Therefore, it is reasonable to assume that planning may impact anxiety associated with the discussion of difficult topics in interpersonal relationships. However, several of the empirical studies explained above suggest that the formation of specific plans, as opposed to general goals, may be more effective in goal pursuit (i.e., Bates \& Samp, 2011). As such, a specific form of planning was evaluated in the present investigation, aimed at creating focused, if-then plans.

\section{Proposed Solution: Implementation Intentions}

Implementation intentions (IIs) are a specific form of planning that have yet to be examined in the communication discipline. They are simple, focused if-then plans that "specify the when, where, and how of responses leading to goal attainment" (Gollwitzer, 1999, p. 494). IIs have the structure of "If $x$ arises, then I will perform response $y$. " They are distinct from goal intentions, which specify a certain end point (e.g., "I intend to reach $x ")$, but not necessarily the when, where, and how that goal will be achieved. The primary aim of IIs is to secure goal attainment through specific plans. Gollwitzer (1999) proposed that the II if-then plans provide better outcomes than simply setting goals, and 
are a necessary secondary act in goal attainment, working specifically to bridge the intention-behavior gap. IIs have been found to be especially effective in the health context, examining issues such as eating a low fat diet (Armitage, 2004), organic food purchase (Bamberg, 2002), exercise (Milne, Orbell, \& Sheeran, 2002; Prestwich, Lawton, \& Conner, 2003), binge drinking (Murgraff, White, \& Phillips, 1996), vitamin supplement use (Sheeran \& Orbell, 1999), smoking (Conner \& Higgins, 2010), and cervical cancer screening (Sheeran \& Orbell, 2000), to name a few. Other contexts in which IIs have been found to be effective include public transportation use (Bamberg, 2000), stereotyping (Bayer, Gollwitzer, \& Achtziger, 2010), effective goal pursuit (Gollwitzer \& Brandstatter, 1997), test distractions (Parks-Stamm, Gollwitzer, \& Oettingen, 2010), and writing a curriculum vitae (Brandstatter, Lengfelder, \& Gollwitzer, 2001). Indeed, IIs are effective in many diverse contexts.

An important component of IIs is that action initiation should be swift, acquiring features of automaticity (Gollwitzer, 1999). Gollwitzer and Sheeran (2006) wrote, "As forming implementation intentions implies the selection of a critical future situation, it is assumed that the mental representation of this situation becomes highly activated" (p. 83). This claim is similar to those set forth by Berger (1997), in that cognitive processes (e.g., long term memory and scripts) play a role in plan development and enactment. Thus, IIs and Planning Theory are highly linked, with IIs simply adding features of specificity to the plan development.

In testing the automatic nature of IIs, Brandstatter, Lengfelder, and Gollwitzer (2001) examined IIs under conditions of high cognitive load. In their investigation, Study 1 tested the effects of IIs on 41opiate addicts going through withdrawal, while 
Study 2 tested the effects of IIs on 20 schizophrenic patients. Results of Study 1 and Study 2 indicated that individuals currently experiencing cognitive load (e.g., withdrawal or mental disorders) benefitted from the use of IIs in completing simple, mundane tasks (e.g., handing in a vitae and completing a computer task).

Further, IIs have also been found to shield goal pursuit from antagonistic priming. Antagonistic priming is a process that makes undesirable behaviors more accessible to participants than the desired behavior (i.e., the goal or II). In order to prime participants to respond quickly or slowly, Gollwitzer, Sheeran, Trotschel, and Webb (2011) asked participants to either read about fast animals (e.g., cheetahs, pumas) or slow animals (e.g., slug, tortoise). Participants then formed an II about completing a visual dot probe test in which they identified words quickly or slowly. Results indicated that priming does not affect behavioral responses if IIs are formed. Further, participants who were primed with a prosocial goal allowed a confederate who asked for help to interrupt their work for a longer period of time than those who formed an II to concentrate on the task. Finally, their results indicated that priming increased driving speed and errors for those who formed goal intentions, but not for those who formed IIs. Again, these results support the automatic nature of IIs, even in the presence of priming. For these reasons, participants in this study were asked to practice their II or goal, in order to make it automatic.

Overall, IIs have demonstrated moderate to high levels of effectiveness in goal achievement. In a meta-analysis of 94 studies conducted by Gollwitzer and Sheeran (2006), IIs had a positive effect of medium-to-large magnitude on goal attainment $(d=$ .65). Importantly, they were found to be effective not only in initiating goal striving, but also in shielding goal pursuit from unwanted influences (e.g., anxiety or internal 
disruptive states), and disengagement from failing courses of action. Thus, the authors concluded that IIs are not only influential in aiding goal attainment, but also in preventing goals from being interrupted by other influences. Again, this claim is similar to those set forth in Berger's (1997) Planning Theory, which suggests that planning may be used to halt internal thwarting (i.e., Proposition 6). Thus, both simple goal formation and IIs should be effective in the pursuit of avoidance goals (i.e., anxiety).

\section{Effects of IIs on Communication and Behavior}

As previously mentioned, IIs have been tested and found to be effective in altering behavior. For example, Armitage (2004) examined the effects of IIs on eating a low fat diet by randomly assigning 264 participants to an II condition or a control group. The II group had to form IIs regarding eating a low fat diet. Results indicated that after one month, fat intake, saturated fat intake, and the proportion of energy derived from fat decreased significantly in the experimental group, but not in the control group, who did not form any kind of plan. Similar results regarding the effectiveness of forming IIs on healthy eating were found by Bamberg (2002).

Other health behaviors that have been examined with regard to II formation include smoking (Connor \& Higgins, 2010), binge drinking (Murgraff et al., 1996), and exercise (Milne et al., 2002). Specifically, Connor and Higgins (2010) randomly assigned participants to one of four conditions: II $(n=48)$, self-efficacy $(n=54)$, control group $1(n=101)$ and control group $2(n=102)$. An II or a self-efficacy manipulation (e.g., "I can say to smoking, even at school!") was completed by intervention

group participants in the lab at $4,8,12,16,20$, and 24 months. They did not receive any reminders between these assessments. Results indicated that there were no differences 
between the two control conditions and the self-efficacy condition. Even when controlling for baseline smoking, sex, attitudes toward smoking, and friends and family smoking, the II manipulation significantly reduced self-reported smoking compared to the other three conditions combined. The authors also objectively assessed smoking (i.e., carbon monoxide breath measure) in a random subsample of the participants, which indicated that the II manipulation significantly reduced smoking compared to the other three conditions.

In a similar study, Murgraff et al. (1996) randomly assigned participants to a control group or a planning group. The control group was given a presentation on the harmful nature of binge drinking, and was asked to moderate their drinking over a twoweek period. Participants in the planning intervention group received an option menu (immediately after the presentation) of possible responses for refusing a drink, and was asked to choose one strategy and specify a time and place in which the chosen strategy would be implemented. At a two-week follow-up, participants in the planning intervention group reported lower drinking frequency than the control group participants. These participants did not receive reminders regarding their II in the two-weeks. Finally, Milne et al. (2002) found that an II intervention significantly increased exercise behavior over two-weeks for undergraduate students. Similar results were found by Prestwich et al. (2003).

Other situations in which IIs have been found to be effective include public transportation use (Bamberg, 2000), cervical cancer screening (Sheeran \& Orbell, 2000), breast self-examinations (Orbell, Hodgkins, \& Sheeran, 1997), and taking a daily vitamin (Sheeran \& Orbell, 1999). Bamberg (2000) randomly assigned participants to an 
experimental or control group. Individuals in the experimental group were asked to form one II (just one time) to use a type of public transportation that they have never used before. Results indicated that forming an II significantly increased public transportation use over a one-week period. Sheeran and Orbell (2000) reported that the Theory of Planned Behavior variables (i.e., knowledge, subjective norms, attitude toward behavior, perceived behavioral control, and behavioral intention) significantly predicted cervical cancer screening attendance. However, participants who formed the II were more likely to attend screening than the control groups ( $92 \%$ vs. $69 \%$ attendance rates). Similarly, Orbell et al. (1997) found that individuals in the II group were more likely to perform a breast self-examination than those in the control group. Finally, Sheeran and Orbell (1999) found that participants who formed IIs were less likely to miss taking a Vitamin C pill every day compared to the control groups, who did not form IIs. Overall, results from these studies suggest that forming IIs is effective in enacting goal pursuit, particularly in the health context, as well as an effective supplement to goal intentions.

Most relevant to the current investigation are studies conducted on IIs and difficult social situations, as well as IIs and anxiety. There are several key studies that inform both of these areas. First, discussing the use of condoms may be perceived as a difficult topic for some individuals. In a study conducted by de Vet et al. (2011), young, single females formed IIs for using condoms (i.e., writing what they would do, where they would do it, and when they would do it), or for buying condoms and discussing their use (i.e., write down what you will say and when you will say it to your partner). These II plans were then assessed for quality and specificity. At a two-month follow-up, results indicated that individuals who formed high quality specific plans were more committed 
to these plans and perceived them as more useful than those with low quality, general plans.

It is plausible that stereotyping and mood management may be perceived as difficult cognitive topics for some individuals as well. In researching this topic, Bayer et al. (2010) found that participants who formed a fairness goal (e.g., "I will form a nonstereotypical impression!") were not able to control the positive mood effect on their impression formation ratings, while those who formed an additional II (e.g., "If I analyze a person, then I will ignore their gender!") were able to control their mood during impression formation. These results indicate that using IIs to plan in advance how one will handle impression formation makes mood management, and perhaps anxiety associated with mood management, more automatic.

Most importantly, IIs are effective in reducing different types of anxiety. ParksStamm et al. (2010) found that as test anxiety increased, temptation-inhibiting IIs (e.g., "If I hear or see the commercials, then I will ignore them!") increasingly benefited performance, whereas task facilitating IIs (e.g., "If I hear or see the commercials, then I will increase my efforts on the math task!") increasingly impaired performance. This suggests that students who experience test anxiety benefit from forming IIs to ignore distractions rather than on intensifying their efforts to focus on the task at hand. Thus, this study had participants in the II condition form an intention focused on selfaffirmation (Connor \& Higgins, 2010), rather than focusing on the task at hand.

IIs may also impact internal affective states that cause anxiety. For example, Schweiger-Gallo, Keil, McCulloch, Rockstroh, and Gollwitzer (2009) showed participants a series of disgusting, bloody images, and a series of fear-inducing spider 
images. Participants' phobias for blood and fear of spiders were carefully controlled for in this experiment. Participants were given no instructions, asked to form goal intentions (e.g., "I will not get disgusted," and "I will not get scared") or were asked to form IIs (e.g., "If I see blood, then I will not get disgusted," and "If I see a spider, then I will remain calm and relaxed"). Findings indicated that only participants in the II group reduced disgust and fear reactions compared to the goal intention and control groups. Further, the II group reported less arousal and negative affect toward the images.

Next, in a series of studies conducted specifically on social anxiety, Webb, Ononaiye, Sheeran, Reidy, and Lavda (2010) examined whether forming IIs can help people with social anxiety to make more realistic appraisals of their performance and control their attention. Using a Visual Dot Probe task with threatening words (e.g., criticized, failure), socially anxious individuals were provided with the II, "If I see a neutral word, then I will focus my attention on it.” IIs were found to be successful in reducing anxiety on this task, also supporting research on attentional biases in social anxiety (Experiments 1-3). In Experiment 4, participants were told that they would have to give a three minute speech that would be rated and evaluated by expert psychologists. High social anxiety participants were randomly assigned to one of three conditions: no instructions, goal intention (e.g., "I will remain calm"), or II ("if I feel concerned, then I will focus on the back wall of the room"). Forming an II prevented the underestimation of performance and promoted more positive and realistic performance appraisals among people with high levels of social anxiety. This was the first study to suggest that forming IIs may provide an effective means for handing self-regulatory problems in social anxiety by redirecting attention from the self to the environment. 
Most recently, Varley, Webb, and Sheeran (2011) investigated the impact of selfhelp materials (i.e., breathing and relaxation techniques) with IIs. Participants were randomly assigned to a standard self-help program $(n=81)$, an augmented self-help program $(n=90)$, or a control group $(n=78)$. Both experimental groups received an online booklet, which was based on the principles of using cognitive-behavioral therapy without therapist intervention. However, only the augmented self-help group was prompted to form two IIs based on what they had learned in the book. Both groups were encouraged to use the book over an eight week period. Results indicated a significant reduction in anxiety for the augmented (i.e., II) condition compared to the standard selfhelp condition and the control group, suggesting that IIs may be used to enhance or supplement self-help materials.

It should be noted that II formation is similar to other types of successful applied research, such as drug resistance strategy programs (e.g., Hecht \& Miller-Day, 2007; 2010). Hecht and Miller-Day $(2007$; 2010) garnered personal narratives from adolescents engaged in risky behavior to begin a successful drug resistance curriculum called keepin' it REAL. These authors explained that the success of this program was achieved by translating their narrative research into "do-able" activities in the classroom. In other words, like IIs, this program was successful due to the simplistic nature of the messages used to teach adolescents refusal skills. They argued that this type of applied research is successful in motivating social change through "practiced-based prevention science" (Hect \& Miller-Day, 2010, p. 224).

Overall, it is clear that IIs may be used both to control anxiety and impact moods and behavioral responses in difficult situations. To date, however, IIs have only been 
used to manage anxiety in intrapersonal situations (e.g., self-help, overcoming phobias, buying condoms), and have not been examined in a dyadic, interpersonal context. It is reasonable to assume that if IIs are effective in reducing anxiety in intrapersonal situations, they may also be effective in reducing anxiety in interpersonal situations (i.e., the discussion of a difficult topic with a friend or partner). Thus, the purpose of this investigation was to examine the effects of goal formation and IIs on the discussion of difficult topics in interpersonal relationships, while also considering the impact of traits on planning.

\section{Rationale}

As suggested in the aforementioned literature, planning and goal formation have been found to affect communication (e.g., fluency, speech pauses, anxiety) and behavior (e.g., initiation of relationships). Further, these studies indicated that IIs, a specific form of planning, share many similarities with Berger's (1995a, 1997) Planning Theory. Based on this research, there are three key reasons to predict that IIs and goal formation will impact anxiety and self-perceived effectiveness associated with the discussion of difficult topics in interpersonal relationships.

First, both Planning Theory and IIs suggest that goals may be formed to block external factors that may inhibit goal attainment. Anxiety is a response that may prevent goal attainment by interfering with thoughts, feelings, and actions, often resulting in physical behavioral symptoms (e.g., heavy breathing, sweating, increased heat rate; Varley et al., 2011). Speech disfluencies may also prevent goal attainment by making a message less effective (e.g., pauses, stutters). Thus, it is possible that IIs and goals may be formed to suppress anxiety responses and enhance speech performance when 
discussing difficult topics. In other words, forming a goal or II to suppress anxiety would be classified as avoidance goals (i.e., to avoid anxiety), a secondary goal. Importantly, both IIs and Planning Theory suggest that plans are influenced by cognitive processes (e.g., long term memory, scripts), and that desire or motivation impact goal pursuit. Hence, it is necessary to allow for goal formation and IIs to be pursued over a period of time, so that they are integrated into the long term memory. Previous II studies have examined the effects of IIs in a time span ranging from immediately (Gollwitzer et al., 2011; Parks-Stamm et al., 2010; Schweiger-Gallo et al., 2009; Webb et al., 2010) to twoyears (Connor \& Higgins, 2010). Additionally, Milne et al. (2002), Murgraff et al. (1996), and Sheeran and Orbell (1999) have found IIs to be effective over a two-week span. Accordingly, the present investigation took place over a two-week period. Further, a measure of motivation was assessed (Berger, 1997).

Second, the appraisal-coping model of social anxiety suggests that social anxiety may be regulated by accurately appraising arousal, emotion, and cognitions when anxious. The coping system embodies behavioral responses. This model suggests that coping plays a role in reducing anxiety (Trower et al., 1990). IIs may be considered a form of "coping" with difficult situations that cause anxiety because they may be formed specifically to appraise a situation (i.e., the "if" portion - "If I feel anxious..."), and direct a coping behavior (i.e., the "then" portion - "Then I will think about what I stand for"). Similarly, simple goal formation may be used to direct coping behavior in a more general sense (e.g., "I will not feel threatened or anxious when I talk about topic $x$ ").

Third, the action initiation of an II should be automatic, given the future orientation of forming such intentions (Gollwitzer, 1999). Berger (1997) also suggested 
that individuals strive to access goals in the most efficient way possible (Proposition 1), which usually entails tapping into the long term memory. Further, he contended that many goals are implicit, and research indicates that social anxiety responses are often immediate, unconscious, and automatic (Ononaiye et al., 2007). If anxiety symptoms are automatic, it may be best to combat them with an automatic remediation effort, such as an II or a planned goal stored in the long term memory. Thus, the purpose of this investigation was to examine the effects of IIs (i.e., if-then statements) versus simple goal formation (e.g. "I will achieve $x$ ") on anxiety and perceived communication effectiveness when discussing difficult situations in interpersonal relationships (i.e., friendships and romantic relationships).

Because the current literature on IIs consistently indicates that IIs are more effective in goal pursuit than simple goal formation (Gollwitzer, 1999; Gollwitzer \& Brandsatter, 1997; Murgraff et al., 1996; Orbell et al., 1997; Parks-Stamm et al., 2010; Prestwich et al., 2003; Schweiger-Gallo et al., 2009; Sheeran \& Orbell, 2000; Webb et al., 2010), the current study predicted similar findings for the discussion of difficult topics in interpersonal relationships. That is, both simple goal formation and II formation should be effective in reducing anxiety associated with the discussion of difficult interpersonal topics, but forming IIs should be more effective. Further, the literature on planning and IIs suggests that desire, or motivation, plays a key role in goal pursuit (Berger, 1997; Gollwitzer, 1999). As such, the hypotheses and research question were as follows:

H1: Planning will affect state anxiety such that (a) individuals who form an implementation intention will report less state anxiety than those in the control 
group and (b) individuals who form a goal will report less state anxiety than those in the control group.

H2: $\quad$ Planning will affect self-perceived communication effectiveness such that (a) individuals who form an implementation intention will report more self-perceived communication effectiveness than those in the control group and (b) individuals who form a goal will report more self-perceived communication effectiveness than those in the control group.

H3: Planning will affect message length such that (a) individuals who form an implementation intention will record longer messages than those in the control group and (b) individuals who form a goal will record longer messages than those in the control group.

H4: Planning will affect motivation such that (a) individuals who form an implementation intention will be more motivated than those in the control group and (b) individuals who form a goal will be more motivated than those in the control group.

H5: Implementation intentions will have a stronger impact on the dependent variables (i.e., state anxiety, self-perceived communication effectiveness, message length, and motivation) than goal formation will have.

RQ1: How do personality traits (i.e., need for cognition, self-efficacy, and cognitive flexibility) impact state anxiety, self-perceived communication effectiveness, message length, and motivation when discussing anxiety-provoking topics in interpersonal relationships? 


\section{Summary}

This study applied Berger's $(1995 a, 1997)$ Planning Theory to a new communication context - the anxiety associated with the discussion of difficult topics in interpersonal relationships. Moreover, this study examined the effects of a new type of planning in the communication field - IIs. IIs have been found to be effective in promoting public transportation use (Bamberg, 2000), cervical cancer screening (Sheeran \& Orbell, 2000), breast self-examinations (Orbell et al., 1997), and taking a daily vitamin (Sheeran \& Orbell, 1999), among other contexts. This study serves to inform current planning theories, while offering valuable information to communication scholars wishing to remediate anxiety in the interpersonal context. Further, this study also considered the role of traits in impacting planning. The next chapter will explain, in depth, the methods used in this investigation. 


\section{Chapter Two}

\section{Method}

The purpose of this study was to examine the effects of planning on state anxiety, self-perceived communication effectiveness, message length, and motivation when discussing anxiety-provoking topics in interpersonal relationships. Specifically, two types of planning were evaluated: II formation and goal formation. Further, the effects of three personality traits on planning were examined: need for cognition, cognitive flexibility, and self-efficacy. The following sections outline the overall design of this experiment, followed by participant information, procedures, and instrumentation.

\section{Design}

This investigation was a post-test only equivalent groups experimental design. Planning was the independent variable that was manipulated and there were two levels of planning: IIs and goal formation, and a control. More specifically, the control group was a no message control group. The dependent variables in this investigation were state anxiety, self-perceived communication effectiveness, message length, and motivation when discussing anxiety-provoking topics in interpersonal relationships. Additionally, there were several covariates including trait dyadic communication apprehension, message realism, and rehearsal effects. Finally, interaction effects among condition and three traits (i.e., need for cognition, cognitive flexibility, and self-efficacy) on the dependent variables were also evaluated.

\section{Participants}

After obtaining IRB approval, undergraduate students who were at least 18 years of age were solicited for participation in courses during the spring 2012 semester. The 
researcher announced that participants had to be able to think of some topic that caused them anxiety with a romantic partner, friend, or family member to participate in this study.

Respondents were required to attend both Time 1 and Time 2 data collections, which were approximately two-weeks apart. Previous II studies have examined the effects of IIs in a time span ranging from immediately (Gollwitzer et al., 2011; ParksStamm et al, 2010; Schweiger-Gallo et al., 2009; Webb et al., 2010) to two years after formation (Connor \& Higgins, 2010). Several studies (Milne et al., 2002; Murgraff et al., 1996; Sheeran \& Orbell, 1999) have found IIs to be effective over a two-week span, which is why this particular length was chosen for this investigation. During recruitment, a sign-up sheet was distributed asking participants to report to a lab for a 30 minute time slot to complete Time 1. All participants who signed up were sent individual e-mail reminders approximately 48 hours prior to their scheduled time slot. Times were offered at various times throughout the day, Monday through Friday, from 9:00 am to 6:00 pm, resulting in a total of 40 hours in the lab for Time 1 . Of the 546 students that were recruited, 318 signed up to participate. Of the 318 that signed up to participate, a total of 202 students completed Time 1 (96 men, 104 women, 2 did not indicate sex).

The final sample consisted of 182 participants ( 85 men, 95 women, 2 did not indicate sex) who completed both Time 1 and Time 2. These final participants ranged in age from 18-32 years $(M=21.07, S D=1.81)$, and consisted of 3 freshmen, 35 sophomores, 69 juniors, 74 seniors, and 1 other. The majority of participants were Caucasian (82.4\%; Asian 3.8\%; Native American .5\%; Black/African American 6.6\%; Hispanic/Latino 2.7\%; and other 3.8\%). Sixty-four indicated that they were not currently 
in a romantic relationship, 37 were casually dating, 71 were seriously dating, and 10 were engaged or married.

\section{Procedures and Instrumentation}

Time 1. Time 1 data collection took place in the lab in small groups ranging from 1 to 8 participants. Upon arriving at the lab, all individuals in the group were randomly assigned (using a random number chart) to one of three conditions: IIs (60 participants), goal formation (64 participants), or control (58 participants). All participants were asked to read and sign an informed consent form. After this, all participants were instructed to complete the Time 1 questionnaire.

The Time 1 questionnaire first asked participants to provide a unique participant code (i.e., the last four digits of their phone number, followed by their two digit birth month) at the top of their questionnaire so that Time 1 and Time 2 data could be matched at the end of the experiment. Participants then completed four personality trait measures (i.e., need for cognition, cognitive flexibility, self-efficacy, and trait dyadic communication apprehension), described in detail below.

Need for Cognition. Need for cognition was assessed in the Time 1 questionnaire using Cacioppo et al.’s (1984) 18-item Need for Cognition Scale (Appendix A). This instrument is used to evaluate individuals enjoyment of cognitive endeavors (e.g., "I prefer complex to simple problems" and "I find satisfaction in deliberating hard for long hours"). Responses were gathered on a 5-point Likert type scale ranging from extremely uncharacteristic of me (1) to extremely characteristic of me (5), and the scale has demonstrated past reliability with Cronbach's alphas ranging from .77 to .90 (Cacioppo et al., 1984; Eckstein, 2005; Williams-Piehota, Pizarro, Navarro Silvera, Mowad, \& 
Salovey, 2006). A similar Cronbach's alpha was found in the present investigation ( $\alpha=$ $.84, M=3.30, S D=.56$ ), and item scores ranged from 2.06 to 4.44 .

Cognitive Flexibility. Individuals willingness to adapt to a situation was measured in the Time 1 questionnaire using Martin and Rubin's (1995) 12-item Cognitive Flexibility Scale (Appendix B). Responses were solicited using a 5-point Likert type scale ranging from strongly disagree (1) to strongly agree (5). Sample items from this instrument include "I can communicate an idea in many different ways" and "In any given situation, I am able to act appropriately.” Previous Cronbach's alpha reliability coefficients ranged from .72 to .82 for this instrument (Martin \& Anderson, 1998; Martin, Anderson, \& Thweatt, 1998). In this study, item scores ranged from 3.00 to $5.00(M=$ 3.94, $S D=.39)$, and this measure was found to have a reliable Cronbach's alpha $(\alpha=.69)$

Self-Efficacy. Following Bandura's (2006) guide for constructing self-efficacy scales, an 8-item scale was constructed to assess beliefs regarding individuals' capabilities to discuss difficult topics (e.g., "How confident are you in your ability to talk about a difficult topic with someone close to you," and "How confident are you in your ability to bring up a topic that gives you anxiety with someone close to you"). Bandura argues that there is no "all-purpose measure of perceived self-efficacy" and that each scale must be "tailored to the particular domain of functioning that is the object of interest" (pp. 307-308). Thus, following his standard response format, eight items were created (Appendix C). Individuals were asked to rate their confidence in performing each behavior on a scale ranging from cannot do at all (0) to highly certain can do (100).

Because this scale was constructed specifically for this study, an exploratory factor analysis was performed. This analysis was conducted utilizing the criteria 
suggested by Comrey and Lee (1992) (i.e., eigenvalues exceeded 1.0 for retained factors, with primary factor loadings of .50 or greater and no secondary loadings greater than .30). As expected, a one-factor solution was obtained for this measure, with all primary factor loadings greater than .50. Item scores ranged from 32.50 to $100.00(M=78.80$, $S D=14.23$ ), and this measure was also found to be reliable with a Cronbach's alpha of .92 .

Trait Dyadic Communication Apprehension. In order to control for general trait anxiety, trait dyadic communication apprehension was assessed using the 6-item Personal Report of Communication Apprehension (PRCA-24; McCroskey, 1982) that is specific to the acquaintance and dyadic apprehension dimension of this scale (e.g., "I am afraid to speak up in conversations"). Responses were collected on a 1 (strongly disagree) to 5 (strongly agree) scale (Appendix D). Previous reliability coefficients ranging from .76 to .90 have been reported for the dyadic dimension of the PRCA-24 (Beatty \& Dobos, 1992; Bodie \& Villaume, 2003; Hsiao, 2010). In the present investigation, item scores ranged from 1.00 to $4.50(M=2.37, S D=.70)$, and the measure had a Cronbach's alpha of .83 .

After completing these four measures, participants were then presented with a prompt that asked them to select and describe a common, difficult topic to talk about in a current interpersonal relationship. In order to be sure that participants would actually be able to think of such topics, a pilot study was first conducted at the end of the Fall 2011 semester. Specifically, 70 students were asked to "describe a common, difficult topic to talk about with a person that influences your day-to-day interactions. In other words, this should be a topic that is hard to bring up, and influences you in some way on a day-today basis." Participants were provided with half of a page of lined paper to answer this 
question. Further, participants were asked to (a) indicate the frequency with which this topic is discussed with the person they have in mind $(1=$ never, $7=$ very frequently $)$ and (b) indicate the general importance of the topic described above ( $1=$ not at all important, $7=$ extremely important $)$.

Pilot study participants reported on relationships spanning from two months to over 16 years $(M=43.07$ months, $S D=36.70$ months $)$. The most frequently cited topic was discussing the future of a relationship $(n=10)$, followed by the discussion of past relationships ( $n=9)$, the current state of the relationship $(n=8)$, extra-dyadic relationships ( $n=7)$, household chores $(n=7)$, family issues $(n=6)$, negative emotions $(n=4)$, drinking $(n=3)$, death or illness of an important person $(n=3)$, relational trust ( $n$ $=3$ ), practical matters (e.g., money; $n=2$ ), smoking $(n=1)$, sex life $(n=1)$, schoolwork $(n=1)$, and weight $(n=1)$. Overall, pilot study results indicated that participants were able to recall common, difficult topics that influence day-to-day interactions. Further, participants reported discussing this topic a mean of $3.67(S D=1.42)$ times, with a general mean importance of $5.16(S D=1.40)$. It was evident that participants in the pilot study were not discussing these topics very frequently. However, topic importance was above the midpoint, showing that these topics mattered to participants.

After the pilot research was completed, the topic prompt was then edited and finalized. The final prompt was as follows:

Everyone experiences anxiety in certain situations, even with those whom we are very close, and there are some situations that create more anxiety than others. Anxiety is a common response to stressful situations, and includes emotional and/or behavioral reactions. Common emotional reactions include fear of negative evaluation, frustration, and worried thoughts. Common behavioral reactions include avoidance, withdrawal, and even physiological reactions such as increased heart rate, sweating, trembling, and dry mouth. 
As a participant in this experiment, we would like you to think of an anxiety provoking discussion topic with an important person in your life. Examples of potential topics could include discussing past romantic/sexual partners, religious beliefs, or trust issues. You might also experience this anxiety surrounding a topic that is very unique to your relationship. This topic should result in any of the emotional or behavioral responses described above with a person with whom you are close. This could be a romantic partner, a close friend, or a family member. In other words, this should be a topic that makes you anxious, nervous, or uneasy when discussing it with someone close to you.

After reading these instructions, participants were asked to write the initials of the person of whom they were thinking, and to indicate the sex of this person, the type of relationship they have with this person (i.e., romantic partner, friend, family member, or other), the length of time they have known this person, the frequency at which they communicate with this person, and their current geographical distance from this person. Of the final participants, 88 reported on a male target and 93 reported on a female target (1 did not indicate sex). More specifically, 82 reported on a romantic partner, 64 reported on a family member, 31 reported on a friend, and 5 reported on other (e.g., boss, exboyfriend/girlfriend, dead grandparent). These relationships ranged from 1 to 25 years $(M=10.66, S D=8.21)$, and the majority of participants $(58.8 \%)$ reported communicating with this person every day (21.4\% a few times a week, $2.7 \%$ once a week, $7.7 \%$ a few times a month, $1.6 \%$ once a month, $4.9 \%$ a few times a year, .5\% once a year, and $2.2 \%$ other). Finally, the majority of participants (45.6\%) indicated being currently within 0-50 miles of this person (9.9\% 51-100 miles, 34.6\% 101-500 miles, and $9.9 \% 501$ miles or more).

After this, participants were asked to "provide a brief description of this topic" and "write about the topic that makes you nervous when discussing it with someone close to you." Complete transcriptions of these topic descriptions may be obtained by 
contacting the first author. Sample topics include discussing the future of a romantic relationship, talking about sexuality, discussing grades, and conversing about religious viewpoints. Further, participants were asked to create a short, two or three word label for their topic (e.g., past relationships), so that they could use this label in the experimental manipulation that followed.

Next, participants were instructed to indicate how important this topic is to them on a scale ranging from 1 (not at all important) to 7 (extremely important) $(M=5.72, S D$ = 1.32); how difficult this topic is to bring up with this person on a scale ranging from 1 (not at all difficult) to 7 (extremely difficult) $(M=5.25, S D=1.55$ ); and how frequently they discuss this topic with the person they have in mind on a scale ranging from 1 (never) to 7 (frequently) $(M=3.58, S D=1.58)$. These measures indicated that the topics being reported on were generally important and difficult for participants to discuss, as evidenced by these means falling above the midpoint of the scale. Further, these were topics that were not being frequently discussed.

Relational Importance. Next, in order to assess relational importance, participants were asked to complete Rusbult, Martz, and Agnew's (1998) 10-item investment size instrument from the Investment Model Scale regarding the person about whom they were thinking (Appendix E). This instrument is used to assess the magnitude and importance of the resources attached to a relationship (e.g., "I have investigated a great deal of time in my relationship with this person," and "This person and I share many memories"). Responses were gathered on a 1 (strongly disagree) to 5 (strongly agree) scale, and has demonstrated sufficient past reliability (Cronbach's alpha $=.84$; Rusbult et al., 1998). This measure was also found to be reliable in the present study ( $\alpha=$ 
$.91, M=4.16, S D=.80$ ) with item scores ranging from 1.30 to 5.00. Further, a global measure of relational importance was assessed by asking participants to indicate, overall, how important this person is to them on a 1 (not at all important) to 10 (extremely important) scale. This measure clearly indicated that participants were reporting on individuals they considered to be very important $(M=9.15, S D=1.54)$. Table 1 reports the summed descriptive statistics, as opposed to item descriptions, for the scales used in Time 1 of this study. 
Table 1

Time 1 Descriptive Statistics

\begin{tabular}{lccccc}
\hline Measure & Minimum & Maximum & $M$ & $S D$ & $\alpha$ \\
& & & & & \\
\hline Need for Cognition & 37.00 & 80.00 & 59.44 & 10.07 & .84 \\
Cognitive Flexibility & 36.00 & 60.00 & 47.25 & 4.63 & .69 \\
Self-Efficacy & 260.00 & 800.00 & 630.36 & 113.82 & .92 \\
Trait Dyadic Apprehension & 6.00 & 27.00 & 14.22 & 4.21 & .83 \\
Relational Importance & 13.00 & 50.00 & 41.58 & 8.01 & .91 \\
& & & & & \\
\hline
\end{tabular}


Understanding Participant Mortality. Although there was only a small mortality rate between Time 1 and Time 2 data collections $(n=20)$, independent samples $t$-tests were conducted to examine the possibility that the initial sample and final sample differed based on individual characteristics. Results indicated that there were no differences in need for cognition $(t(198)=-1.73, p=.09)$, self-efficacy $(t(200)=-.02, p$ $=.98)$, cognitive flexibility $(t(198)=-.43, p=.67)$, or trait dyadic communication apprehension $(t(199)=-.30, p=.77)$, between those who completed Time 1 and Time 2 . However, an independent samples $t$-test did reveal that those who completed both Time 1 and Time 2 indicated more relational importance $(M=4.20, S D=.76)$ in the interpersonal relationship they reported on compared to those who did not come back to complete Time $2(M=3.76, S D=1.09, t(199)=2.27, p=.02)$.

Experimental Manipulations. Upon completing the Time 1 questionnaire, participants were presented with the experimental manipulation for their group, which is described in detail below.

II Group. Participants in the II group $(n=60)$ were presented with their experimental manipulation materials (Appendix F) immediately after completing the Time 1 questionnaire. These materials guided participants through creating an effective II. First, participants were provided with the following instructions:

In order to help you relieve your anxiety associated with this topic, we would like you to form an implementation intention. An implementation intention is an ifthen plan to help you achieve a goal (e.g., If $x$, then $y$ ). Please follow the instructions below in order to form your implementation intention.

After reading these instructions, II participants were carefully guided in forming an II regarding the topic they selected with the same target individual in mind. Specifically, they were presented with the stem of the II, "If I feel threatened or anxious 
when talking about with , then I will...” This stem was adapted from Harris, Napper, Griffin, Schuez, and Stride's (2011) work, as well as Armitage, Harris, and Arden's (2011) investigation on self-affirming IIs. This stem was chosen because it specifically relates to anxiety, which is a dependent variable in the present study. Participants were asked to write in the topic label they created in the Time 1 questionnaire, as well as the initials of the person whom they had in mind.

Next, II participants were presented with three options to complete the stem, and were asked to select one of the three options. These options were also adapted from Harris et al.’s (2011) work on threatening stimuli and Armitage et al.'s (2011) investigation on self-affirmation. The options were as follows: (a) “...think about why this topic is important to me,” (b) “...think about what I stand for,” and (c) “...think about what I value in myself." These options were selected because they focus on selfaffirmation. According to Self-Affirmation Theory (Steele, 1988), a self-affirming thought should offset threats to the self (Armitage et al., 2011). Therefore, these thoughts should work to focus participants' thoughts on self-kindness, reducing their attention toward the threatening stimuli, bolstering self-image, and defending global self-worth (Armitage et al., 2011). Of the 60 participants in the II condition, 37 selected option (a), 13 selected option (b) and 10 selected option (c). Importantly, Armitage et al. found no effects for the choice of the self-affirmation II on the dependent variable (i.e., alcohol consumption). Similarly, results of one-way analyses of variance (ANOVAs) indicated no differences in stem completion choice on state anxiety $(F(2,56)=.26, p=.81)$, effectiveness $(F(2,57)=.33, p=.72)$, message length $(F(2,57)=.18, p=.84)$, or motivation $(F(2,57)=.33, p=.72)$ in the current investigation. 
Finally, participants were asked to write out their entire II on three blank lines. Following the procedures used in Armitage et al.'s (2011) study, each blank line started with the word "If..." so that participants would gain practice in writing out the full II in order to aid in making their II automatic. Further, using the procedures set forth by Varley et al. (2011), participants were also asked to go over the II in their head until they could repeat it, word-for-word, without having to read off of the paper. The researcher then went around the room to make sure this exercise was completed by checking that each participant wrote his or her II three times. Participants were also provided with a colored slip of paper on which they were asked to write their II one final time to take home and practice. Participants were encouraged to review/practice the II statement over the next two-weeks. Before leaving the lab, participants were asked to sign up for a 10 minute time slot to complete Time 2 of this study approximately two-weeks later.

Goal Formation Group. Similarly, after completing the Time 1 questionnaire, participants in the goal formation group $(n=64)$ were presented with the following instructions, "In order to help you relieve your anxiety associated with this topic, we would like you to form a goal. Please follow the instructions below in order to form your goal about this topic" (Appendix G). This group was then provided with the goal, "I will not feel threatened or anxious when talking about topic with !" This goal closely reflects the stem of the II, and participants were asked to write in the topic label they created in the Time 1 questionnaire, as well as the initials of the person whom they had in mind. Participants were then asked to write this exact goal out fully on three blank lines (Armitage et al., 2011), and repeat the goal to themselves until it was memorized (Varley et al., 2011). Like the II group, participants were also provided with 
a colored slip of paper on which they were asked to write their goal one final time to take home and practice. Participants were encouraged to review/practice the goal over the next two-weeks. Before leaving the lab, participants were asked to sign up for a 10 minute time slot to complete Time 2 of this study approximately two-weeks later.

Control Group. Because the control group $(n=58)$ in this experiment was a no message control group, participants in this group were not asked to form any kind of plan. Thus, immediately after completing the Time 1 questionnaire, they were simply instructed to sign up for a Time 2 data collection time slot (approximately two-weeks later), and exit the lab.

All participants in all groups were sent individual e-mail reminders of their Time 2 data collection time slot and location approximately 48 hours in advance. A reminder announcement was also made by the researcher in all classes in which participants were recruited prior to Time 2 data collection. Time 2 data collection took place over a seven day period with times offered Monday through Friday from 9:00 am to 6:00 pm, resulting in a total of 60 hours in the lab for Time 2. Participants were not told that they would be recording a message at Time 2 .

Time 2. At Time 2, all participants came to the lab individually, as they were asked to audio-record a message. Immediately upon entering the lab, participants in all groups were read the following script, which was modeled after Knobloch's (2006) date request instructions:

Two-weeks ago, you were asked to think of an anxiety-provoking discussion topic with an important person in your life. Today, you will be asked to record a message in which you bring up this topic with the person you had in mind. In other words, you are being asked to imagine and record exactly what you would say to this person regarding the topic you described two-weeks ago. The message can be as long or as short as you would like, and I would like for you to imagine 
that you are actually talking to the person you have in mind when recording this message. Record the message as if you were actually talking to this person. You will have one minute to prepare, and you may begin recording when you are ready.

After reading these instructions out loud to participants and providing them with no more than one minute to prepare, the researcher instructed participants to begin recording their message. Complete transcriptions of all audio-recordings may be obtained by contacting the first author.

After recording the message, all participants in all groups were asked to complete the Time 2 questionnaire. This questionnaire first asked participants for their unique code again, followed by measures of the dependent variables and covariates. Each of these measures is described in detail below.

Measures of the Dependent Variables. The following measures were used to assess the outcome variables in this experiment.

State Anxiety. After recording the message, state anxiety was assessed using the state version of the State-Trait Anxiety Inventory (STAI; Spielberger, Gorsuch, Lushene, Vagg, \& Jacobs, 1983). Participants were instructed to report how they felt when recording the message. This measure consists of 20 items and responses are gathered on a 1 (not at all) to 4 (very much so) Likert type scale (e.g., "I felt calm," and "I felt anxious"). This measure demonstrated a reliability of .93 (Cronbach's alpha) in Varley et al.'s (2011) investigation on IIs versus goal intentions in promoting effective selfmanagement of anxiety symptoms. This measure was also found to be reliable in the present study $(\alpha=.93, M=2.73, S D=.68)$ with item scores ranging from 1.11 to 4.00 (Appendix H). 
Self-Perceived Communication Effectiveness. Participants' self-reported message effectiveness was assessed using a modified version of the self-reported effectiveness measure employed in Knobloch's (2006) study (Appendix I). Specifically, the three items used in Knobloch's (2006) study were modified to fit the context of the current investigation (e.g., "My message was effective for letting this person know I want to spend time with him or her" was modified to "My message was effective for letting this person know my feelings on this topic"). Further, a fourth item was added to this scale to increase reliability. Thus, participants were asked to indicate their agreement on a 1 (strongly disagree) to 5 (strongly agree) scale with items prefaced by the prompt "My message was..." (a) effective for letting this person know my feelings on this topic, (b) effective for signaling to this person that I want to talk about this topic, (c) successful for communicating to this person the importance of this topic, and (d) effective in communicating my viewpoints on this topic. Again, because this scale was modified for this investigation, an exploratory factor analysis was conducted (Comrey \& Lee, 1992). As expected, a one-factor solution was obtained with all primary factor loadings greater than .50 . This measure was found to be reliable in the present study $(\alpha=.80, M=3.63$, $S D=.78)$ with item scores ranging from 1.00 to 5.00 .

Message Length. Also following the procedures of Knobloch (2006), messages were transcribed and length was computed by counting the number of words in the recorded message $(M=42.81$ words, $S D=36.43)$. Two individuals said that they would say nothing ( 0 words), and the longest message contained 270 words.

Motivation. Participants' motivation to communicate about the topic and to relieve their anxiety associated with the topic was also assessed in the Time 2 
questionnaire (Appendix J). This measure consisted of 5 items and was developed by the researcher to be specific to the context of the study (e.g., "How motivated were you to talk about this topic with the person you had in mind?," and "How motivated were you to relieve your anxiety associated with this topic?”). Responses were gathered on a 5-point Likert type scale ranging from not at all motivated (1) to extremely motivated (5). Results of an exploratory factor analysis (Comrey \& Lee, 1992) indicated a one-factor solution with all primary factor loadings greater than .50 . Further, this measure was found to be reliable in the present study $(\alpha=.77, M=3.38, S D=.74)$ with item scores ranging from 1.00 to 5.00 .

Covariate Measures. The following measures were assessed in the Time 2 questionnaire, and served as covariates in subsequent data analyses.

Message Realism. Communication realism was evaluated after participants recorded their message (Appendix K). This assessment used the same three items as Knobloch's (2006) date request study, which employed a similar methodology. Further, an additional item was added in order to increase precision when assessing reliability. Participants indicated their agreement with statements completing the stem, "My message was..." $(1=$ strongly disagree, $5=$ strongly agree $)$. Four items were used in this measure: (a) realistic of how I communicate with this person, (b) typical of how I communicate with this person, (c) similar to how I ordinarily communicate with this person, and (d) characteristic of how I typically communicate with this person. An exploratory factor analysis (Comrey \& Lee, 1992) indicated a one-factor solution with all primary factor loadings greater than .50 . This measure was also found to be reliable in 
the present study ( $\alpha=.91, M=3.50, S D=.93$ ) with item scores ranging from 1.00 to 5.00 .

Rehearsal Effects. Rehearsal effects were also measured for all participants (including the control group). Specifically, participants were asked to (a) indicate the number of times over the past two-weeks that they practiced what they would say to the person about their topic $(M=3.22, S D=3.71$, range $=.00$ to 20.00$)$, and (b) indicate the number of times over the past two-weeks that they actually talked to the person about this topic $(M=1.81, S D=2.12$, range $=.00$ to 12.00$)$. Participants who indicated that they did talk about this topic were asked to briefly describe the outcome of this conversation in an open-ended question. Transcriptions of all outcomes may be obtained by contacting the first author. Table 2 reports the summed descriptive statistics, as opposed to item descriptions, for the scales used in Time 2 of this study. Tables 3,4 , and 5 report the summed descriptive statistics for all measures used in this study by condition (i.e., II, goal formation, and control, respectively). 
Table 2

Time 2 Descriptive Statistics

\begin{tabular}{llccrr}
\hline Measure & Minimum & Maximum & $M$ & $S D$ & $\alpha$ \\
& & & & \\
\hline State Anxiety & 22.00 & 80.00 & 54.60 & 13.60 & .93 \\
Communication Effectiveness & 4.00 & 20.00 & 14.52 & 3.12 & .80 \\
Motivation & 5.00 & 25.00 & 16.90 & 3.70 & .77 \\
Realism & 4.00 & 20.00 & 14.00 & 3.72 & .91 \\
Message Length (\# of words) & 0.00 & 270.00 & 42.81 & 36.43 & -- \\
\hline
\end{tabular}


Table 3

Implementation Intention Group Descriptive Statistics

\begin{tabular}{llccc}
\hline Measure & Minimum & Maximum & $M$ & $S D$ \\
\hline Need for Cognition & 34.92 & 80.00 & 60.30 & 10.00 \\
Cognitive Flexibility & 38.04 & 57.96 & 47.55 & 4.48 \\
Self-Efficacy & 358.72 & 800.00 & 632.96 & 107.60 \\
Trait Dyadic Apprehension & 6.00 & 22.98 & 13.86 & 4.18 \\
Relational Importance & 13.00 & 50.00 & 41.72 & 8.33 \\
State Anxiety & 22.20 & 80.00 & 54.60 & 13.00 \\
Communication Effectiveness & 5.00 & 20.00 & 14.68 & 3.23 \\
Motivation & 9.00 & 24.00 & 17.05 & 3.60 \\
Realism & 4.00 & 20.00 & 14.40 & 3.80 \\
Message Length (\# of words) & 0.00 & 188.00 & 39.93 & 33.40 \\
\# of Times Speaking to Target & 0.00 & 10.00 & 1.77 & 1.99 \\
\hline
\end{tabular}


Table 4

Goal Formation Group Descriptive Statistics

\begin{tabular}{lcccc}
\hline Measure & Minimum & Maximum & $M$ & $S D$ \\
\hline Need for Cognition & 37.08 & 79.92 & 58.32 & 10.08 \\
Cognitive Flexibility & 36.00 & 54.00 & 45.84 & 3.90 \\
Self-Efficacy & 252.48 & 800.00 & 591.76 & 133.52 \\
Trait Dyadic Apprehension & 7.98 & 27.00 & 15.36 & 3.95 \\
Relational Importance & 15.00 & 50.00 & 41.16 & 8.31 \\
State Anxiety & 23.40 & 80.00 & 54.60 & 14.00 \\
Communication Effectiveness & 4.00 & 20.00 & 14.16 & 2.95 \\
Motivation & 10.00 & 25.00 & 17.15 & 3.60 \\
Realism & 4.00 & 20.00 & 13.44 & 3.88 \\
Message Length (\# of words) & 4.00 & 165.00 & 36.72 & 31.03 \\
\# of Times Speaking to Target & 0.00 & 12.00 & 2.16 & 2.54 \\
\hline
\end{tabular}


Table 5

Control Group Descriptive Statistics

\begin{tabular}{lcccc}
\hline Measure & Minimum & Maximum & $M$ & $S D$ \\
\hline Need for Cognition & 36.00 & 82.98 & 59.58 & 10.26 \\
Cognitive Flexibility & 36.00 & 60.00 & 48.36 & 5.16 \\
Self-Efficacy & 288.72 & 777.52 & 631.44 & 111.44 \\
Trait Dyadic Apprehension & 6.00 & 24.00 & 13.44 & 4.32 \\
Relational Importance & 17.00 & 50.00 & 41.99 & 7.44 \\
State Anxiety & 27.80 & 80.00 & 54.60 & 13.80 \\
Communication Effectiveness & 5.00 & 20.00 & 14.72 & 3.28 \\
Motivation & 5.00 & 23.00 & 16.45 & 3.90 \\
Realism & 4.00 & 20.00 & 14.20 & 3.30 \\
Message Length (\# of words) & 0.00 & 270.00 & 52.52 & 43.03 \\
\# of Times Speaking to Target & 0.00 & 5.00 & 1.47 & 1.66 \\
\hline
\end{tabular}




\section{Data Analysis Plan}

First, a correlation matrix among all variables was evaluated to gain an initial understanding of the relationships present in this investigation, and to determine potential covariates used in subsequent analyses. Hypotheses one through four predicted group differences in the dependent variables (i.e., state anxiety, self-perceived communication effectiveness, message length, and motivation) by condition (i.e., II, goal formation, and control). There were two different tests conducted for each of these hypotheses: an independent samples $t$-test and an analysis of covariance (ANCOVA). The independent samples $t$-test was used to determine if group differences existed between the experimental group and the control group. In other words, differences in the dependent variables were examined by comparing the means between the experimental group (i.e., II or goal formation) and the control group for each hypothesis. This provided an initial understanding of group differences.

After this, an ANCOVA was used to further examine group differences in the dependent variables when controlling for trait apprehension, realism, and/or rehearsal effects (i.e., number of times practicing the goal or II) that were correlated with the dependent variable being tested. Thus, trait apprehension, realism, and rehearsal effects were entered as the covariates if they were related to the dependent variable (based on the initial correlation matrix), condition was the independent variable, and each dependent variable was entered separately.

Hypothesis five predicted that IIs would have more impact on the dependent variables than goal formation. This hypothesis was first assessed with a series of independent samples $t$-tests comparing differences in the dependent variables between the 
two experimental groups (i.e., II and goal formation). Further, a multivariate analysis of covariance (MANCOVA) was also conducted for this hypothesis, entering all of the dependent variables and controlling trait apprehension, realism, and rehearsal effects. Effect sizes were evaluated for each group.

Finally, the research question asked how personality traits (i.e., need for cognition, self-efficacy, and cognitive flexibility) would impact state anxiety, selfperceived communication effectiveness, message length, and motivation when discussing anxiety-provoking topics in interpersonal relationships. In order to answer this question, Pearson Correlations were conducted to examine the relationships among each of these traits and the dependent variables. After this, linear regressions were conducted to examine the ways in which the traits interacted with each condition to impact the dependent variables.

\section{Summary}

This chapter described, in depth, the participants, experimental procedures, and measures used in this investigation. These methods were designed to evaluate the effects of planning on anxiety and communication effectiveness associated with the discussion of difficult topics in interpersonal relationships. Additionally, the data analysis plan was outlined. Chapter Three describes the results of each hypothesis and research question. 


\section{Chapter Three}

\section{Results}

This study examined the impact of planning on state anxiety and communication effectiveness when discussion difficult interpersonal topics. Specifically, this study evaluated differences in state anxiety, self-perceived communication effectiveness, message length, and motivation by condition (i.e., II formation, goal formation, or control). In addition, four personality traits (i.e., need for cognition, cognitive flexibility, self-efficacy, and trait dyadic communication apprehension) were examined in order to further understand the role of these traits in impacting planning and associated outcomes. This chapter will explain the results of each hypothesis and research question.

\section{Preliminary Data Analyses}

In order to gain an initial understanding of the relationships among all variables in this investigation, Pearson Correlations were conducted. Table 6 displays all two-tailed correlations. These correlations were used to guide subsequent data analyses in determining which variables should be included as covariates in each test. Overall, results indicated negative relationships between state anxiety and the following dependent variables: self-perceived communication effectiveness $(r=-.25)$, motivation $(r=-.19)$, and realism $(r=-.27)$. Additionally, self-perceived communication effectiveness was positively related to motivation $(r=.40)$, realism $(r=.36)$, and message length $(r=.20)$. Motivation to talk about the topic with another person was positively related to message realism $(r=.29)$, message length $(r=.15)$, and practice $(r=$ $.30)$. 
Table 6

Correlation Matrix for Traits, Dependent Variables, and Covariates

\begin{tabular}{|c|c|c|c|c|c|c|c|c|c|c|}
\hline Variable & 1 & 2 & 3 & 4 & 5 & 6 & 7 & 8 & 9 & 10 \\
\hline 1. Need for Cognition & --- & & & & & & & & & \\
\hline 2. Cognitive Flexibility & $.41 * *$ & --- & & & & & & & & \\
\hline 3. Self-Efficacy & $.20 * *$ & $.27 * *$ & --- & & & & & & & \\
\hline 4. Trait Dyadic Apprehension & $-.31 * *$ & $-.54 * *$ & $-.31 * *$ & --- & & & & & & \\
\hline 5. Relational Importance & -.01 & .07 & -.00 & -.00 & --- & & & & & \\
\hline 6. State Anxiety & -.05 & -.13 & $-.29 * *$ & $.26 * *$ & .09 & --- & & & & \\
\hline 7. Effectiveness & .10 & .13 & .14 & -.08 & .06 & $-.25 * *$ & --- & & & \\
\hline 8. Motivation & .14 & $.16^{*}$ & .09 & -.06 & $.15^{*}$ & $-.19 * *$ & $.40 * *$ & --- & & \\
\hline 9. Realism & .05 & .14 & .14 & $-.15^{*}$ & .04 & $-.27 * *$ & $.36 * *$ & $.29 * *$ & --- & \\
\hline 10. Message Length (\# words) & .10 & $.17 *$ & .01 & $-.22 * *$ & .04 & -.10 & $.20 * *$ & $.15^{*}$ & .09 & --- \\
\hline 11. Rehearsal Effects (Practice) & .13 & -.02 & -.10 & .05 & .02 & .01 & -.03 & $.30 * *$ & -.05 & $-.18 *$ \\
\hline
\end{tabular}

Note. $* p<.05 . * * p<.01$. 
Next, it was suspected that the difficulty of the topic being reported on would impact the dependent variables. Therefore, two-tailed correlations of topic difficulty with the dependent variables were assessed. Topic difficulty was significantly related to state anxiety $(r=.26, p<.001)$, but no other dependent variables. Given this finding, an analysis of covariance (ANCOVA) was conducted entering state anxiety as the dependent variable, condition as the fixed factor, and topic difficulty as the covariate. The Levene's test of equality of error variances was not significant $(p=.70)$, assuring homogeneity (i.e., groups had approximately equal variances). However, results indicated no significant differences in state anxiety by condition when controlling for topic difficulty $\left(F(2,176)=.01, p=.98, \eta_{\mathrm{p}}^{2}=.00\right)$. Therefore, even though topic difficulty was positively related to state anxiety, it did not impact this outcome when controlled for in an ANCOVA.

Finally, it was also expected that the number of times participants indicated speaking to their target person about their topic would impact the dependent variables (means by condition are reported in Tables 3, 4, and 5). Results of two-tailed correlations indicated that the amount of times participants reported actually speaking to their target about their topic was weakly correlated with motivation $(r=.17, p<.05)$, and no other dependent variable. Given this finding, an ANCOVA was conducted entering motivation as the dependent variable, condition as the fixed factor, and number of times speaking to the target person as the covariate. The Levene's test of equality of error variances was not significant $(p=.94)$, assuring homogeneity. However, results indicated no significant differences in motivation by condition when controlling for number of times speaking to the target person about the topic $\left(F(2,177)=.55, p=.56, \eta_{\mathrm{p}}{ }^{2}=.01\right)$. 


\section{Tests of Hypotheses}

Hypothesis 1. Hypothesis 1 predicted that planning would affect state anxiety such that (a) individuals who formed an II would report less state anxiety than those who did not form an II and (b) individuals who formed a goal would report less state anxiety than those who did not form a goal. This hypothesis was first explored using independent samples $t$-tests comparing the experimental groups (i.e., II group and goal formation group) to the control group. Results indicated no significant differences in state anxiety between the II group and the control group $(t(114)=-.04, p=.97$; power $=.05)$. More specifically, the mean for the II group was $2.72(S D=.65)$ and the control group was $2.73(S D=.69)$. Results also indicated no significant differences in state anxiety between the goal formation group $(M=2.73, S D=.70)$ and the control group $(M=2.73, S D=$ $.69, t(119)=.02, p=.98)$.

Next, this hypothesis was further explored using an analysis of covariance ANCOVA. Using a covariate can (a) reduce error variance, (b) take any pre-existing mean group difference on the covariate into account, (c) take into account the relationship between the covariate and the dependent variable, and (d) yield a more precise and less biased estimate of the treatment effect. Based on communication apprehension literature (Beatty, 1987; Richmond \& McCroskey, 1998) and theoretical underpinnings proposed in Planning Theory (Berger, 1997), three potential covariates were proposed: trait dyadic communication apprehension, realism, and rehearsal effects (i.e., number of times practicing the II or goal). However, in examining the initial correlation matrix among all variables, only trait dyadic communication apprehension $(r=.26)$, and realism $(r=-.27)$ were related to state anxiety. Because practice $(r=.01)$ was not related to state anxiety, 
this was not included as a covariate. State anxiety was entered as the dependent variable, condition was the fixed factor, and trait dyadic communication apprehension and realism served as the covariates. The Levene's test of equality of error variances was not significant $(p=.98)$, assuring homogeneity (i.e., groups had approximately equal variances). However, results indicated no differences in state anxiety by condition even when controlling for these variables $\left(F(2,175)=.70, p=.50, \eta_{\mathrm{p}}^{2}=.01\right.$, power $\left.=.17\right)$. Thus, hypothesis 1 was not supported.

Hypothesis 2. Hypothesis 2 stated that planning would affect self-perceived communication effectiveness such that (a) individuals who formed an II would report more self-perceived communication effectiveness than those who did not form an II and (b) individuals who formed a goal would report more self-perceived communication effectiveness than those who did not form a goal. Results of an independent samples $t$ test comparing the II group to the control group did not indicate any differences in selfperceived communication effectiveness $(t(115)=-.06, p=.95$; power $=.15)$.

Specifically, the mean for self-perceived communication effectiveness in the II group was $3.67(S D=.80)$, and mean for the control group was $3.68(S D=.82)$. Further, results of an independent samples $t$-test comparing the goal formation group $(M=3.54, S D=.74)$ to the control group $(M=3.68, S D=.82)$ was also non-significant $(t(119)=-.97, p=$ $.34)$.

Next, an ANCOVA was conducted to further explore this hypothesis. Although three potential covariates were proposed (i.e. trait dyadic communication apprehension, realism, and rehearsal effects), realism was the only variable related to self-perceived communication effectiveness $(r=.36)$. Thus, self-perceived communication 
effectiveness was entered as the dependent variable, condition served as the fixed factor, and realism was the covariate. The Levene's test was not significant $(p=.88)$, confirming homogeneity. However, results indicated no significant differences in communication effectiveness by condition when controlling for realism $(F(2,177)=.17$, $p=.84, \eta_{\mathrm{p}}^{2}=.00$, power $\left.=.08\right)$. Thus, hypothesis 2 was not supported.

Hypothesis 3. Hypothesis 3 asserted that planning would affect message length such that (a) individuals who formed an II would record longer messages than those who did not form an II and (b) individuals who formed a goal would record longer messages than those who did not form a goal. Following the procedures of Knobloch (2006), message length was computed as the number of words in the message. Results of an independent samples $t$-test comparing the II group $(M=39.93, S D=33.40)$ to the control group $(M=52.52, S D=43.03)$ was not significant $(t(116)=-1.78, p=.08$; power $=.61)$. However, there were significant differences in message length between the goal formation group and the control group $(t(120)=-2.34, p=.02)$. A closer examination of the means indicated that individuals in the goal formation group $(M=$ $36.72, S D=31.03)$ recorded shorter messages than individuals in the control group $(M=$ 52.52, $S D=43.03)$. Therefore, this relationship was significant, but in the opposite direction predicted.

Of the three proposed covariates (i.e., trait dyadic communication apprehension, realism, and rehearsal effects), only trait dyadic communication apprehension $(r=-.22)$ and rehearsal effects $(r=-.18)$ were related to message length. Therefore, an ANCOVA was conducted with message length as the dependent variable, condition as the fixed factor, and trait dyadic communication apprehension and rehearsal effects as the 
covariates. Again, the Levene's test assured homogeneity $(p=.22)$, but the model was not significant even when controlling for these variables $\left(F(2,176)=1.18, p=.31, \eta_{\mathrm{p}}{ }^{2}=\right.$ .01 ; power $=.26)$. Hypothesis 3 was not supported.

Hypothesis 4. Hypothesis 4 predicted that planning would affect motivation such that (a) individuals who formed an II would be more motivated than those who did not form an II and (b) individuals who formed a goal would be more motivated than those who did not form a goal. Results of an independent samples $t$-test comparing the IIs group $(M=3.41, S D=.72)$ to the control group $(M=3.28, S D=.78)$ was not significant $(t(116)=.87, p=.39$; power $=.16)$. Similarly, results of an independent samples $t$-test comparing the goal formation group $(M=3.43, S D=.72)$ to the control group $(M=$ $3.28, S D=.78)$ was also non-significant $(t(120)=1.05, p=.30)$.

Next, this hypothesis was also explored with an ANCOVA. Given the relationships between motivation and realism $(r=.29)$ and motivation and rehearsal effects $(p=.30)$, these two variables served as covariates. Trait dyadic communication apprehension was not related to motivation $(r=-.06)$. Thus, motivation was entered as the dependent variable, condition as the fixed factor, and realism and rehearsal effects served as the covariates. The Levene's test was not significant, confirming homogeneity. However, the results of the ANCOVA failed to indicate any significant differences in motivation by condition even when controlling for these variables $(F(2,176)=.22, p=$ $.80, \eta_{\mathrm{p}}{ }^{2}=.00$, power $\left.=.09\right)$. Hypothesis 4 was not supported.

Hypothesis 5. Hypothesis 5 stated that IIs would have more impact on the dependent variables (i.e., state anxiety, self-perceived communication effectiveness, message length, and motivation) than goal formation. First, independent sample $t$-tests 
were used to compare the dependent variables in the II group with the goal formation group (as opposed to the control group, as was done in H1-H4). Results of a series of independent samples $t$-tests did not indicate any significant differences in state anxiety $(t$ $(121)=-.06, p=.95)$, self-perceived communication effectiveness $(t(122)=.92, p=$ $.36)$, message length $(t(122)=.57, p=.58)$, or motivation $(t(122)=-.17, p=.87)$ between the II group and the goal formation group.

Next, in order to further explore this hypothesis, a multivariate analysis of covariance (MANCOVA) was conducted to compare group difference in the dependent variables when controlling for the three proposed covariates: trait dyadic communication apprehension, realism, and rehearsal effects. The Levene's test assured homogeneity across all conditions. Results indicated that only the goal formation group $(M=36.72$, $S D=31.03)$ and the control group $(M=52.52, S D=43.03)$ differed in message length $\left(F(2,177)=3.53, p=.03, \eta_{\mathrm{p}}{ }^{2}=.04\right)$. Therefore, it is evident that goal formation had more of an impact on message length than II formation. Hypothesis 5 was not supported.

In order to summarize the main results of Hypotheses 1 through 5, Table 7 displays the results of a one-way analysis of variance (ANOVA) comparing the means and standard deviations for each dependent variable (i.e., state anxiety, self-perceived communication effectiveness, message length, and motivation) by condition. 
Table 7

Results of One-Way Analyses of Variance Comparing the Means and Standard Deviations of each Dependent Variable

\begin{tabular}{|c|c|c|c|c|c|}
\hline & \multicolumn{3}{|c|}{ Condition } & \multirow{3}{*}{$F$} & \multirow{3}{*}{$p$} \\
\hline & Implementation Intentions & Goal Formation & Control & & \\
\hline & $\operatorname{Mean}(S D)$ & $\operatorname{Mean}(S D)$ & $\operatorname{Mean}(S D)$ & & \\
\hline State Anxiety & $2.73(.65)$ & $2.73(.70)$ & $2.73(.69)$ & .02 & .99 \\
\hline Effectiveness & $3.67(.80)$ & $3.54(.74)$ & $3.68(.82)$ & .59 & .56 \\
\hline Message Length & $39.93(33.39)_{\mathrm{AB}}$ & $36.72(31.03)_{\mathrm{A}}$ & $52.52(43.03)_{\mathrm{B}}$ & 3.22 & .04 \\
\hline Motivation & $3.41(.72)$ & $3.43(.72)$ & $3.29(.78)$ & .64 & .53 \\
\hline
\end{tabular}

Notes: (a) $d f=2,180 ;$ (b) for message length, means with no subscripts in common are different at a statistically significant level of $p<.05$. 


\section{Research Question Analyses}

Research Question 1. Research question 1 asked how personality traits (i.e., need for cognition, self-efficacy, and cognitive flexibility) would impact state anxiety, self-perceived communication effectiveness, message length, and motivation when discussing anxiety-provoking topics in interpersonal relationships. This research question was first evaluated with Pearson two-tailed correlations among the traits and the dependent variables. Results indicated that need for cognition was not related to any of the dependent variables. Second, self-efficacy was negatively related to state anxiety ( $r$ $=-.29, p<.01)$, but not any other dependent variable. Third, cognitive flexibility was positively related to message length $(r=.17, p<.05)$ and motivation $(r=.16, p<.05)$.

In order to further understand this research question, linear regressions were conducted to examine the ways in which the traits interacted with each condition to impact the dependent variables. First, interaction terms were created by computing new variables with the z-scores (i.e., standardized values) for each variable by condition. Table 8 displays the standardized beta weights for each linear regression. Results were non-significant for the interaction among condition and need for cognition in predicting state anxiety $\left(F(1,178)=.23, p=.63, R^{2}=.00\right)$, effectiveness $(F(1,179)=.32, p=.57$, $\left.R^{2}=.00\right)$, motivation $\left(F(1,180)=3.39, p=.07, R^{2}=.02\right)$, and message length $(F(1$, $\left.180)=.03, p=.87, R^{2}=.00\right)$. Further, results were non-significant for the interaction among condition and self-efficacy in predicting state anxiety $(F(1,178)=.34, p=.56$, $\left.R^{2}=.00\right)$, effectiveness $\left(F(1,180)=.48, p=.49, R^{2}=.00\right)$, and motivation $(F(1,181)=$ $.30, p=.59, R^{2}=.00$ ). However, the interaction among condition and self-efficacy in 
predicting message length was significant $\left(F(1,181)=4.62, p=.03, R^{2}=.03\right)$. Thus, self-efficacy interacted with condition to influence message length.

In order to understand the interaction among condition and self-efficacy in predicting message length, self-efficacy was broken into three groups: low self-efficacy (one standard deviation below the mean), moderate self-efficacy, and high self-efficacy (one standard deviation above the mean). Thus individuals with low self-efficacy scored 0.00 to 62.45 , moderates were 62.46 to 92.20 , and highs were 92.21 to 100.00 . An examination of the means for message length in each group indicated that individuals who were high in self-efficacy and in the goal group produced messages with fewer words than those in the II group or control group. Means for each group are presented in Table 9.

Next, results were non-significant for the interaction among condition and cognitive flexibility for state anxiety $\left(F(1,178)=.01, p=.95, R^{2}=.00\right)$, effectiveness $(F$ $\left.(1,179)=.04, p=.84, R^{2}=.00\right)$, motivation $\left(F(1,180)=.06, p=.81, R^{2}=.00\right)$, and message length $\left(F(1,180)=2.08, p=.15, R^{2}=.01\right)$. Finally, interactions were also examined with trait dyadic communication apprehension and results were also nonsignificant for the interaction among condition and trait dyadic communication apprehension for state anxiety $\left(F(1,179)=.01, p=.94, R^{2}=.00\right)$, effectiveness $(F(1$, $\left.180)=.72, p=.40, R^{2}=.00\right)$, motivation $\left(F(1,181)=1.92, p=.17, R^{2}=.01\right)$, and message length $\left(F(1,181)=.84, p=.36, R^{2}=.00\right)$. 
Table 8

Linear Regression Standardized Regression Weights for Interactions among Traits and Condition

Interaction Term

Cond. x Need for Cog. Condition x Self-Eff. Cond x Cog. Flex. Cond. x CA

\begin{tabular}{lcccc} 
Dependent Variable & $\beta$ & $\beta$ & $\beta$ & .01 \\
\hline State Anxiety & .04 & -.04 & -.02 & -.01 \\
Effectiveness & -.04 & .05 & -.02 & .06 \\
Motivation & -.14 & .04 & .12 & -.07 \\
Message Length & -.01 & $.16^{*}$ & & \\
\hline
\end{tabular}

Notes: $\beta$ refers to the standardized regression coefficient, $* p<.05$. 
Table 9

Means and Standard Deviations for the Message Length by Group and Condition

\begin{tabular}{|c|c|c|c|}
\hline \multirow{2}{*}{ Condition } & \multicolumn{3}{|c|}{ Self-Efficacy Group } \\
\hline & Low & Moderate & High \\
\hline \multirow[t]{2}{*}{ Implementation Intentions } & $56.33(50.79)$ & $36.65(28.84)$ & $42.09(30.84)$ \\
\hline & $n=9$ & $n=40$ & $n=11$ \\
\hline \multirow[t]{2}{*}{ Goal Formation } & $43.29(43.27)$ & $35.94(27.12)$ & $26.50(12.68)$ \\
\hline & $n=17$ & $n=39$ & $n=8$ \\
\hline \multirow[t]{2}{*}{ Control } & $35.00(33.80)$ & $59.93(47.22)$ & $40.40(18.75)$ \\
\hline & $n=7$ & $n=40$ & $n=10$ \\
\hline
\end{tabular}




\section{Post Hoc Analyses}

In light of these results, several post hoc analyses were performed in order to gain a deeper understanding of why the experimental manipulation had relatively no impact on the dependent variables. First, because the analyses reported above evaluated two types of planning independently, planning in general was re-examined. In order to understand if planning in general had an impact on the dependent variables (as opposed to two specific types of planning) the two experimental groups (i.e., II and goal formation) were collapsed and compared to the control group (i.e., planning verses no planning). Results of a series of independent samples $t$-tests did not indicate any differences in state anxiety $(t(178)=-.01, p=.99)$, self-perceived communication effectiveness $(t(179)=-.60, p=$ $.55)$, or motivation $(t(180)=1.12, p=.27)$ between the collapsed planning group and the control group. However, an independent samples $t$-test did indicate differences between the collapsed planning group and the control group for message length $(t(180)=-2.49, p$ $<.05)$. The planning group $(M=38.27, S D=32.10)$ recorded shorter messages than the control group $(M=52.51, S D=43.03)$.

Additionally, a MANCOVA was performed to examine group differences between the collapsed planning group and the control group when controlling for trait dyadic communication apprehension, realism, and rehearsal effects. Results of this MANCOVA failed to indicate any group differences in state anxiety $(F(1,175)=.47, p$ $\left.=.49, \eta_{\mathrm{p}}{ }^{2}=.00\right)$, communication effectiveness $\left(F(1,175)=.14, p=.71, \eta_{\mathrm{p}}{ }^{2}=.00\right)$, words in message $\left(F(1,175)=2.07, p=.15, \eta_{\mathrm{p}}{ }^{2}=.01\right)$, or motivation $(F(1,175)=.04$, $\left.p=.84, \eta_{\mathrm{p}}^{2}=.00\right)$. 
Next, it was suspected that there could be differences in the dependent variables depending on the sex of target for whom the participant was recording a message, as previous research indicates sex differences in anxiety (Afifi \& Guerrero, 1998; Afifi, Joseph, \& Aldeis, 2008; LaGreca \& Lopez, 1998). Results of an independent samples $t$ test with the target's sex entered as the independent variable indicated differences in state anxiety depending on the sex of the target individual $(t(177)=2.59, p<.05)$.

Participants recording a message for a male target $(M=2.86, S D=.66)$ reported more state anxiety than participants recording a message for a female target $(M=2.59, S D=$ .67). There were no differences in communication effectiveness $(t(178)=-.04, p=.96)$, motivation $(t(179)=.52, p=.61)$, or message length $(t(179)=-1.24, p=.22)$ depending on the target's sex.

In light of this finding, it was also suspected that there could be differences in the dependent variables depending on the type of relationship the participant had with the target (i.e., romantic partner, family member, friend, or other). Results of an ANOVA failed to indicate any difference in state anxiety $(F(3,179)=1.74, p=.16)$, communication effectiveness $(F(3,180)=.52, p=.67)$, motivation $(F(3,181)=1.30, p$ $=.28)$, or message length $(F(3,181)=1.78, p=.15)$ depending on the relationship the participant had with the person on whom they reported. Further, a series of ANOVAs also failed to indicate any differences in the dependent variables depending on how often the participant reported communicating with the target (e.g., every day, a few times a week, once a week, etc.), or how geographically close they were to the target (e.g., 0-50 miles, 51-100 miles, 101-500 miles, 501 miles or more). 
Finally, because previous studies (Gollwitzer et al., 2011; Parks-Stamm et al., 2010; Schweiger-Gallo et al., 2009; Webb et al., 2010) examined the effects of IIs on specific topics (e.g., condom use, public speaking, vitamin consumption), the last post hoc analysis examined the impact of the nature of the topic that was being recorded on the dependent variables. The topic that emerged the most frequently was discussing the future of a relationship $(n=46)$. Thus, a one-way ANOVA was conducted to examine group differences in each of the dependent variables with only the participants that reported on feeling anxious about discussing the future of a relationship. There were 16 participants in the II group, 11 in the goal formation group, and 19 in the control group that reported on this topic. ANOVA results indicated no group differences in state anxiety $(F(2,45)=.46, p=.64)$, effectiveness $(F(2,45)=.24, p=.79)$, motivation $(F$ $(2,45)=1.09, p=.34)$, or message length $(F(2,45)=.35, p=.71)$ for participants reporting on the most frequently cited topic (i.e., future of a relationship).

Further, independent samples $t$-tests were conducted to explore differences in the dependent variables when comparing the most frequently cited topic (i.e. future of the relationship, $n=46$ ) with all other topics. There were no significant differences in state anxiety $(t(178)=.76, p=.45)$, communication effectiveness $(t(179)=-.31, p=.76)$, motivation $(t(180)=-.16, p=.87)$, or message length $(t(180)=.98, p=.33)$ when comparing those who reported feeling anxious about the future of a relationship versus all other topics.

\section{Summary}

This chapter reported the findings of this investigation. Overwhelmingly, results indicated that planning had no impact on the outcome variables, with the exception of the 
message length. Specifically, individuals in the goal formation group recorded shorter messages than participants in the control group. Overall, these results suggest that II formation and goal formation do not impact state anxiety, communication effectiveness, or motivation, even when controlling for trait dyadic communication apprehension, realism, and/or rehearsal effects.

Further, with the exception of self-efficacy interacting with condition to influence message length, the traits of need for cognition, cognitive flexibility, and trait dyadic communication apprehension did not interact with the condition to impact the dependent variables. The final chapter discusses the research findings in detail, offering several explanations for the results, practical applications, limitations, and areas of future research. 


\section{Chapter Four}

\section{Discussion}

This study was undertaken to learn more about the effects of two specific types of planning (i.e., goal formation and II formation) on the discussion of a diverse range of topics that people perceive as difficult in interpersonal relationships (e.g., talking about the future of a relationship, talking about past relationships, talking about grades). More specifically, it was expected that planning would reduce state anxiety when recording a message for another person about an anxiety-provoking discussion topic. Additionally, the role of several traits (i.e., need for cognition, self-efficacy, cognitive flexibility, and trait dyadic communication apprehension) were evaluated to understand the interactions among conditions, traits, and the dependent variables. Results revealed that planning did not impact state anxiety, self-perceived communication effectiveness, or motivation, and had minimal influence on message length. Additionally, self-efficacy interacted with the goal formation condition to impact message length, such that individuals with high selfefficacy recorded shorter messages than those in the control group.

Before discussing the specific results of the hypotheses and research question, it is relevant to review the preliminary data to gain a deeper understanding of the types of topics and relationships that were referenced, as well as the relationships among all variables. First, participants did indeed report on topics that they perceived to be relatively important and difficult to talk about, as indicated by the means of each measure falling above the midpoint of the 7-point scales ( $M=5.72$ and 5.25, respectively). Further, participants reported that they did not frequently discuss these topics with other individuals $(M=3.58$, 7-point scale). These findings provide initial evidence that the 
topics referenced in this experiment were difficult and anxiety-provoking. Therefore, it is clear that the description used in Time 1 to explain anxiety-provoking discussion topics was, in fact, successful in getting participants to report on such topics in the present investigation.

On a similar note, preliminary analyses indicated that state anxiety was the only dependent variable significantly related to topic difficulty. In other words, the more difficult the participant perceived the topic to be in Time 1, the more state anxiety he/she reported after discussing this topic in Time 2. This finding supports previous research conducted by Roloff and Ifert Johnson (2001), which indicated that reintroducing taboo topics in dating relationships is a common cause of anxiety.

Unexpectedly, topic difficulty was not related to self-perceived communication effectiveness, message length, or motivation. A plausible reason for these findings may be that participants were not focused on how effective or long the messages were, as much as they were focused on simply getting the message out because they were impeded by anxiety. Stated differently, state anxiety may have overwhelmed planning. The anxiety that was stimulated due to the difficult nature of the topic may have been more salient for participants recording a message than the other outcomes of interest (i.e., communication effectiveness, message length, and motivation). This idea supports the notion that anxiety may impede effective communication, and the anxiety present in the current investigation was stimulated through the difficult nature of the topics being discussed.

Second, with regard to rehearsal effects, participants reported practicing what they would say to target individuals (regarding the difficult topic) an average of 3.22 times 
over the two-week period, and reported actually talking to target individuals about the difficult topic an average of 1.81 times over the two-week period. The number of times that participants reported actually talking to target individuals about the difficult topic did not differ by condition, with II participants reporting talking to target individuals an average of 1.76 times, goal group participants 2.15 times, and control group participants 1.47 times over the two-week lapse. Further, analyses failed to indicate any differences by condition on the dependent variables when controlling for these rehearsal effects. Overall, these results suggest that rehearsal effects did not impact state anxiety, selfperceived communication effectiveness, message length, or motivation.

Although surprising, a possible explanation for these findings may be that rehearsal effects were simply not frequent enough to impact the outcomes in any significant way. That is, practicing an anxiety-provoking message approximately three times over a two-week period may not be enough repetition to effectively impact the dependent variables. Similarly, participants reported actually talking to the targets approximately one or two times over a two-week period, which may also not have been enough to make a significant impact on anxiety, effectiveness, message length, or motivation. Comparatively, in Varley et al.'s (2010) investigation, participants reported using IIs to relieve social anxiety an average of $3.65(S D=.80)$ times a day over an 8week period. In contrast, Schweiger Gallo et al. (2009) and Webb et al. (2010) had participants write an II just one time, and then immediately presented participants with the experimental manipulation. Based on these findings, the current investigation could have required more practice from participants over the two-week period, or had participants rewrite the goal or II one last time immediately before recording the 
message. Recall, IIs should be swift and automatic (Gollwitzer, 1999), and it is likely that participants were not able to achieve such automaticity, given the lack of practice.

Finally, the relationships among all variables in this investigation were generally as expected, confirming past literature and indicating that participants were answering the measures as predicted. Preliminary analyses revealed that individuals who reported more state anxiety also had less self-efficacy and more trait dyadic communication apprehension. Further, individuals who reported having more state anxiety also indicated less self-perceived communication effectiveness, motivation, and realism when recording a message. A diagram of these relationships is presented in Table 10. Consistent with literature using this state anxiety measure (Spielberger et al., 1983), these relationships again highlight the correlates of anxiety and demonstrate the negative outcomes associated with anxiety. In addition, participants who recorded messages they perceived as effective also recorded longer, more realistic messages, and indicated feeling more motivated to talk about the topic. 
Table 10

Relationships among State Anxiety, Traits, and Outcome Variables

Dependent Variable Outcome

$\uparrow$ State anxiety


The next sections of this chapter discuss the results concerning the hypotheses and research question for this investigation. Findings related to state anxiety will be explored first, followed by a detailed discussion on communication effectiveness, message length, and motivation. The influence of need for cognition, self-efficacy, cognitive flexibility, and trait dyadic communication apprehension on the dependent variables will also be delineated. Finally, theoretical implications, limitations, and future research will be addressed.

\section{Planning and State Anxiety}

Results of hypotheses one revealed that planning did not affect state anxiety. Even when controlling for trait dyadic communication apprehension and realism, there were no group differences among the II group, the goal formation group, or the control group. In order to interpret why this hypothesis was not supported, it is necessary to examine the measure used for state anxiety and the experimental manipulation.

Past research indicates that planning should lower state anxiety, and that II formation should be more effective than goal formation in relieving state anxiety (Connor \& Higgins, 2010; Schweiger-Gallo et al., 2009; Varley et al., 2011; Webb et al., 2010). Although the current investigation used the same measure of state anxiety (i.e., Spielberger, 1985) as previous II studies (Varley et al., 2011; Webb et al., 2010), this study did not limit the sample to only those who were extremely high or extremely low in trait anxiety before administering treatment, as did Varley et al.'s (2011) study. Varley et al. used a general social anxiety disorder measure (SAD) to screen participants for trait anxiety, whereas the current investigation could have used the trait dyadic communication apprehension measure to screen participants. However, the overall state 
anxiety mean in the present investigation was $54.60(S D=13.60)$, which was similar to that of Varley et al. (2011) mean of $53.03(S D=10.37)$. Thus, while overall state anxiety sample means were similar across studies, the current investigation could have limited the sample to extreme highs or lows before administering treatment.

Next, it is also necessary to evaluate the experimental manipulation in order to understand why hypothesis one was not supported. Recall, participants were asked to form an II, goal, or no plan at all (control). Although this study followed the exact procedures for forming IIs and goals as previous studies (e.g., Connor \& Higgins, 2010; Webb et al. 2010) it is possible that the IIs and goals were too simplistic for the moderately anxious sample used in this study. Simplistic plans may be effective for those who are highly anxious because extreme anxiety may interfere with cognitive processing (Webb et al., 2010). However, because this study did not consist of solely high or low anxious individuals, it is plausible that the simplistic plans did not affect the groups in the same way that they would a highly anxious sample. For example, BoothButterfield (1984) found that highly apprehensive students prefer structure compared to students who are low in communication apprehension and find structure "stifling." Thus, it may be that the simplistic structure of the if-then statements was not as effective as it could have been with a highly apprehensive sample. Nevertheless, one of the practical benefits and selling points for the use IIs and goal formation is the simplicity of these plans that elicit "strong effects for simple plans" (Gollwitzer, 1999, p. 493).

Further, as previously mentioned in the discussion of the preliminary analyses, participants did not report frequently practicing or actually talking about the topics to targets over the two-week period. To that end, it is possible that the planning groups did 
not achieve automaticity, which is a crucial component of II effectiveness (Gollwitzer, 1999). In fact, this was evident in lab observations made throughout the experiment when several participants (approximately 15; condition unknown) commented that they forgot their topic or needed a second to recall the topic they wrote about in Time 1. Every participant was eventually able to remember their topic before recording the message; however, these observations indicate that several plans were not automatic. Further, individuals must want to decrease their anxiety in order for planning to work (Gollwitzer, 1999). Perhaps automaticity could have been increased by actually having participants write their II or goal throughout the two-week period. Although they were encouraged to think about the plan over the two-weeks, these plans may have been more effective if participants were required to rewrite them, or even send an email to the researcher in which they type out the plan every few days.

Finally, anxiety is a complex emotional and behavioral reaction to a perceived threat (McCroskey \& Beatty, 1998; Trower et al., 1990). Several remediation efforts target just one of these reactions: emotional or behavioral. Therefore, it is necessary to consider whether planning was targeting emotions or behaviors. In examining the experimental manipulation more closely, it is evident that the IIs focused on emotionallyrelated anxiety symptoms, having participants "think about what they stand for," or "what they value" in order to purposefully elicit self-affirmation (Harris et al., 2011). Participants were then asked to record a message in which they talked to the person they had in mind in Time 1 about the topic they described in Time 1. More specifically, they were asked to speak to that person as if they were currently in the room. Thus, it is possible that the planning manipulations were targeting emotional responses, whereas the 
outcome of state anxiety was based on the behavior (i.e. recording a message). Of course, emotional and behavioral reactions are complexly intertwined (Trower et al., 1990), but this possibility may provide more explanation for the state anxiety results. With all of this in mind, the following section will review and discuss the results concerning communication effectiveness.

\section{Planning and Self-Perceived Communication Effectiveness}

Results of hypothesis two indicated that planning did not affect perceptions of communication effectiveness, even when controlling for message realism. In other words, there were no differences in the II group, goal formation group, or control group regarding how effective participants perceived messages to be. Again, although unexpected, there are plausible reasons for these findings.

First, Gollwitzer (1999) explained that II formation and planning are most effective in establishing habitual acts (e.g., healthy eating behavior, exercise), but may also be used to prevent unwanted behavior (e.g., anxiety) that may inhibit goal attainment (Gollwitzer \& Sheeran, 2006). Talking about anxiety-provoking discussion topics in interpersonal relationships is not necessarily a habitual act, given that these topics are often avoided. In fact, participants indicated that the topics they reported on were not talked about frequently. Therefore, in the current study, it may be that planning was not as effective at improving self-perceived communication effectiveness because the behaviors being manipulated were not habitual. It may be that IIs should remain focused on habitual acts rather than specific communication episodes, as was done in this investigation. 
Second, it is necessary to examine the measure of communication effectiveness. The measure used in this investigation was based on Knobloch's (2006) date request study, in which participants were asked to evaluate their effectiveness in recording a message in which they asked another person on a date. In Knobloch's study, the mean effectiveness rating was 3.70. Comparatively, the mean in the present investigation was 3.63. Therefore, it is clear that the different contexts in which effectiveness was evaluated did not seem to differ across studies. Regardless, communication effectiveness did not differ across groups in the present study.

Finally, it is possible that communication effectiveness was influenced by participants' predicted valence of the conversation outcome, such that participants who expected a positive outcome after discussing their topic had less state anxiety, thus feeling more effective than those who expected a negative outcome as a result of talking about the topic. This reasoning is in line with the theory of Predicted Outcome Value (POV), which suggests that individuals assess relationships based on predictions of future outcomes (Sunnafrank, 1986; 1988; 1990). Further, this theory proposed that individuals seek to maximize future outcomes, and will engage in conversation if these future outcomes are expected to be positive. Therefore, it would have been beneficial to assess participants' predicted valence of the conversation as well, as this could have impacted perceptions of state anxiety and communication effectiveness. The following section will review findings concerned with planning and message length.

\section{Planning and Message Length}

Results of hypothesis three on message length indicated significant findings in the opposite direction predicted. Specifically, the goal formation group formed messages 
with fewer words than the control group. Additionally, differences in message length between the II group and the control group were approaching significance $(p=.08)$, such that individuals in the II group also formed messages with fewer words than the control group. There were no differences in message length between the two experimental groups. Hypothesis three predicted that the planning groups would have longer messages. This reasoning followed from Proposition 3 of Berger's (1997) Planning Theory, which stated "As the desire to reach a social goal increases, the complexity with which plans are formulated also tends to increase" (p. 29). This study predicted that if participants were reporting on important topics that were made to be salient in the experimental manipulation, then complexity would increase, and message length would increase as well. Instead, results revealed that individuals who formed a goal actually produced more concise messages.

Perhaps the reason for this finding is that goal formation participants entered the lab with more organized thoughts on the topic being recorded. It may be that the goal formation manipulation was successful in getting participants to think about complex topics ahead of time, thus entering the lab with a premeditated idea of what would be said on the topic. In comparison, the control group did not form a plan, and perhaps did not think about what would be said regarding the topic, explaining why control group messages were longer.

Further, results of the research question indicated an interaction among condition, self-efficacy, and message length, such that individuals who were high in self-efficacy and in the goal formation group formed messages with fewer words than those who were low or moderate in self-efficacy and in the other conditions. This indicates that 
individuals who were confident in their abilities to talk about difficult topics in general, and who formed a simple goal about that topic, formed shorter messages than those with low self-efficacy. However, it is still surprising that self-efficacy did not interact with the II condition in a similar manner. Perhaps a reason for this is that self-efficacious individuals do not need to focus on self-affirmation (which was the focus of the II manipulation) because they are already confident in their abilities to discuss difficult topics. Therefore, the simple goal formation, as opposed to the II focused on selfaffirmation, was somewhat more impactful for those who were already high in selfefficacy. Further, it should be noted that sample sizes were low in this analysis, as participants were separated into three groups (i.e., low, moderate, or high self-efficacy) and three conditions (i.e., II, goal formation, or control). Thus, the lows ranged from 717 participants, the moderates ranged from 39-40 participants, and the highs ranged from 8-11 participants. In light of these findings, the next section will discuss the results associated with planning and motivation.

\section{Planning and Motivation}

Results of hypothesis four indicated that planning did not impact motivation to communicate with another person about the topic, even when controlling for rehearsal effects and realism. It is important to note, however, that motivation was positively correlated with number of times practicing the goal or II and effectiveness. Thus, while there were no group differences in motivation, it is evident that motivation still played a role in practice and effectiveness. These findings support the notion that remediation efforts should be targeted specifically at individuals who are motivated and willing to attempt the remediation (Kelly \& Keaten, 2000), as opposed to those who are low in 
willingness and motivation. Again, perhaps recruiting just the individuals who are high in anxiety would be beneficial in future anxiety remediation investigations because this may result in a highly motivated sample that is willing to fully engage in the remediation techniques.

Given the results of hypotheses one through four, hypothesis five was also not supported. Specifically, IIs did not impact the dependent variables more than goal formation. In fact, goal formation was more influential in impacting message length than II formation, which did not impact any of the dependent variables. In reality, neither type of planning had much of an impact on the dependent variables. Consequently, the following section will assess the post hoc analyses in order to further understand why the manipulation did not have more impact on the outcome variables.

\section{Post Hoc Analyses}

In order to further understand the results, post hoc analyses were conducted. Overall, results indicated that even when collapsing the experimental groups, message length was the only dependent variable that differed from the control group, with the collapsed group recording shorter messages overall than the control group. Post hoc analyses also explored the impact of participants' relationship with the targets (i.e., romantic partners, friends, family), how frequently participants communicated with the targets, and participants' geographical closeness with the targets. None of these analyses revealed group differences in the dependent variables, further suggesting that the overall experimental manipulation was weak.

Next, in order to rule out that participant-chosen topics interfered with the experimental manipulation, post hoc analyses were evaluated for group differences 
among the most frequently cited topic (i.e., talking about the future of the relationship) and all other topics. Again, there were no significant differences among the groups in topics, and topic choice did not appear to impact the dependent variables in different ways. However, maybe the types of topics reported and the focus of the topics (e.g., focus on self versus focus on another person) impacted the dependent variables in different ways. That is, perhaps individuals experience different levels of anxiety if they are talking to another person about themselves versus someone else, or even the actual target. Therefore, this should be analyzed in future research.

The only post hoc analysis that indicated any significant differences was whether the target of the message was male or female. More specifically, participants reported less state anxiety when recording a message for a female target as opposed to a male target. According to Wood (2009), both men and women are more likely to disclose to women because of socialized stereotypes of feminine speech communities, which embrace and welcome support, closeness, and understanding. The findings regarding sex differences in this study are consistent with these claims and past research in this area (Afifi \& Guerrero, 1998), suggesting that participants felt more at ease when recording a message for a female target compared to a male target.

\section{Implications}

Although the hypotheses of this study were not supported, the results garnered here help to present a more realistic depiction of the effects of planning on anxiety. That is, implementation intentions and goal formation have little impact on state anxiety, communication effectiveness, and motivation when discussing difficult interpersonal topics. Nevertheless, Levine, Asada, and Carpenter (2009) argued that insignificant 
findings can help researchers to draw better conclusions. Thus, this study still adds to the larger literature on planning and IIs and may be used to make more accurate predictions regarding planning and anxiety remediation in future studies. Accordingly, the following section outlines the theoretical implications of this study.

\section{Theoretical Implications}

Importantly, this is one of the first known studies to suggest that IIs are not successful in shielding goal attainment from disruptive internal states (i.e., anxiety). Collectively, results failed to replicate previous findings obtained in II research that demonstrated the effectiveness of IIs in improving behavior (Armitage, 2004; Bamberg, 2002; Milne, et al., 2002; Murgraff et al., 1996) and anxiety (Varley et al., 2011; Webb et al., 2010). Even when following exact procedures used in previous studies (e.g., Armitage et al., 2011; Harris et al., 2011), the current investigation found no support for II or goal formation in relieving anxiety when discussing difficult interpersonal topics. Further, many studies indicated that IIs are more effective in goal pursuit than simple goal formation (Gollwitzer, 1999; Gollwitzer \& Brandsatter, 1997; Murgraff et al., 1996; Orbell et al., 1997; Parks-Stamm et al., 2010; Prestwich et al., 2003; Schweiger-Gallo et al., 2009; Sheeran \& Orbell, 2000; Webb et al., 2010), and this study found no such support. Thus, it is necessary to review methodological discrepancies in order to understand the theoretical implications of this study.

Perhaps the major difference between this study and previous II investigations is the context in which the goals and IIs were evaluated. Specifically, this was the first study to examine IIs with regard to interpersonal interactions. It may be that IIs and goal formation are too simplistic for complex interpersonal interactions, compared to 
intrapersonal health behaviors (e.g., taking a daily vitamin or exercising). To that end, this study indicates that IIs may not be effective for complex interpersonal interactions, and perhaps should remain focused on health behaviors.

Next, it is also necessary to call into question the salience of the topics that were reported in the present investigation. It is possible that participants were reporting on difficult topics that may not have been especially salient over the two-week period in which this experiment took place, thus providing participants with little motivation to practice. Therefore, topic salience and motivation to practice are two further explanations for the failure of IIs and goals formation.

\section{Limitations}

The findings of this study should be interpreted with recognized design, sample, and methodological limitations. Most notably, although the design of this study was modeled after Knobloch's (2006) date request message investigation, as well as Connor and Higgins (2010) study, all of the proposed relationships were contingent upon the participant imagining that the person they were speaking to was in the room while they were recording the message. Participants knew that they were role-playing and that the person they were speaking with would not actually hear the message. Although participants indicated that recorded messages were moderately realistic of how they typically communicate $(M=3.50,5$-point scale), the artificial nature of the design may have elicited message recordings that were not entirely reflective of what would be said if the situation actually occurred (Bertrand \& Mullainathan, 2001). Further, this type of design may have given participants stage fright, as they were asked to perform a speaking-oriented task. However, given the sensitive nature of the topics, these situations 
are particularly difficult to examine in situ. Further, the procedure used in this study may illuminate message production more than asking participants to write out their plans for speaking about this topic, but is still less naturalistic than asking the participant to actually engage in conversation with another person (Knobloch, 2006).

On a related note, having participants actually engage in conversation with another person would allow scholars to analyze streams of conversation and the backand-forth flow of interaction in anxiety provoking situations (Knobloch, 2006). Berger (2002) suggests that online planning (i.e., planning that takes place during an interaction) may be altered based on a response of a target individual. Further, Dillard's (1990) Goals-Plans-Actions sequence explains that planning often occurs based on the target's response and is influenced by the interaction. Thus, future research may replicate this investigation by having participants speak with an actual target.

Moreover, participants were not told that they would be recording a message in Time 2 when they came to the lab in Time 1, and it is possible that since they did not know they would be performing, they did not practice as much as they may have if they were told in advance. Perhaps participants should have been told that they would be recording a message in order to increase overall practice. Further, with regard to practice, it would have been beneficial to ask participants not only how much they practiced their goal or II, but also how much they thought about the goal or II over the two-week span in order to explore differences in practice versus thinking about a goal.

Methodologically, the reliability estimate for the cognitive flexibility scale was only marginally acceptable (i.e., Cronbach's alpha was .69). Thus, the observed correlations involving this scale were not as robust as they might have been using more 
reliable assessments (Furr \& Bacharach, 2008). Further, although the self efficacy, selfperceived communication effectiveness, motivation, and realism measures yielded acceptable Cronbach alpha reliabilities (i.e., .92, .80, .77, and .91, respectively), it should be noted that these scales were created and/or modified by the researcher specifically for this study, and have not yet been validated. If this study is replicated and/or extended in the future, these measures should be validated.

Finally, as indicated in the results, observed power in all analyses was low (i.e., below .80). According to Cohen and Cohen (1983), observed power should be .80 or above. Therefore, more participants were needed in each condition to achieve sufficient power in order to decrease the chance of Type II errors (i.e., false negatives; Cohen \& Cohen, 1983).

\section{Future Directions}

This investigation offers several avenues for future research. Studying the effects of IIs on interpersonal communication is a relatively understudied area, as previous literature on this topic has examined the effects of II formation primarily in intrapersonal settings (e.g., Bayer et al., 2010; Webb et al., 2010) and in a health context (e.g., Armitage, 2004; Conner \& Higgens, 2010; Orbell et al., 1997, Sheeran \& Orbell, 2000). De Vet et al.'s (2011) study is one of the few investigations that focused on the communication associated with forming an II. Recall, this study examined the effects of II formation on buying, carrying, and discussing condom use, finding that young, single females who formed high quality specific IIs were more committed to these plans and perceived them as more useful than those with low quality, general plans. That is, participants who specified exactly what they would say and when they would say it to a 
prospective sexual partner were more committed to using condoms. The current investigation examined the effects of II formation on communication associated with a wide variety of anxiety-provoking discussion topics (as opposed to one specific topic), and had all participants use the same template (e.g., "If I feel threatened or anxious when talking about topic $x$ with person $x$, then I will...") and select from the same options (e.g., think about why this topic is important to me, think about what I stand for, or think about what I value in myself) when forming the II (Armitage et al., 2011). There were no differences in choice selections for completing the IIs. Therefore, taking de Vet et al.'s findings into consideration, future research examining the effects of IIs on communication in general should consider allowing participants to form their own II that is as specific as possible. In other words, this study could be replicated by having participants come up with the entire II on their own, rather than providing them with a template. Of course, this may decrease experimental control; however, it may result in more specific IIs that could potentially increase commitment toward the plan (de Vet et al., 2011).

Next, future research should consider examining the physiological effects of implementation intentions on the anxiety associated with discussing difficult interpersonal topics. There is an extensive body of literature illustrating the physiological effects of anxiety (see Bodie 2010), and scholars found that planning may reduce those physiological responses (Beatty \& Heisel, 2007). Thus, future research may examine the role of implementation intention formation versus goal formation on physiological reactions (e.g., blood pressure and heart rate) when discussing anxiety-provoking discussion topics. 
Future research should also examine the audio recording gathered in this study. For example, messages could be coded for effectiveness, appropriateness, complexity, and length of time in order to see if differences emerge among conditions. In addition, the current investigation also lends itself nicely to a future paralinguistic investigation. For example, the audio-recorded messages may be analyzed for speech fluency (e.g., pauses, hesitations, repetition, stutters). An analysis of all audio-recordings is warranted, and it is plausible that there may be group differences in speech fluency.

Finally, future research may examine the outcomes associated with engaging in an anxiety-provoking discussion topic with a target person outside of the lab. In the present study, participants who indicated carrying out their plan and talking to their target individual were also asked to describe the outcome of this conversation. Future research should analyze these outcomes for success in order to understand if talking about these anxiety-provoking discussion topics actually improves or hinders relationships.

\section{Conclusion}

Berger (1997) wrote,

...there is no flaw-free method for indexing the effectiveness of planning, especially at the level of the single case... using the same plan to reach the same goal across a wide variety of circumstances might provide some indication of the plan's effectiveness, assuming that the outcomes across the various situations were similar (p. 94).

This study examined the impact of planning on the discussion of a wide variety of difficult topics in interpersonal relationships. Results indicated that there were no differences in state anxiety, self-perceived communication effectiveness, or motivation to 
talk about the topic by condition. Additionally, this study considered the role of traits (i.e., cognitive flexibility, self-efficacy, need for cognition, and trait dyadic communication apprehension) in impacting planning and state anxiety associated with the discussion of difficult topics. Specifically, individuals in the goal formation group formed shorter messages than the control group, and self-efficacy interacted with the condition to affect message length. That is, individuals who were high in self-efficacy and in the goal formation condition recorded shorter messages than those in the control group.

Overall, this study was successful in getting participants to think about and talk about a difficult topic that they were currently dealing with in their life. Berger (1997) suggested that "Using such techniques as role playing, plans can be realized in a social situation that approximates the one in which the plan eventually will be enacted" (p. 105). Even though the hypotheses of this investigation were not supported, it is possible that respondents will eventually benefit from participating in this investigation if they enact their plans in interpersonal relationships in the future. Planning is an important aspect of all communicative situations (Berger, 1997) and is especially salient when preparing to discuss anxiety-provoking topics. Future research should continue to explore the cognitive processes associated with the discussion of anxiety-provoking discussion topics in order to identify effective remediation methods for those who suffer from such anxiety. 


\section{References}

Afifi, T. D., Joseph, A., \& Aldeis, D. (2008). Why can't we just talk about it? An observational study of parents' and adolescents' conversations about sex. Journal of Adolescent Research, 23, 689-721. doi: 10.1177/0743558408323841

Afifi, W. A., \& Guerrero, L. K. (1998). Some things are better left unsaid II: Topic avoidance in friendships. Communication Quarterly, 46, 231-249. doi: 10.1080/01463379809370099

Allen, M., Bourhis, J., Emmers-Sommer, T., \& Sahlstein, E. (1998). Reducing dating anxiety: A meta-analysis. Communication Reports, 11, 49-55. doi:10.1080/08934219809367684

Allen, T. H., \& Honeycutt, J. M. (1997). Planning, imagined interaction, and the nonverbal display of anxiety. Communication Research, 24, 64-82. doi:10.1177/009365097024001003

Allen, M., Hunter, J. E., \& Donohue, W. A. (1989). Meta-analysis of self-report data on the effectiveness of public speaking anxiety treatment techniques. Communication Education, 38, 54-76. doi:10.1080/03634528909378740

Andersen, M., Kunkel, A., \& Dennis, M. R. (2011). "Let's (not) talk about that": Bridging the past sexual experiences taboo to build healthy romantic relationships. Journal of Sex Research, 48, 381-391. doi:

$10.1080 / 00224499.2010 .482215$

Armitage, C. J. (2004). Implementation intentions and eating a low fat diet: A randomized controlled trial. Health Psychology, 23, 319-323. doi: 10.1057/a0879678 
Armitage, C. J., Harris, P. R., \& Arden, M. A. (2011). Evidence that self-affirmation reduces alcohol consumption: Randomized exploratory trail with a new, brief means of self-affirming. Health Psychology, 30, 633-641. doi: 10.1037/a0023738

Ayres, J. (2005). Performance visualization and behavioral disruption: A clarification. Communication Reports, 18, 55-63. doi: 10.1080/08934210500084271

Ayres, J., \& Ayres, T. A. (2003). Using images to enhance the impact of visualization. Communication Reports, 16, 47-55. doi:10.1080/08934210309384489

Ayres, J., \& Ayres Sonandre, D. M. (2003). Performance visualization: Does the nature of the speech model matter? Communication Research Reports, 20, 260-268. doi:10.1080/08824090309388824

Ayres, J., \& Heuett, B. L. (2000). An examination of the long term effect of performance visualization. Communication Research Reports, 17, 229-236. doi:10.1080/08824090009388770

Ayres, J., \& Hopf, T. (1985). Visualization: A means of reducing speech anxiety. Communication Education, 34, 289-296. doi: 10.1080/03634528509378623

Ayres, J., \& Hopf, T. (1989). Visualization: Is it more than extra-attention? Communication Education, 38, 1-5. doi: 10.1080/03634528909378735

Ayres, J., \& Hopf, T. (1990). The long-term effect of visualization in the classroom: A brief research report. Communication Education, 39, 75-78. doi: $10.1080 / 03634529009378788$

Ayres, J., \& Hopf, T. (1991). Visualization: The next generation. Communication Research Reports, 8, 133-140. doi: 10.1080/08824099109359885 
Ayres, J., \& Hopf, T. (1992). Visualization: Reducing speech anxiety and enhancing performance. Communication Reports, 5, 1-10. doi:10.1080/08934219209367538

Ayres, J., Wongprasert, T. K., Silva, J., Story, T., Hsu, C. S., \& Sawant, D. D. (2001). Effects of performance visualization on employment interviews. Communication Quarterly, 49, 160-171. doi:10.1080/01463370109385623

Bamberg, S. (2000). The promotion of a new behavior by forming an implementation intention: Results of a field experiment in the domain of travel mode choice. Journal of Applied Social Psychology, 23, 573-587. doi: 17895674893.847636281

Bamberg, S. (2002). Implementation intentions versus monetary incentive comparing the effects of interventions to promote the purchase of organically produced food. Journal of Economic Psychology, 23, 573-587. doi:10.1016/S01674870(02)00118-6

Bandura, A. (1997). Self-efficacy: The exercise of control. New York: Freeman.

Bandura, A. (2006). Guide for constructing self-efficacy scales. In F. Pajares \& T. Urdan (Eds.), Self-efficacy beliefs of adolescents (pp. 307-337). Charlotte, NC: Information Age Publishing.

Bates, C. E., \& Samp, J. A. (2011). Examining the effects of planning and empathetic accuracy on communication in relational and nonrelational conflict interactions. Communication Studies, 62, 207-223. doi: 10.1080/10510974.2010.517597

Battman, W. (1989). Planning as a method of stress prevention: Will it pay off? In C. D. Spielberger, I. G. Sarason, \& J. Streslau (Eds.), Stress and anxiety (pp. 259-275). New York, NY: Hemisphere. 
Baxter, L. A., \& Wilmot, W. W. (1985). Taboo topics in close relationships. Journal of Social and Personal Relationships, 2, 253-269. doi: 10.1177/0265407585023002

Bayer, U. C., Gollwitzer, P. M., \& Achtziger, A. (2010). Staying on track: Planned goal striving from disruptive internal states. Journal of Experimental Psychology, 46, 505-514. doi: doi:10.1016/j.jesp.2010.01.002

Beatty, M. J. (1987). Communication apprehension as a determinant of avoidance, withdrawal, and performance anxiety. Communication Quarterly, 35, 202-217. doi:10.1080/01463378709369681

Beatty, M. J., \& Beatty, P. J. (1976). Interpersonal communications anxiety. Theory into Practice, 15, 368-372. doi: 10.1080/00405847609542660

Beatty, M. J., Behnke, R. R., \& McCallum, K. (1978). Situational determinants of communication apprehension. Communication Monographs, 45, 187-191. doi:10.1080/03637757809375964

Beatty, M. J., \& Dobos, J. A. (1992). Adult sons' satisfaction with their relationships with fathers and person-group (father) communication apprehension. Communication Quarterly, 40, 162-176. doi:10.1080/89712764859382

Beatty, M. J., \& Heisel, A. D. (2007). Spectrum analysis of cortical activity during verbal planning: Physical evidence for the formation of social interaction routines. Human Communication Research, 33, 48-63. doi:10.1111/j.14682958.2007.00288.x

Beatty, M. J., McCroskey, J. C., \& Heisel, A D. (1998). Communication apprehension as a temperamental expression: A communibiological paradigm. Communication Monographs, 65, 197-219. doi:10.1080/03637759809376448 
Beatty, M. J., Plax, T. G., \& Kearney, P. (1985). Reinforcement versus modeling in the development of communication apprehension. Communication Research Reports, 2, 80-85. doi: 10.1008768760786546360

Beatty, M. J., \& Valencic, K. M. (2000). Context-based apprehension versus planning demands: A communibiological analysis of anticipatory public speaking anxiety. Communication Education, 49, 58-71. doi:10.1080/03634520009379193

Berger, C. R. (1995a). A plan-based approach to strategic communication. In D. E. Hewes (Ed.), The cognitive bases of interpersonal communication (pp. 141-179). Hillsdale, NJ: Lawrence Erlbaum.

Berger, C. R. (1995b). Inscrutable goals, uncertain plans, and the production of communicative action. In C. R. Berger \& M. Burgoon (Eds.), Communication and social influence processes (pp. 1-21). East Lansing, MI: Michigan State University Press.

Berger, C. R. (1997). Planning strategic interaction: Attaining goals through communicative action. Mahwah, NJ: Lawrence Erlbaum.

Berger, C. R. (2002). Communication: A goal-directed, plan-guided process. In D. R. Roskos-Ewoldsen \& J. L. Monahan (Eds.), Communication and social cognition (pp.47-70). Mahwah, NJ: Lawrence Erlbaum.

Berger, C. R., \& Bell, R. A. (1988). Plans and the initiation of social relationships. Human Communication Research, 15, 217-235. doi:10.1111/j.14682958.1988.tb00182.x 
Berger, C. R., \& Jordan, J. M. (1992). Planning sources, planning difficulty, and verbal fluency. Communication Monographs, 59, 130-149. doi:10.1080/03637759209376257

Berger, C. R., Karol, S. H., \& Jordan, J. M. (1989). When a lot of knowledge is a dangerous thing: The debilitating effects of plan complexity on verbal fluency. Human Communication Research, 16, 91-119. doi:10.1111/j.14682958.1989.tb00206.x

Berger, C. R., \& Kellermann, K. (1994). Acquiring social information. In J. A. Daly \& J. M. Wiemann (Eds.), Strategic interpersonal communication (pp. 1-31). Hillsdale, NJ: Lawrence Erlbaum.

Bertrand, M., \& Mullainathan, S. (2001). Do people mean what they say? Implications for subjective survey data. American Economic Review, 91, 67-72. doi: 89786785424648977

Bodie, G. D. (2010). A racing heart, rattling knees, and ruminative thoughts: Defining, explaining, and treating public speaking anxiety. Communication Education, 59, 70-105. doi:10.1080/03634520903443849

Bodie, G. D., \& Villaume, W. A. (2003). Aspects of receiving information: The relationship between listening preferences, communication apprehension, receiver apprehension, and communicator style. International Journal of Listening, 17, 4767. doi:10.1070/7864598712986

Booth-Butterfield, M. (1986). Stifle of stimulate: The effects of task structure on apprehensive and non-apprehensive students. Communication Education, 35, 337348. doi:10.1080/03634528609388358 
Booth-Butterfield, M., \& Booth-Butterfield, S. (2004). Communication apprehension and avoidance in the classroom: $A$ text and course outline ( $\left({ }^{\text {nd }}\right.$ Edition). Littleton, MA: Tapestry Press.

Brandstatter, V., Lengfelder, A., \& Gollwitzer, P. M. (2001). Implementation intentions and efficient action initiation. Journal of Personality and Social Psychology, 81, 946-960. doi:10.1037/0022-3514.81.5.946

Burke, R. S., \& Stephens, R. S. (1999). Social anxiety and drinking in college students: A social cognitive theory analysis. Clinical Psychology Review, 19, 513-530. doi:10.1016/S0272-7358(98)00058-0

Cacioppo, J. T, \& Petty, R. E. (1982). The need for cognition. Journal of Personality and Social Psychology, 42, 116-131. doi:10.1037//0022-3514.42.1.116

Cacioppo, J. T., Petty, R. E., \& Kao, C. F. (1984). The efficient assessment of need for cognition. Journal of Personality Assessment, 48, 306-307. doi:10.1207/s15327752jpa4803_13

Cacioppo, J. T., Petty, R. E., \& Morris, K. J. (1983). Effects of the need for cognition on message evaluation, recall, and persuasion. Journal of Personality and Social Psychology, 45, 805-818. doi:10.1037//0022-3514.45.4.805

Chesebro, J. L., \& Martin, M. M. (2003). The relationship between conversational sensitivity, cognitive flexibility, verbal aggressiveness, and indirect interpersonal aggressiveness. Communication Research Reports, 20, 143-150.

doi:10.1080/08824090309388810 
Chorney, D. B., \& Morris, T. L. (2008). The changing face of dating anxiety: Issues in assessment with special populations. Clinical Psychology: Science \& Practice, 15, 224-238. doi: 10.1111/j.1468-2850.2008.00132.x

Cohen, J., \& Cohen, P. (1983). Applied Multiple Regression/Correlation Analysis for the Behavioral Sciences. Hillsdale, NJ: Lawrence Erlbaum Associates Inc.

Collins, A. M., \& Loftus, E.S. (1975). A spreading-activation theory of semantic processing. Psychological Review, 82, 407-428. doi:10.1037//0033295X.82.6.407

Collins, N. L., \& Miller, L. C. (1994). Self-disclosure and liking: A meta-analytic review. Psychological Bulletin, 116, 457-475. doi: 0033-2909/94/

Comrey, A. L., \& Lee, H. B. (1992). A First Course in Factor Analysis ( $2^{\text {nd }}$ Ed.). Hillsdale, NJ: Lawrence Erlbaum Associates Inc.

Conner, M., \& Higgins, A. R. (2010). Long-term effects of implementation intentions on prevention of smoking and uptake among adolescents. Health Psychology, 29, 529-538. doi:10.1037/a0020317

Crocker, J., Canevello, A., Breines, J. G., \& Flynn, H. (2010). Interpersonal goals and change in anxiety and dysphoria in first-semester college students. Journal of Personality and Social Psychology, 98, 1009-1024. doi: 10.1037/a0019400

Darwin, C. (1965). Expression of emotions in man and animals. Chicago, IL: University of Chicago Press. (Originally published in 1872).

de Vet, E., Gebhardt, W. A., Sinnige, J., Van Puffelen, A. Van Lettow, B., \& De Wit, J. B. F. (2011). Implementation intentions for buying, carrying, discussing, and 
using condoms: The role of the quality of plans. Health Education Research, 26, 443-455. doi: 10.1093/her/cyr006

Dillard, J. P. (1990). A goal-driven model of interpersonal influence. In J. P. Dillard (Ed.), Seeking compliance: The production of interpersonal influence messages (pp. 41-56). Scottsdale, AZ: Gorsuch Scarisbrick.

Dillard, J. P. (1997). Explicating the goal construct: Tools for theorists. In J. O. Greene (Ed.), Message production: advances in communication theory (pp. 47-69). Mahwah, NJ: Lawrence Erlbaum.

Dillard, J. P., Segrin, C., \& Harden, J. M. (1989). Primary and secondary goals in the production of interpersonal influence messages. Communication Monographs, 56, 19-38. doi:10.1080/03637758909390247

Dowbiggin, I. R. (2009). High anxieties: The social construction of anxiety disorders. The Canadian Journal of Psychiatry, 54, 429-435. http://dx.doi.org/10.1037/0033-295X.82.6.407

Eckstein, J. J. (2005). Conversation conundrums: Listener perceptions of affective influence attempts as mediated by personality and individual differences. Communication Quarterly, 53, 401-419. doi: 10.1080/01463370500101394

Eysenck, H. J., \& Eysenck, M. W. (1985). Personality and individual differences: A natural science approach. New York: Plenum.

Freud, S. (1936). The problem of anxiety. New York, NY: W. W. Norton.

Furr, R. M., \& Bacharach, V. R. (2008). Psychometrics: An introduction. Thousand Oaks, CA: Sage Publications Inc. 
Glasgow, R. E., \& Arkowitz, H. (1975). The behavioral assessment of male and female social competence in dyadic heterosexual interactions. Behavior Therapy, 6, 488498. doi:10.1016/S0005-7894(75)80005-0

Glick, D. M., \& Orsillo, S. M. (2011). Relationships among social anxiety, self-focused attention, and experiential distress and avoidance. Journal of Cognitive and Behavioral Psychotherapies, 11, 1-12. doi:602893094//87/1/1221

Glickman, A. R., \& La Greca, A. M. (2004). The dating anxiety scale for adolescents: Scale development and associations with adolescent functioning. Journal of Clinical Child and Adolescent Psychology, 33, 566-578. doi: $10.1207 / \mathrm{s} 15374424 \mathrm{jccp} 3303 \_14$

Gollwitzer, P. M. (1999). Implementation intentions: Strong effects of simple plans. American Psychologist, 54, 493-503. doi:10.1037//0003-066X.54.7.493

Gollwitzer, P. M., \& Brandsatter, V. (1997). Implementation intentions and effective goal pursuit. Journal of Personality and Social Psychology, 73, 186-199. doi:10.1037//0022-3514.73.1.186

Gollwitzer, P. M., \& Sheeran, P. (2006). Implementation intentions and goal achievement: A meta-analysis of effects and processes. Advances in Experimental Social Psychology, 38, 69-119. doi:10.1016/S0065-2601(06)38002-1

Gollwitzer, P. M., Sheeran, P., Trotschel, R., \& Webb, T. L. (2011). Self-regulation of priming effects on behavior. Psychological Science OnlineFirst, 1-7. doi:10.1177/0956797611411586

Greene, J. O., McDaniel, T. L., Buska, K., \& Ravizza, S. M. (1993). Cognitive processes in the production of multiple goal messages: Evidence from the temporal 
characteristics of speech. Western Journal of Communication, 57, 65-86. doi:10.1080/10570319309374431

Haddock, G, Maio, G. R., Arnold, K, \& Huskinson, T. (2008). Should persuasion be affective or cognitive? The moderating effects of need for affect and need for cognition. Personality and Social Psychology Bulletin, 34, 769-778. doi: $10.1177 / 0146167208314871$

Harris, P. R., Napper, L., Griffin, D. W., Schuez, B., \& Stride, C. (2011). Developing a measure of spontaneous self-affirmation. Manuscript in preparation.

Haugtvedt, C. P., \& Petty, R. E. (1992). Personality and persuasion: Need for cognition moderates the persistence and resistance of attitude changes. Journal of Personality and Social Psychology, 63, 308-319. doi:10.1037//00223514.63.2.308

Hecht, M. L., \& Miller-Day, M. (2007). The drug resistance strategies project as translational research. Journal of Applied Communication Research, 35, 343-349. doi: $10.1080 / 00909880701611086$

Hecht, M. L., \& Miller-Day, M. (2010). In point of practice: “Applied” aspects of the drug resistance strategies project. Journal of Applied Communication Research, 38, 215-229. doi: 10.1080/00909882.2010.490848

Hope, D. A., \& Heimberg, R. G. (1990). Dating anxiety. In H. Leitenberg (Ed.), Handbook of social and evaluation anxiety (pp. 217-246). New York, NY: Plentum Press. 
Hsiao, T. Y. (2010). Testing rival measurement models of the personal report of communication apprehension in two Taiwanese samples. Psychological Reports, 107, 127-138. doi: 10.2466/02.07.11.20.PRO.107.4.127-138

Kalkan, M. (2008). Dating anxiety on adolescents: Scale development and effectiveness of cognitive-behavioral group counseling. Egitim Arastirmalari-Eurasian Journal of Educational Research, 32, 55-68.

Kellermann, K. (1991). The conversation MOP II: Progression through scenes in discourse. Human Communication Research, 17, 385-414. doi:10.1111/j.14682958.1991.tb00238.x

Kellermann, K. (1992). Communication: Inherently strategic and primarily automatic. Communication Monographs, 59, 288-300. doi:10.1080/03637759209376270

Kellermann, K. (1995). The conversation MOP: A model of patterned and pliable behavior. In D. E. Hewes (Ed.), Cognitive bases of interpersonal communication (pp. 181-221). Hillsdale, NJ: Lawrence Erlbaum Associates.

Kellermann, K., \& Lim T. (1990). The conversation MOP III: Timing scenes in discourse. Journal of Personality and Social Psychology, 59, 1163-1179. doi:10.1037//0022-3514.59.6.1163

Kelly, L. (1989). Implementing a skills training program for reticent communicators. Communication Education, 38, 85-101. doi:10.1080/03634528909378743

Kelly, L., \& Keaten, J. A. (2000). Treating communication anxiety: Implications of the communibiological paradigm. Communication Education, 49, 45-57. doi:10.1080/03634520009379192 
Knobloch, L. K. (2006). Relational uncertainty and message production within courtship: Features of date request messages. Human Communication Research, 32, 244273. doi: 10.1111/j.1468-2958.2006.00275.x

LaGreca, A. M., \& Harrison, H. M. (2005). Adolescent peer relations, friendships, and romantic relationships: Do they predict social anxiety and depression? Journal of Clinical Child and Adolescent Psychology, 34, 49-61.

LaGreca, A. M., \& Lopez, N. (1998). Social anxiety among adolescents: Linkages with peer relations and friendships. Journal of Abnormal Child Psychology, 26, 83-94.

La Greca, A. M., \& Mackey, E. R. (2007). Adolescents' anxiety in dating situations: The potential role of friends and romantic partners. Journal of Clinical Child and Adolescent Psychology, 36, 522-533. doi:10.1080/15374410701662097

Leary, M. R., \& Dobbins, S. E. (1983). Social anxiety, sexual behavior, and contraceptive use. Journal of Personality and Social Psychology, 45, 1357-1354. doi:10.1037//0022-3514.45.6.1347

Leck, K. (2006). Correlates of minimal dating. The Journal of Social Psychology, 146, 549-567. doi:10.3200/SOCP.146.5.549-567

Lesure-Lester E. G. (2001). Dating competence, social assertion, and social anxiety among college students. College Student Journal, 35, 317-320.

Levine, T., Asada, K. J., \& Carpenter, C. (2009). Sample sizes and effect sizes are negatively correlated in meta-analyses: Evidence and implications of a publication bias against nonsignificant findings. Communication Monographs, 76, 286-302. doi: 10.1080/03637750903074685 
Martin, M. M., \& Anderson, C. M. (1998). The cognitive flexibility scale: Three validity studies. Communication Reports, 11, 19. doi:10.1080/08934219809367680

Martin, M. M., Anderson, C. M., \& Thweatt, K. S. (1998). Aggressive communication traits and their relationships with the cognitive flexibility scale and the communication flexibility scale. Journal of Social Behavior and Personality, 13, $531-540$.

Martin, M. M., \& Rubin, R. B. (1995). A new measure of cognitive flexibility. Psychological Reports, 76, 623-626. doi:10.2466/pr0.1995.76.2.623

Martin, M. M., Staggers, S. M., \& Anderson, C. M. (2011). The relationships between cognitive flexibility with dogmatism, intellectual flexibility, preference for consistency, and self-compassion. Communication Research Reports, 28, 275280. doi: $10.1080 / 08824096.2011 .587555$

Martinson, W. D., \& Zerface, J. P. (1970). Comparison of individual counseling and a social program with nondaters. Journal of Counseling Psychology, 17, 36-40. doi: $10.1037 / \mathrm{h} 0028633$

McCroskey, J. C. (1970). Measures of communication bound anxiety. Speech Monographs, 37, 269-277. doi:10.1080/03637757009375677

McCroskey, J. C. (1977). Classroom consequences of communication apprehension. Communication Education, 26, 27-33. doi:10.1080/03634527709378196

McCroskey, J. C. (1982). An introduction to rhetorical communication $\left(4^{\text {th }} \mathrm{Ed}\right)$. Englewood Cliffs, NJ.: Prentice-Hall

McCroskey, J. C. (1997). Willingness to communicate, communication apprehension, and self-perceived communication competence: Conceptualizations and 
perspectives. In J. A. Daly, J. C. McCroskey, J. Ayres, T. Hopf, \& D. M. Ayres (Eds.), Avoiding communication: Shyness, reticence, and communication apprehension ( $2^{\text {nd }}$ Ed.) (pp. 75-108). Cresskill, NJ: Hampton Press.

McCroskey, J. C., \& Beatty, M. J. (1984). Communication apprehension and accumulated communication state anxiety experiences: A research note. Communication Monographs, 51, 77-84. doi:10.1080/03637758409390185

McCroskey, J. C., \& Beatty, M. J. (1998). Communication apprehension. In J. C. McCroskey, J. A. Daly, M. M. Martin, \& M. J. Beatty (Eds.), Communication and personality: Trait perspectives (pp. 215-232). Cresskill, NJ: Hampton Press.

Milne, S., Orbell, S., \& Sheeran, P. (2002). Combining motivational and volitional interventions to promote exercise participation: Protection motivation theory and implementation intentions. British Journal of Health Psychology, 7, 163-184. doi:10.1348/135910702169420

Monsour, M. (1996). Communication and cross-sex friendships across the life cycle: A review of the literature. In B. Burleson (Ed.), Communication Yearbook, 20 (pp. 375 - 414). Thousand Oaks, CA: Sage.

Murgraff, V., White, D., \& Phillips, K. (1996). Moderating binge drinking: Is it possible to change behavior if you plan it in advance. Alcohol and Alcoholism, 6, 577-582.

Ononaiye, M., Turpin, G., \& Reidy, J. (2007). Attentional bias in social anxiety: Manipulation of stimulus duration and social-evaluative anxiety. Cognitive Therapy and Research, 31, 727-740. doi:10.1007/s10608-006-9096-8 
Orbell, S., Hodgkins, A., \& Sheeran, P. (1997). Implementation intentions and the theory of planned behavior. Personality and Social Psychology Bulletin, 23, 945-954. doi:10.1177/0146167297239004

Parks, M. R., \& Floyd, K. (1996). Meanings for closeness and intimacy in friendship. Journal of Social and Personal Relationships, 13, 85-107. doi:10.1177/0265407596131005

Parks-Stamm, E. J., Gollwitzer, P. M., \& Oettingen, G. (2010). Implementation intentions and test anxiety: Shielding academic performance from distraction. Learning and Individual Differences, 20, 30-33. doi: 10.1016/j.lindif.2009.09.001

Posner, M. I., \& Snyder, C. R. R. (1975). Facilitation and inhibition in the processing of signals. In P. M. A. Rabbitt \& S. Dornic (Eds.), Attention and performance V (pp. 669-682). New York: Academic Press.

Prestwich, A., Lawton, R., \& Conner, M. (2003). The use of implementation decisions and the decision balance sheet in promoting exercise behavior. Psychology and Health, 18, 707-722. doi:10.1080/08870440310001594493

Prisbell, M. (1988). Dating competence as related to levels of loneliness. Communication Reports, 1, 54-59. doi:10.1080/08934218809367465

Richmond, V. P., \& McCroskey, J. C. (1998). Communication apprehension, avoidance, and effectiveness. Allyn \& Bacon: Boston.

Roloff, M. E., \& Ifert Johnson, D. (2001). Reintroducing taboo topics: Antecedents and consequences of putting topics back on the table. Communication Studies, 52, 3750. doi:10.1080/10510970109388539 
Rusbult, C. E., Martz, J. M., \& Agnew, C. R. (1998). The Investment Model Scale: Measuring commitment level, satisfaction level, quality of alternatives, and investment size. Personal Relationships, 5, 357-391. doi:10.1111/j.14756811.1998.tb00177.x

Schweiger-Gallo, I., Keil, A., McCulloch, K. C., Rockstroh, B., \& Gollwitzer, P. M. (2009). Strategic automation of emotion regulation. Journal of Personality and Social Psychology, 96, 11-31. doi: 10.1037/a0013460

Sheeran, P., \& Orbell, S. (1999). Implementation intentions and repeated behavior: Augmenting the predictive validity of the theory of planned behavior. European Journal of Social Psychology, 29, 349-369. doi:10.1002/(SICI)10990992(199903/05)29:2/3<349::AID-EJSP931>3.0.CO;2-Y

Sheeran, P., \& Orbell, S. (2000). Using implementation intentions to increase attendance for cervical cancer screening. Healthy Psychology, 19, 283-289. doi:10.1037//0278-6133.19.3.283

Sidelinger, R. J., Frisby, B. N., \& Booth-Butterfield, M. (2009). Dating anxiety among young adults: The impact of communicative attributes, mate value, and baggage on the dating experience. Presented at the annual meeting of the National Communication Association, Chicago, IL.

Spielberger, C. D. (1985). Assessment of state and trait anxiety: Conceptual and methodological issues. The Southern Psychologist, 2, 6-16.

Spielberger, C. D., Gorsuch, R. L., Lushene, R. E., Vagg, P. R., \& Jacobs, G. A. (1983). Manual for the State-Trait Anxiety Inventory. Palto Alto, CA: Consulting Psychologists Press. 
Steele, C. M. (1988). The psychology of self-affirmation: Sustaining the integrity of the self. In L. Berkowitz (Ed.), Advances in experimental social psychology (Vol. 21, pp. 261-302). New York: Academic Press.

Stutman, R. K., \& Newell, S. E. (1990). Rehearsing for confrontation. Argumentation, 4, 185-198. doi:10.1007/BF00175422

Sunnafrank, M. (1986). Predicted outcome value during initial interactions: A reformulation of Uncertainty Reduction Theory. Human Communication Research, 33, 3-33. doi:10.1111/j.1468-2958.1986.tb00092.x

Sunnafrank, M. (1988). Predicted outcome value in initial conversations. Communication Research Reports, 5, 169-172. doi:10.1080/08824098809359819

Sunnafrank, M. (1990). Predicted outcome value and uncertainty reduction theories: A test of competing perspectives. Human Communication Research, 17, 76-103. doi: 10.1111/j.1468-2958.1990.tb00227.x

Trower, P., Gilbert, P., \& Sherling, G. (1990). Social anxiety, evolution, and selfpresentation: An interdisciplinary perspective. In H. Leitenberg (Ed.), Handbook of social and evaluation anxiety (pp. 11-45). New York, NY: Plentum Press.

Twentyman, C. T., \& McFall, R. M. (1975). Behavioral training of social skills in shy males. Journal of Consulting and Clinical Psychology, 43, 384-395. doi:10.1037/h0076743

Varley, R., Webb, T. L., \& Sheeran, P. (2011). Making self-help more helpful: A randomized controlled trial of the impact of augmenting self-help materials with implementation intentions on promoting the effective self-management of anxiety 
symptoms. Journal of Consulting and Clinical Psychology, 79, 123-128. doi: $10.1037 / \mathrm{a} 0021889$

Webb, T. L., Ononaiye, M. S. P., Sheeran, P., Reidy, J. G., \& Lavda, A. (2010). Using implementation intentions to overcome the effects of social anxiety on attention and appraisals of performance. Personality and Social Psychology Bulletin, 36, 612-627.doi:10.1177/01461672103677

Williams-Piehota, P., Pizarro, J., Navarro Silvera, S. A., Mowad, L., Salovey, P. (2006). Need for cognition and message complexity in motivating fruit and vegetable intake among callers to the cancer information service. Health Communication, 19, 75-84. doi: doi:10.1207/s15327027hc1901_8

Wood, J. T. (2009). Gendered lives: Communication, gender, and culture $\left(9^{\text {th }}\right.$ Ed.). Boston, MA: Wadsworth. 
Appendix A

Need for Cognition Scale (Cacioppo, Petty, \& Kao, 1984)

\section{Directions: For each of the statements below, please indicate whether or not the statement is characteristic of you or of what you believe.}

Extremely uncharacteristic of me

1
Extremely characteristic of me

4

5

1. I prefer complex to simple problems.

2. I like to have the responsibility of handling a situation that requires a lot of thinking.

3. Thinking is not my idea of fun.

4. I would rather do something that requires little thought than something that is sure to challenge my thinking abilities.

5. I try to anticipate and avoid situations where there is a likely chance I will have to think in depth about something.

6. I find satisfaction in deliberating hard and for long hours.

7. I only think as hard as I have to.

8. I prefer to think about small daily projects to long term ones.

9. I like tasks that require little thought once I've learned them.

10. The idea of relying on thought to make my way to the top appeals to me.

11. I really enjoy a task that involves coming up with new solutions to problems.

12. Learning new ways to think doesn't excite me very much.

13. I prefer my life to be filled with puzzles I must solve.

14. The notion of thinking abstractly is appealing to me.

15. I would prefer a task that is intellectual, difficult, and important to one that is somewhat important but does not require much thought.

16. I feel relief rather than satisfaction after completing a task that requires a lot of mental effort.

17. It's enough for me that something gets the job done; I don't care how or why it works.

18. I usually end up deliberating about issues even when they do not affect me personally.

Reverse code: $3,4,5,7,8,9,12,16,17$ 
Appendix B

Cognitive Flexibility Scale (Martin \& Rubin, 1995)

Directions: The following statements deal with your beliefs and feelings about your own behavior. Using the scale below, please indicate your agreement with each statement.

Strongly Disagree

1
2
3
Strongly Agree

4

1. I can communicate an idea in many different ways.

2. I avoid new and unusual situations.

3. I feel like I never get to make decisions.

4. In any given situation, I am able to act appropriately.

5. I can find workable solutions to seemingly unsolvable problems.

6. I seldom have choices to choose from when deciding how to behave.

7. I am willing to work at creative solutions to problems.

8. My behavior is a result of conscious decisions that I make.

9. I have many possible ways of behaving in any given situation.

10. I have difficulty using my knowledge on a given topic in real life situations.

11. I am willing to listen and consider alternatives for handling a problem.

12. I have the self-confidence necessary to try different ways of behavior.

Reverse code: $2,3,6,10$ 
Appendix C

Self-Efficacy Scale (Based on Bandura's 2006 guide)

Directions: This questionnaire is designed to help us gain a better understanding of how people communicate in difficult situations. Please rate how confident you are now in your ability to do each of the following behaviors. Rate your degree of confidence by recording a number from 0 to 100 using the scale given below:

Cannot do at all

$0 \quad 10$

20

30

$40 \quad 50$

$60 \quad 70$

Highly certain can do

$\begin{array}{lll}80 & 90 & 100\end{array}$

Confidence Rating (0-100)

How confident are you in your ability to:

1. Carry on a conversation about an important topic with someone close to you

2. Express your views freely on an important topic with someone close to you

3. Talk about a difficult topic with someone close to you

4. Bring up a sensitive topic with someone close to you

5. Discuss an important topic that is bothering you with someone close to you

6. Initiate conversation on a controversial, important topic with someone close to you

7. Talk about an important topic that is hard to bring up with someone close to you

8. Bring up an important topic that gives you anxiety with someone close to you

No reverse code 


\section{Appendix D}

Trait Dyadic Communication Apprehension Scale (McCroskey, 1982)

Directions: This instrument is composed of six statements concerning feelings about communicating with others. Please indicate the degree to which each statement applies to you by marking whether you:

Strongly Disagree

1

2

3

4

Strongly Agree 5

1. I have no fear of speaking up in conversations.

2. Ordinarily I am very calm and relaxed in conversations.

3. While conversing with a new acquaintance, I feel very relaxed.

4. While participating in a conversation with a new acquaintance, I feel very nervous.

5. Ordinarily I am very tense and nervous in conversations.

6. I'm afraid to speak up in conversations.

Reverse code: $1,2,3$ 
Appendix E

Relational Closeness: Investment Size (Rusbult, Martz, \& Agnew, 1998)

Directions: With the same person in mind, please use the scale below to answer the following questions about your relationship with this person.

Strongly Disagree

1
2

3

4 Strongly Agree 5

1. I have invested a great deal of time in my relationship with this person.

2. I have told this person many private things about myself (i.e., I disclose secrets to him/her).

3. This person and I have an intellectual life together that would be difficult to replace.

4. My sense of personal identity (who I am) is linked to this person and our relationship.

5. This person and I share many memories.

6. I have put a great deal into this relationship that I would lose if this relationship were to end.

7. Many aspects of my life have become linked to this person (e.g., recreational activities, etc.) and I would lose all of this if our relationship were to end.

8. I feel very involved in this relationship - like I have put a great deal into it.

9. My relationships with other people would become complicated if my relationship with this person were to end (e.g., this person is friends with other people I care about).

10. Compared to other people I know, I have invested a great deal in my relationship with this person

No reverse code 


\section{Appendix F}

Implementation Intention Manipulation

Directions: In order to help you relieve your anxiety associated with this topic, we would like you to form an implementation intention. An implementation intention is an "if-then" plan to help you achieve a goal (e.g., If $x$, then $y$ ). Please follow the instructions below in order to form your implementation intention.

Please select one of the three options below (A, B, or C) to complete the following statement:

If I feel threatened or anxious when talking about with , then I will:

(topic label here) (initials here)

Please circle one
A. Think about why this topic is important to me
B. Think about what I stand for
C. Think about what I value most in myself

Next, we would like for you to practice making this implementation intention automatic, by writing it out in full three times. In other words, please write out your complete "if-then" statement, followed by your selection. Please, write out your full implementation intention three times on the lines below, with the statement (A, B, or C) that you selected.

1. If

2. If

3. If

Now, please take a few moments to repeat this implementation intention to yourself until you can say it without having to read it from the paper.

Please practice your implementation intention over the next two-weeks. 
Appendix G

Goal Formation Manipulation

Directions: In order to help you relieve your anxiety associated with this topic, we would like you to form a goal. Please follow the instructions below in order to form your goal about this topic.

Your goal will be as follows:

"I will not feel threatened or anxious when talking about with !" (topic label here) (initials here)

In order to help you remember this goal over the next two-weeks, please practice writing this goal out fully three times on the blank lines below.

1.

2.

3.

Now, please take a few moments to repeat this goal to yourself until you can say it without having to read it from the paper.

Please practice your goal over the next two-weeks. 
Appendix $\mathrm{H}$

State Anxiety (Spielberger, Gorsuch, Lushene, Vagg, \& Jacobs, 1983)

Directions: Using the scale below, please indicate how you felt as you were recording the message. There are no right or wrong answers. Do not spend too much time on any one statement, but give the answer which describes your feelings best.

Not at all

1 2 3

Very much so 4

When recording the message...

1. I felt calm.

2. I felt secure.

3. I felt tense.

4. I was regretful.

5. I felt at ease.

6. I felt upset.

7. I was worrying over possible misfortunes.

8. I felt rested.

9. I felt anxious.

10. I felt comfortable.

11. I felt self-confident.

12. I felt nervous.

13. I was jittery.

14. I felt "high strung."

15. I was relaxed.

16. I felt content.

17. I was worried.

18. I felt over-excited and "rattled."

19. I felt joyful.

20. I felt pleasant.

Reverse code: 1, 2, 5, 8, 10, 11, 15, 16, 19, 20 


\section{Appendix I}

Self-Perceived Communication Effectiveness (Based on Knobloch, 2006)

Strongly Disagree

1

2

3

4

Strongly Agree

5

\section{My recorded message was...}

1. Effective in letting this person know my feelings on this topic.

2. Effective for signaling to this person that I want to talk about this topic.

3. Successful for communicating to this person the importance of this topic.

4. Effective in communicating my viewpoints on this topic.

No reverse code 
Appendix $\mathbf{J}$

Motivation Scale (Developed by the Researcher)

Directions: Using the scale below, please indicate your motivation for each of the following statements.

Not motivated at all

1

Extremely motivated 5

1. How motivated were you to talk about this topic with the person you had in mind?

2. How motivated were you to practice talking about this topic with the person you had in mind?

3. How motivated were you to relieve your anxiety associated with this topic?

4. How motivated were you to communicate your feelings on this topic?

5. How motivated were you to improve your feelings on this topic?

No reverse code 
Appendix K

Message Realism (Based on Knobloch, 2006)

Directions: Please use the scale below to answer the following questions regarding the message you just recorded.

Strongly Disagree

1

2

3

4

Strongly Agree 5

My recorded message was...

1. Realistic of how I communicate with this person.

2. Typical of how I communicate with this person.

3. Similar to how I ordinarily communicate with this person.

4. Characteristic of how I typically communicate with this person.

No reverse code 